\title{
Monitoramento de Eventos Compostos em Sistemas Distribuídos
}

\author{
Douglas Moreto \\ DISSERTAÇÃO APRESENTADA \\ $\mathrm{AO}$ \\ INSTITUTO DE MATEMÁTICA E ESTATÍSTICA \\ DA \\ UNIVERSIDADE DE SÃO PAULO \\ PARA \\ OBTENÇÃO DO GRAU DE MESTRE \\ EM \\ MATEMÁTICA APLICADA \\ Área de Concentração: Ciência da Computação \\ Orientador: Prof. Dr. Markus Endler
}

Durante a elaboração deste trabalho o autor recebeu apoio financeiro do CNPq

-São Paulo, setembro de 1998- 


\section{Monitoramento de Eventos Compostos em Sistemas Distribuídos}

Este exemplar corresponde à redação final da dissertação devidamente corrigida

e defendida por Douglas Moreto

e aprovada pela comissão julgadora.

São Paulo, 18 de setembro de 1998.

\section{Banca examinadora:}

Prof. Dr. Markus Endler (orientador) - IME-USP

Prof. Dr. Marcelo Finger - IME-USP

Profa. Dra. Cecilia Mary Fischer Rubira - Unicamp 


\title{
Resumo
}

Esta dissertação trata do projeto e implementação de um monitor de eventos (EPS) capaz de processar eventos genéricos. Isso possibilita que o mesmo possa ser utilizado em uma grande variedade de aplicações, tais como Banco de Dados, Gerência de Redes de Computadores, ou Sistemas de Automação Industrial.

Para processar eventos adotou-se a estrutura de árvores agregadas onde diversos nós raízes representando eventos compostos, compartilham subárvores comuns. Essa estrutura permite que o processamento de uma subárvore seja realizado apenas uma vez independente do número de nós raízes existentes, aumentando a eficiência no processamento dos eventos. O processamento de eventos do EPS também leva em consideração os problemas decorrentes do uso do monitor em um ambiente distribuído, tais como, atrasos na entrega de mensagens e sua entrega fora de ordem.

\begin{abstract}
In this thesis we designed and implemented a monitor for distributed and composite events (EPS) which is able to process generic events. Since it is general-purpose, it can be used for a wide range of applications, such as Database Systems, Network Management and Industrial Automation.

Event processing within the monitor is based on aggregate trees. This structure enables root nodes representing composite eventes to share common sub-trees and allows for sub-trees to be processed just once, independent of the number of root nodes. This increase the efficiency of the event processing. The monitor also handles problems related to its use in a distributed setting, such as message latency and delivery of messages out of order
\end{abstract}




\section{Sumário}

1 Introdução 4

1.1 Noções de Eventos . . . . . . . . . . . . . . . . . . 5

1.1.1 Eventos Primitivos vs. Eventos Compostos . . . . . 5

1.1.2 Nomenclatura . . . . . . . . . . . . . . 6

1.2 Principais Contribuições . . . . . . . . . . . . . 7

1.3 Organização da dissertação $\ldots \ldots \ldots \ldots$

2 Trabalhos Relacionados 9

2.1 Os Monitores de Eventos . . . . . . . . . . . . . . . . 9

2.1 .1 Sentinel . . . . . . . . . . . . . . . 11

$2.1 .2 \quad$ SAMOS . . . . . . . . . . . . . . 12

2.1 .3 Ode . . . . . . . . . . . . . . . 15

2.1 .4 Eve . . . . . . . . . . . . . . . 15

2.1 .5 GEM . . . . . . . . . . . . . 16

2.2 Comparando os Monitores . . . . . . . . . . . . . . . . . 19

3 Serviço de Processamento de Eventos - EPS 21

3.1 Interface . . . . . . . . . . . . . . . 21

3.2 Arquitetura . . . . . . . . . . . . . . . . . 22

3.3 Pedido-de-Notificação . . . . . . . . . . . . . . . 24

3.4 Expressão de Eventos . . . . . . . . . . . . . . . 25

3.4.1 Eventos Compostos . . . . . . . . . . . . . 25

3.4 .2 Eventos de Tempo . . . . . . . . . . . . . . . 26

3.4.3 Gramática de Eventos . . . . . . . . . . . . . . . 27

3.5 Trabalhando com Atrasos . . . . . . . . . . . . . . . 28

3.6 Processamento de Eventos . . . . . . . . . . . . . . 30

4 Processamento de Eventos 34

4.1 Atributos internos . . . . . . . . . . . . 35 
4.2 Primeira fase . . . . . . . . . . . . . . . 37

4.3 Segunda e Terceira fases . . . . . . . . . . . . . 38

4.4 Quarta fase . . . . . . . . . . . . . . . . . . . . . . . . . . 42

4.5 Limpeza da árvore . . . . . . . . . . . . . . . . . . 44

5 Exemplos $\quad 46$

5.1 Tolerância a Falhas . . . . . . . . . . . . . . . . . . . . 46

5.2 Automação Industrial . . . . . . . . . . . . . . . . . . . . 49

5.3 Fluxo de Informação . . . . . . . . . . . . . . . . . 50

6 Implementação $\quad 54$

6.1 Módulos do EPS . . . . . . . . . . . . . . . . . 54

6.2 Comunicação entre processos . . . . . . . . . . 56

6.2 .1 RMI - Remote Method Invocation . . . . . . . . . 56

6.2 .2 Utilização do RMI pelo EPS . . . . . . . . . . 56

6.3 Funcionamento do EPS . . . . . . . . . . . . . . 58

6.3 .1 Principais Threads . . . . . . . . . . . . . . 58

6.3.2 Controle de Concorrência . . . . . . . . . . . . 59

6.3.3 Construção da árvore agregada . . . . . . . . . . 59

6.4 Calculando as Condições . . . . . . . . . . . . . . . . 60

6.5 Testando o EPS . . . . . . . . . . . . . . . . 63

6.5.1 Desempenho do EPS . . . . . . . . . . . . . . 64

6.5.2 Comparação entre árvores Agregadas e Árvores Simples 69

7 Conclusão $\quad 73$

7.1 Trabalhos Futuros . . . . . . . . . . . . . . . 74

A Regras da Gramática de Atributos. $\quad 76$

A.1 Regras que definem a Primeira fase . . . . . . . . . . 77

A.2 Regras que definem a Segunda fase. . . . . . . . . . . 82

A.3 Regras que definem a Terceira fase . . . . . . . . . . . . 83

A.4 Regras que definem a Quarta fase . . . . . . . . . . . . . . 84

$\begin{array}{ll}\text { B Diagrama de Classes do EPS } & 87\end{array}$

C Classes do EPS $\quad 93$

C.1 Classes do Package Eps . . . . . . . . . . . . . . . . 93

C.1.1 Classe Eps.EpsMain . . . . . . . . . . . . . . . . 93

C.1.2 Classe Eps.FuncGen . . . . . . . . . . . . . . . 93

C.2 Classes do Package ProcessTree . . . . . . . . . . . . 95

C.2.1 Classe Eps.ProcessTree.Aplicacao . . . . . . . . . . . 95 
C.2.2 Classe Eps.ProcessTree.Atributo _ . . . . . . . . . 97

C.2.3 Classe Eps.ProcessTree.Conjuncao . . . . . . . . . . 97

C.2.4 Classe Eps.ProcessTree.Disjuncao . . . . . . . . . . 97

C.2.5 Classe Eps.ProcessTree.Folha . . . . . . . . . . . 98

C.2.6 Classe Eps.ProcessTree.Identificador . . . . . . . . . . 99

C.2.7 Classe Eps.ProcessTree.Instancia . . . . . . . . . . . 100

C.2.8 Interface Eps.ProcessTree.NoArvore . . . . . . . . . 101

C.2.9 Interface Eps.ProcessTree.NoInstancia . . . . . . . . . 102

C.2.10 Interface Eps.ProcessTree.NotificaApl . . . . . . . . . 102

C.2.11 Classe ProcessTree.Operador . . . . . . . . . . . . 102

C.2.12 Classe Eps.ProcessTree.ProcessaNotificacao . . . . . . 103

C.2.13 Classe Eps.ProcessTree.Sequencia . . . . . . . . . . . 104

C.2.14 Classe Eps.ProcessTree.Status . . . . . . . . . . . . 104

C.2.15 Classe Eps.ProcessTree.TempoRelativo . . . . . . . 105

C.2.16 Classe Eps.ProcessTree.TimesDf . . . . . . . . . . 105

C.2.17 Classe Eps.ProcessTree.TimesEq . . . . . . . . . . 106

C.2.18 Classe Eps.ProcessTree.Validade . . . . . . . . . . 107

C.3 Classes do Package ManagerTree . . . . . . . . . . . . . 107

C.3.1 Classe Eps.ManagerTree.Arvore . . . . . . . . . . . 107

C.3.2 Classe Eps.ManagerTree.Escalonador . . . . . . . . . 108

C.3.3 Interface Eps.ManagerTree.GerenciaEventos . . . . 109

C.3.4 Interface Eps.ManagerTree.GerenciaPedidos . . . . 109

C.3.5 Classe Eps.ManagerTree.InfoSimbAtrib . . . . . . . . 109

C.3.6 Classe Eps.ManagerTree.ListaTokens . . . . . . . 110

C.3.7 Classe Eps.ManagerTree.ReceptorPedidos . . . . . . . 110

C.3.8 Classe Eps.ManagerTree.Simbolo . . . . . . . . . . 111

C.3.9 Classe Eps.ManagerTree.Sincronizador . . . . . . . 111

C.3.10 Classe Eps.ManagerTree.TipoEvento . . . . . . . . . 111

C.4 Classes do Package Timer . . . . . . . . . . . . . . . . . 112

C.4.1 Classe Eps.Timer.EventoDeTempo . . . . . . . . . . 112

C.4.2 Classe Eps.Timer.Relogio . . . . . . . . . . . . . . . 113

C.5 Classes do Package Display . . . . . . . . . . . . . 113

C.5.1 Classe Eps.Display.SaidaDados . . . . . . . . . 113 


\section{Capítulo 1}

\section{Introdução}

O processamento de eventos assíncronos vêm sendo empregado em várias áreas da computação para modelar a interação entre processos concorrentes. Como exemplos podemos citar algumas áreas: Banco de Dados Ativos, Sistemas de Monitoramento e Sistemas Interativos. Em Banco de Dados Ativos, regras que, por exemplo, garantem a consistência dos dados são disparadas pela ocorrência de eventos pré-definidos, tais como, a alteração de um dado em um registro. Sistemas baseados em interfaces gráficas com o usuário (GUI) também utilizam eventos para representar o acionamento dos diferentes elementos gráficos da entrada pelo usuário. Aplicações com interesse em controle de processos e em tempo real estão baseadas essencialmente em eventos. Nelas, eventos correspondem a sinais enviados por sensores para indicar a localização ou características físicas de peças, máquinas ou reagentes que estão sendo monitorados, como por exemplo temperatura, pressão, fluxo, etc.

Sistemas de Monitoramento para sistemas centralizados ou distribuídos se baseiam em eventos assíncronos para notificar o estado das componentes que estão sendo monitoradas e permitir a deteç̧ão de sobrecarga e/ou falhas em algumas componentes. Em tais aplicações, muitas vezes é impossível determinar seu estado observando-se apenas os eventos individualmente. Em vez disso, faz-se necessário que um monitor de eventos seja capaz de relacionar eventos diferentes. Enquanto monitores para o tratamento de eventos individuais são bastante difundidos, existem poucos sistemas capazes de relacionar eventos e tratá-los como um único evento. Entre esses monitores, a maioria foi desenvolvida para ambientes centralizados e visa uma área específica, como por exemplo Banco de Dados Ativos [10, 18]. 
Neste trabalho tivemos como objetivo projetar e implementar um serviço genérico de monitoramento de eventos (chamado de Event Processing Service (EPS)) que pudesse ser utilizado em diferentes áreas e que permitisse a usuários e aplicações registrarem interesse em ocorrências de eventos compostos. Os eventos compostos são definidos por expressões que informam quais eventos primitivos devem ser relacionados e qual deve ser a relação lógica e temporal entre eles. Denominaremos por Pedido-de-Notificação um registro de interesse realizado por uma aplicação cliente do EPS.

Para isto utilizamos os operadores de conjunção, disjunção, seqüência e repetição que serão vistos em detalhes no Capítulo 3. Não disponibilizamos um operador de negação pelo fato de que a semântica deste operador necessitaria de um processamento em lógica de intervalos temporais [19], assunto que foge ao escopo do trabalho.

O desenvolvimento deste trabalho foi realizado no contexto de um projeto maior que objetiva desenvolver um sistema de suporte à execução e gerenciamento de aplicações distribuídas e tolerantes a falhas. Este projeto chama-se SAMPA (System for Availability Management of Process-based Applications) [6] e incorpora outros serviços além do serviço de monitoramento de eventos, tais como, "checkpointing", gerenciamento de grupos e gerenciamento de configuração.

\subsection{Noções de Eventos}

\subsubsection{Eventos Primitivos vs. Eventos Compostos}

Um evento é qualquer acontecimento de interesse que ocorre em um instante específico no tempo [17,21]. Eventos primitivos correspondem a acontecimentos elementares, como por exemplo, a perda de uma mensagem, a ocorrência de um "timeout", o término da execução de uma tarefa ou um "click" do mouse, no caso de interfaces gráficas. Eventos compostos correspondem a acontecimentos complexos, ou seja, correspondem a combinações de eventos primitivos. Os eventos compostos são constituídos de eventos primitivos relacionados entre si através de uma relação derivada de uma expressão de eventos e uma condição sobre alguns de seus atributos, conforme será detalhado na Seção 3.4.

Seguindo a terminologia utilizada em $[4,8]$, pode-se classificar os eventos primitivos em três categorias:

Eventos internos: são eventos que estão pré-definidos pelo monitor. Even- 
tos dessa categoria são eventos primitivos específicos da aplicação na qual o monitor está sendo utilizado. Por exemplo, em Banco de Dados eventos internos são eventos relacionados com a manipulação do Banco de Dados (inserção, remoção,...). Além disso, a verificação da existência de eventos dessa categoria é realizada pelo próprio ambiente (o sistema gerenciador do Banco de Dados);

Eventos externos: são eventos definidos pelos usuários e/ou aplicações que estão utilizando o monitor e que precisam ser gerados explicitamente por um sensor e enviados para o monitor de eventos;

Eventos de tempo: são eventos que estão relacionados com o tempo. Eventos desta categoria incluem: eventos absolutos, que especificam um instante exato no tempo, eventos periódicos, que especificam a periodicidade de geração de instâncias de evento, e eventos relativos, que especificam um tempo de espera para eventos pertencentes às categorias interno e externo.

\subsubsection{Nomenclatura}

Ao longo deste trabalho utilizaremos as seguintes definições:

Tipo de Evento: refere-se aos possíveis acontecimentos que estarão sendo detectados e gerados durante a execução do sistema, ou seja, o tipo de evento define os atributos destes acontecimentos;

Instância de Evento: refere-se ao acontecimento simples ou complexo propriamente dito, ou seja, representa uma ocorrência de um acontecimento que associa valores concretos a todos os atributos deste acontecimento;

Evento Detectado: dizemos que um evento foi detectado quando sensores da aplicação verificarem a ocorrência de um acontecimento elementar;

Instâncias Geradas: dizemos que uma instância de evento foi gerada quando um sensor detectar um evento primitivo ou quando uma nova instância for criada a partir de outras instâncias previamente geradas dentro do próprio monitor. Isto ficará mais claro na discussão do processamento de eventos que será discutido na Seção 3.6 e no Capítulo 4 
Sensores de Aplicação: considera-se como sensores de aplicação qualquer processo (programa) capaz de detectar algum acontecimento e enviar uma mensagem ao monitor avisando da sua geração. Estes processos podem ser capazes de detectar acontecimentos tanto físicos, como por exemplo a mudança de temperatura de um reservatório, como acontecimentos que são decorrentes de algum outro processamento lógico, como por exemplo a verificação da validade de um plano de saúde. Neste último caso, o próprio "programa" verifica se um determinado plano de saúde ainda está válido e, ele próprio, pode enviar uma mensagem (evento) para o monitor avisando que o plano é válido ou não.

Adotamos a seguinte notação nos exemplos utilizados neste trabalho: Tipos de eventos são representados por letras maiúsculas com um índice inferior $\left(E_{i}\right)$, instâncias de eventos são representadas por letras minúsculas com índices inferior e superior $\left(e_{i}^{j}\right)$, onde o índice superior representa o instante de geração desta instância de evento primitivo.

\subsection{Principais Contribuições}

Esta dissertação tem como principal contribuição o desenvolvimento de um monitor de eventos capaz de processar eventos genéricos em árvores agregadas. Embora existisse um monitor que já utilizava ávores agregadas para processar eventos (Sentinel [2]), este impunha algumas restrições ao processamento impossibilitando o seu uso de maneira genérica. Além disso, o monitor desenvolvido nesta dissertação está preparado para trabalhar em ambientes distribuídos, onde problemas como o atraso na entrega de mensagens e a entrega fora de ordem podem acontecer. 


\subsection{Organização da dissertação}

Os demais Capítulos dessa dissertação estão organizados da seguinte maneira. No Capítulo 2 apresentamos alguns trabalhos que tratam da construção de monitores de eventos, mostrando suas características, semelhanças e diferenças com relação à nossa abordagem.

No Capítulo 3 especificamos como foi construído o monitor que propomos, explicando sua arquitetura e sua interface. No Capítulo 4 detalhamos como é realizado o processamento de eventos dentro do monitor proposto, apresentando a idéia do processamento, bem como, a sua representação em árvores agregadas e, no Capítulo seguinte, apresentamos alguns exemplos práticos de possíveis utilizações de um monitor de eventos.

Detalhes a respeito da implementação e dos testes realizados para medir o desempenho do monitor implementado neste trabalho são apresentados no capítulo 6. No Capítulo 7 concluímos a dissertação apresentando um resumo do trabalho e algumas sugestões para trabalhos futuros. 


\section{Capítulo 2}

\section{Trabalhos Relacionados}

A maior parte dos trabalhos encontrados na literatura para monitoramento de eventos compostos estão focados em Banco de Dados Ativos e consideram apenas ambientes centralizados. Alguns trabalhos, como GEM e Eve tratam do monitoramento de eventos em ambientes distribuídos.

No decorrer do capítulo, estaremos comentando alguns monitores construídos para Banco de Dados Ativo, Workflow e Monitores Genéricos.

\subsection{Os Monitores de Eventos}

No decorrer desta seção estaremos comentando os monitores de cinco trabalhos analisados. Os três primeiros foram feitos para Banco de Dados: Sentinel $[18,4,20]$, um projeto de um banco de dados ativo que define uma linguagem (Snoop) para o processamento de eventos compostos; SAMOS [10, $8,9]$, um projeto de banco de dados ativo orientado a objeto; e Ode [13, 12 , 11]. Na seqüência comentamos um monitor desenvolvido especialmente para Workflow e um monitor de eventos genérico para ambientes distribuídos.

Os monitores dos trabalhos voltados para Banco de Dados Ativo estão integrados ao banco de dados e estão aptos a reconhecer eventos internos relacionados às operações de banco de dados, tais como, inserção, atualização, início de uma transação e outras operações afins. A idéia é permitir que a geração destes eventos dispare automaticamente regras no banco de dados à fim de mantê-lo consistente ou efetuar uma notificação ao usuário.

Cada banco de dados está baseado em um modelo computacional que determina a especificação do monitor de eventos. 


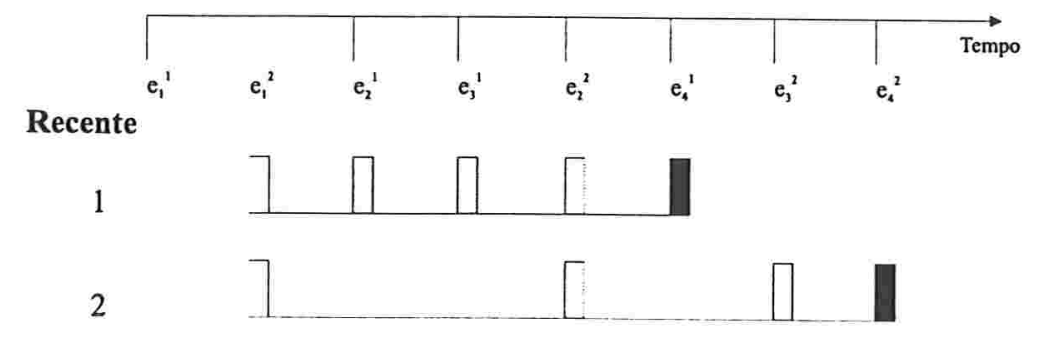

\section{Cronológico}

3

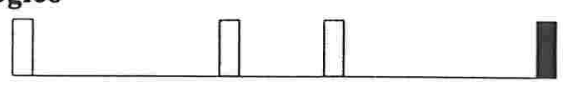

4

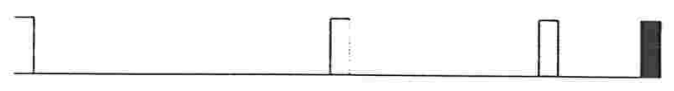

\section{Continuo}

5

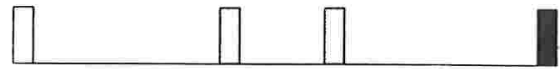

6

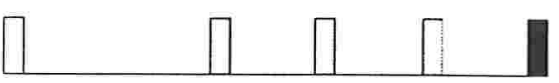

7

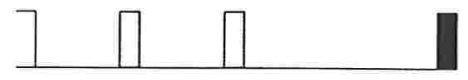

8

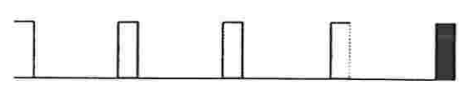

Acumulativo

9
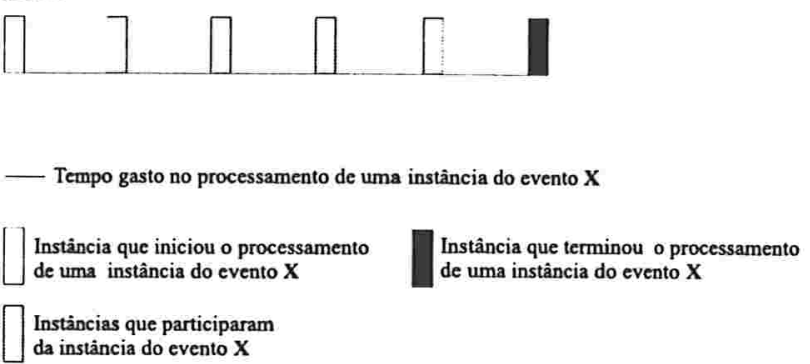

Figura 2.1: Exemplo do processamento de eventos utilizando-se os quatro parâmetros de contexto de Snoop para o evento de interesse: $X=\left(\left(E_{1} \&\right.\right.$ $\left.\left.E_{2}\right) ; E_{3}\right) ;\left(E_{2} \& E_{4}\right)$. 


\subsubsection{Sentinel}

Sentinel $[18,4,20]$ é um projeto de banco de dados que, em sua maior parte, teve como objetivo o desenvolvimento de uma linguagem de especificação de eventos (Snoop) e de algoritmos para o processamento de eventos dessa linguagem.

Para construir o monitor de eventos responsável por processar os eventos de Snoop, Sentinel não adotou nenhum modelo computacional, preferindo basear seu monitor em árvores, uma estrutura de dados. Como árvores não são um modelo computacional, a comparação com autômatos e Redes de Petri não é muito apropriada. Contudo, utilizando-se árvores é possível especificar e processar eventos tanto seqüencialmente como concorrentemente. Por ser simples e ter uma implementação eficiente, sua estrutura é também utilizada em outros monitores (Eve, Gem e o que estamos propondo).

O monitor Snoop processa os eventos de acordo com um contexto. Snoop define quatro contextos, recente, cronológico, acumulativo e contínuo, e para cada um as instâncias são processadas de maneira diferente. O objetivo de introdução destes parâmetros de contexto é diminuir a quantidade final de notificações aos processos de aplicação. Em um contexto genérico, o evento $X=\left(\left(E_{1} \& E_{2}\right) ; E_{3}\right) ;\left(E_{2} \& E_{4}\right)$, onde '\&' é o operador de conjunção e ';' é o operador de seqüência, teria 16 instâncias geradas após o processamento das seguintes instâncias primitivas: $e_{1}^{1}, e_{1}^{2}, e_{2}^{3}, e_{3}^{4}, e_{2}^{5}, e_{4}^{6}, e_{3}^{7}$ e $e_{4}^{8}$, devido ao fato de se considerar todas as possíveis combinações de instâncias relativas a um mesmo evento.

Utilizando o contexto recente teríamos apenas duas instâncias do evento $X$. Neste contexto só as instâncias mais recentes seriam utilizadas. Por exemplo, quando a instância $e_{1}^{2}$ fosse recebida, a instância $e_{1}^{1}$ seria descartada. No contexto cronológico, as instâncias de evento composto seriam constituídas pelas instâncias mais velhas dos eventos filhos. Por exemplo, $\left(E_{1} \& E_{2}\right)$ teria como instâncias $\left(e_{1}^{1} \& e_{2}^{3}\right)$ e $\left(e_{1}^{2} \& e_{2}^{5}\right)$. Neste contexto apenas duas instâncias do evento $X$ seriam geradas. Outro contexto é o acumulativo. Neste contexto, as instâncias de um evento composto seriam formadas pela união das instâncias dos eventos filhos. No exemplo, uma instância do evento $X$ seria formada pelas instâncias : $\left(e_{1}^{1}, e_{1}^{2}, e_{2}^{3}, e_{3}^{4}, e_{2}^{5}, e_{4}^{6}\right)$ e apenas uma instâncias do evento $X$ seria gerada. O último contexto é o contínuo. Neste contexto, a instância que finaliza o processamento de um evento composto formaria um par com cada instância do outro evento filho. No exemplo, considerando o evento composto $\left(E_{1} \& E_{2}\right)$ e apenas as seguintes instâncias primitivas $e_{1}^{1}, e_{1}^{2}, e_{2}^{3}$, seriam geradas as seguintes instâncias 
deste evento composto: $\left(e_{1}^{1} \& e_{2}^{3}\right)$ e $\left(e_{1}^{2} \& e_{2}^{3}\right)$.

A Figura 2.1 mostra o resultado do processamento utilizando estes quatro parâmetros de contexto.

Introduzindo os parâmetros de contexto, Snoop reduz a quantidade de processamento aumentando, portanto, a sua eficiência. Porém, deixa de processar diversas instâncias. Como pudemos ver no exemplo, 16 instâncias seriam geradas no contexto geral, enquanto que no máximo duas instâncias foram geradas em cada contexto. Para monitores que pretendem oferecer um serviço genérico, a utilização de contextos não pode ser aplicada.

As árvores de processamento do Snoop são combinadas para compartilharem subárvores em comum. Nas árvores as folhas representam eventos primitivos e os nós não-folhas das árvores representam os eventos compostos. O processamento é iniciado toda vez que uma instância de evento primitivo é recebida pelo monitor. Essa instância de evento primitivo é associada à folha correspondente na árvore. Esta folha envia para todos os seus pais uma cópia desta instância e não a armazena em lugar algum. Ao receber a cópia da instância, o nó pai faz uma análise da possibilidade de gerar uma nova instância do evento composto definido pelo nó. A análise depende do contexto e do operador. Se uma nova instância puder ser gerada, uma cópia é enviada para todos os pais do nó. Se não puder ser gerada uma nova instância, o processamento aguarda a chegada de novas instâncias primitivas. Após realizar a análise e ter gerado ou não a instância do evento composto, o nó ainda decide se armazena ou não a cópia da instância recebida do nó filho. Se a instância não for armazenada, ela não poderá ser utilizada futuramente (novamente a decisão depende do contexto e do operador).

Usando este método de processamento de eventos para o contexto geral, as instâncias, junto com todos seus atributos, teriam que ser replicadas em todos os nós superiores da árvore pelos quais passasse. Portanto, usando essa técnica de processamento o espaço requerido para o armazenamento seria muito grande. Incluindo os parâmetros de contexto Sentinel consegue diminuir o espaço de armazenamento em detrimento das possíveis instâncias de eventos a serem processadas.

\subsubsection{SAMOS}

SAMOS (Swiss Active Mechanism-based Object-oriented database System) é um projeto que visa a especificação do comportamento ativo de um banco de dados $[10,8,9]$. 


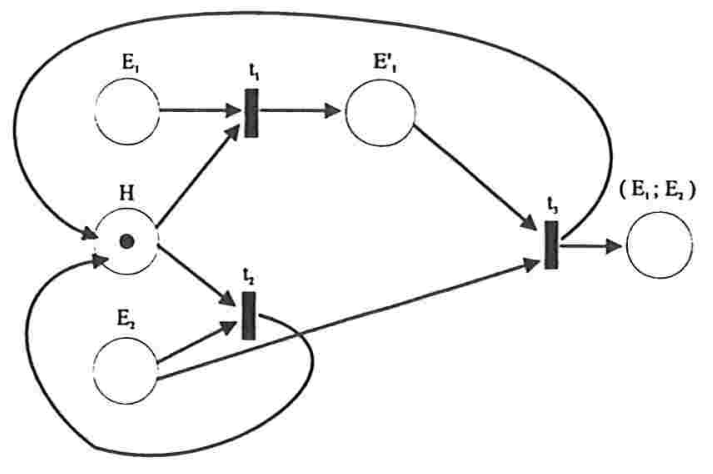

Figura 2.2: Exemplo de uma rede de Petri para o evento $E_{1} ; E_{2}$.

Para especificar o comportamento ativo e seu processamento, Samos utiliza Redes de Petri Colorida como modelo computacional. Usando-se Redes de Petri Colorida como modelo computacional pode-se modelar um comportamento concorrente e, ainda, realizar o processamento concorrente por diversos fluxos de controle.

A figura 2.2 mostra a Rede de Petri Colorida construída para o evento $E_{1} ; E_{2}\left(E_{1}\right.$ seguido de $\left.E_{2}\right)$. A Rede de Petri é constituída de diversos estados $\left(E_{1}, E_{2}, H, E_{1}^{\prime}\right.$ e $\left.E_{1} ; E_{2}\right)$, de transições $\left(t_{1}, t_{2}\right.$ e $\left.t_{3}\right)$ e de tokens (representado por uma bolinha preta nas figuras 2.2 e 2.3).

$\mathrm{Na}$ figura 2.3 exemplificamos o processamento de eventos utilizando o mesmo evento da figura $2.2 \mathrm{com}$ a seguinte seqüência de instâncias: $e_{2}^{1} ; e_{1}^{2}$; $e_{1}^{3}$ e $e_{2}^{4}$. Ao processar-se a instância $e_{2}^{1}$, um token é inserido no estado $E_{2}$. Esse novo token dispara a transição $t_{2}$ porque os dois estados de entrada desta transição possuem tokens. Após o disparo da transição os tokens são removidos dos estados de entrada e um token é inserido no estado de saída (estado $H$ ). Recebendo a instância $e_{1}^{2}$, um token é inserido no estado $E_{1}$ e a transição $t_{1}$ é disparada. Uma nova instância do evento $E_{1}\left(e_{1}^{3}\right)$ é recebida e esta é armazenada, em forma de token, no estado $E_{1}$ sem disparar nenhuma transição. Com o recebimento de uma instância do estado $E_{2}$ $\left(e_{2}^{4}\right)$ duas transições são disparadas ( $t_{3}$ e $t_{1}$, nesta ordem). A transição $t_{3}$ finaliza o processamento do evento composto de interesse $\left(E_{1} ; E_{2}\right)$ e a transição $t_{1}$ permite que a segunda instância do evento $E_{1}\left(e_{1}^{3}\right)$ continue o seu processamento.

Apesar de ser um excelente modelo, sua implementação é complexa e é comparativamente ineficiente na execução do processamento de eventos [15]. 

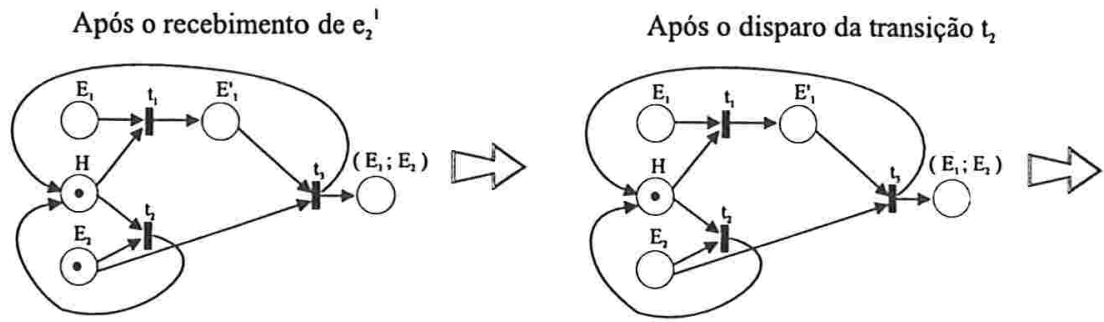

Após o recebimento de $\mathrm{e}_{1}{ }^{2}$

Após o disparo da transição $t_{1}$
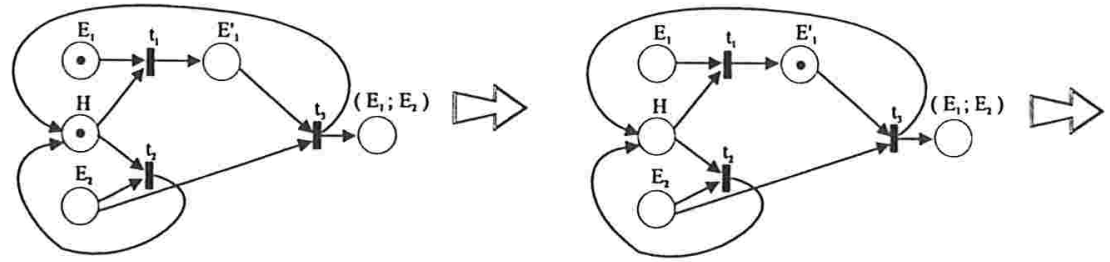

Após o recebimento de $\mathrm{e}_{1}{ }^{3}$

Após o recebimento de $\mathrm{e}_{2}{ }^{4}$
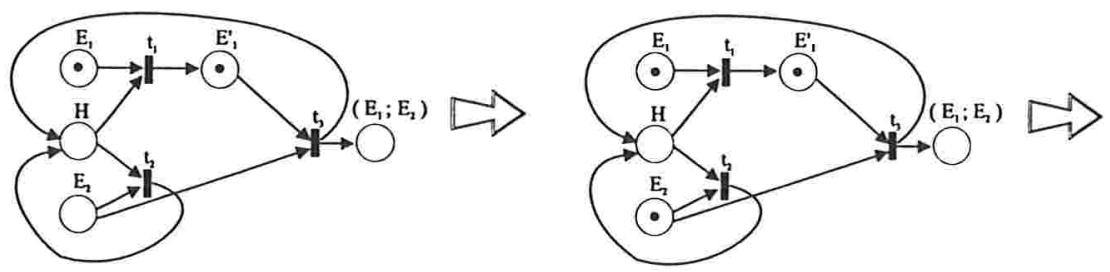

Após o disparo da transição $t_{3}$

Após o disparo da transição $t_{1}$
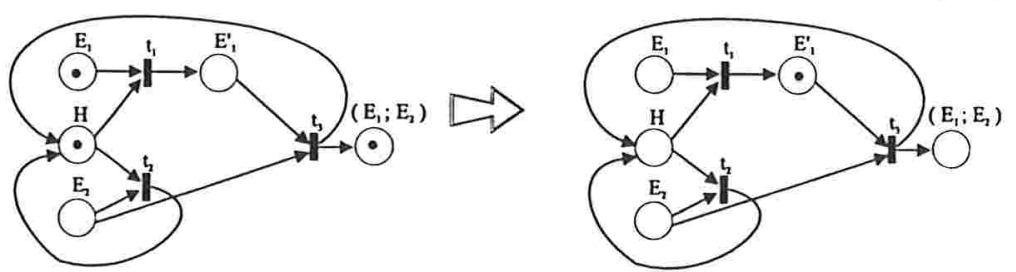

Figura 2.3: Exemplo do processamento de eventos em SAMOS. 


\subsubsection{Ode}

Ode $[13,12,11]$ é um banco de dados orientado a objeto que está sendo desenvolvido na AT\&T Bell Labs. Uma de suas características principais é a presença de gatilhos (triggers) que automaticamente realizam ações dependendo do estado do banco de dados.

Para construir seu monitor de eventos, Ode optou pelo modelo de autômatos finitos. Este modelo é apropriado para ambientes onde não ocorre concorrência entre as instâncias de evento e onde as instâncias de evento estão todas disponíveis no momento do processamento. Além disso, o processamento é seqüencial. Por isso, os eventos e o processamento em Ode são definidos baseando-se em um histórico de instâncias de evento. Esse histórico é uma seqüência de instâncias onde duas instâncias não podem ter a mesma marca de tempo, ou seja, duas instâncias de evento não podem ser geradas simultaneamente.

\subsubsection{Eve}

Eve [14] é um monitor voltado para a área de apoio ao fluxo de trabalho (workflow) que trata dos problemas encontrados em ambientes distribuídos. Eve assume que os relógios locais estão sincronizados com uma precisão de $p$ para poder impor uma ordem total aos eventos gerados globalmente. Para ordenar instâncias de evento que foram geradas em locais distintos, a diferença entre os instantes de geração destas instâncias deve ser superior a $2 p$, caso contrário as instâncias são consideradas concorrentes. Instâncias geradas no mesmo local são ordenadas de acordo com suas marcas de tempo, não importando se a diferença é superior ou inferior a $2 p$. Outra característica particular deste monitor é a existência de um operador de eventos que permite a definição de um evento composto de concorrência. Instâncias de evento deste tipo só são geradas quando as instâncias dos eventos filhos forem geradas concorrentemente, isso é, quando as instâncias filhas forem geradas dentro de um intervalo de tempo menor do que $2 p$.

$\mathrm{O}$ processamento de eventos em Eve também utiliza árvores e, ao contrário de Sentinel, Eve não compartilha subárvores comuns. Em Eve cada árvore corresponde a um único evento composto. O processamento na árvore é parecido com o processamento efetuado em Sentinel, exceto pelos contextos. 


\subsubsection{GEM}

Pensando em situações mais genéricas, GEM (Generalized Event Monitoring) [17] propõem uma linguagem que tratar de eventos genéricos e que podem estar acontecendo em ambientes distribuídos.

Em um ambiente distribuído, cada máquina estará executando um monitor GEM. Para "programar" estes monitores utiliza-se scripts. Estes scripts informam aos monitores de eventos o que eles devem e como devem tratar os eventos gerados. Esses scripts podem ser carregados (load) e removidos $(\sim)$ dos monitores em qualquer instante do processamento. Comandos deste tipo são chamados de comandos top level e agem na configuração do monitor de eventos. Além desses dois comandos top level, há outros quatros: enable, disable (habilitam e desabilitam eventos ou regras), stop (encerra o processamento do monitor) e ? (exibe como o monitor está configurado).

A definição de quais eventos e quais regras o monitor estará processando é fornecida nos scripts de acordo com a sintaxe abaixo.

Definição de eventos:

event <identificação_de_evento $>\quad[(<$ declaração_dos_atributos $>)]$

Definição de regras:

rule $<$ nome_da_regra $>\left[<j a n e l a_{-} d e_{-}\right.$detecção $\left.>\right]$

$\{<$ expressão_de_eventos $>==><a c ̧ a \tilde{o}>\}$

onde:

nome_da_regra: define um nome para o evento compostos que estará sendo definido;

janela_de_detecção: especifica por quanto tempo os eventos desta regra são considerados válidos;

expressão_de_eventos: informa qual o evento composto que será processado e uma possível condição a ser satisfeita;

ação: define a ação a ser executada quando o evento composto definido for gerado. A ação pode ser formada por um conjunto de comandos. Esses comandos podem ser: comandos "top level" ou um comando de notifica. 
Dentro dos scripts também podemos encontrar comandos "top level", como vemos na tabela 2.1. Neste script temos a definição de três eventos (gauge_change, upper_exceeded e lower_exceeded), duas regras (gauge_rue1 e gauge rule2 e um comando "top level" (enable). Os eventos declarados indicam ao monitor GEM quais tipos de eventos estarão sendo gerados no sistema (mudança no medidor, limites superior ou inferior excedidos). As regras definem os eventos compostos que estarão sendo processados, as condições que as instâncias destes eventos deverão satisfazer e as ações a serem executadas quando o evento composto for processado.

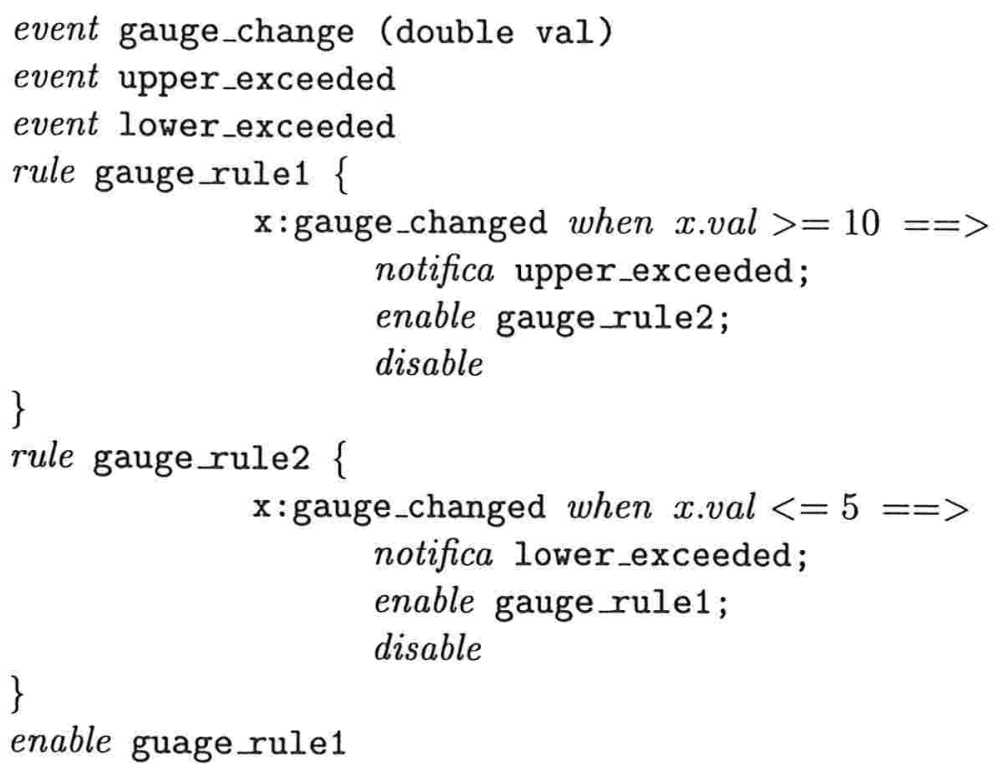

Tabela 2.1: Exemplo de um script GEM.

O processamento de eventos em GEM é análogo ao realizado pelo Eve, GEM também não compartilha subárvores comuns. A diferença do processamento efetuado pelo GEM é que cada nó da árvore armazena uma lista de todas as instâncias que já foram geradas deste evento. Estas listas são ordenadas pela marca de tempo das instâncias. Com esta ordenação, as instâncias são consumidas na ordem em que foram geradas (da mais antiga para a mais nova) e caso uma instância chegue atrasada, ela é colocada na posição correta, evitando um processamento incorreto, como veremos na Seção 3.5. Outra característica é a janela de deteç̧ão adotada para cada evento composto, o que evita o processamento de instâncias muito antigas.

Com a possibilidade de definição de nomes para os eventos compostos, 
pode-se definir um outro evento composto que tenha como um de seus eventos constituintes um evento previamente definido, utilizando, para tal, o nome da regra em vez de toda a expressão. Devido a essa facilidade e ao fato de que em ambientes distribuídos pode-se configurar um monitor GEM em cada máquina, um evento composto pode ser particionado para ser processado em diversas máquinas do ambiente. Nestes casos, são dados nomes às partes do evento composto global e, estas partes, podem ser carregadas nos diversos monitores. Um desses monitores fica com a raiz do evento global, onde as folhas da árvore neste monitor correspondem às partes que foram distribuídas. Na figura 2.4 vemos um exemplo de como distribuir um evento global.

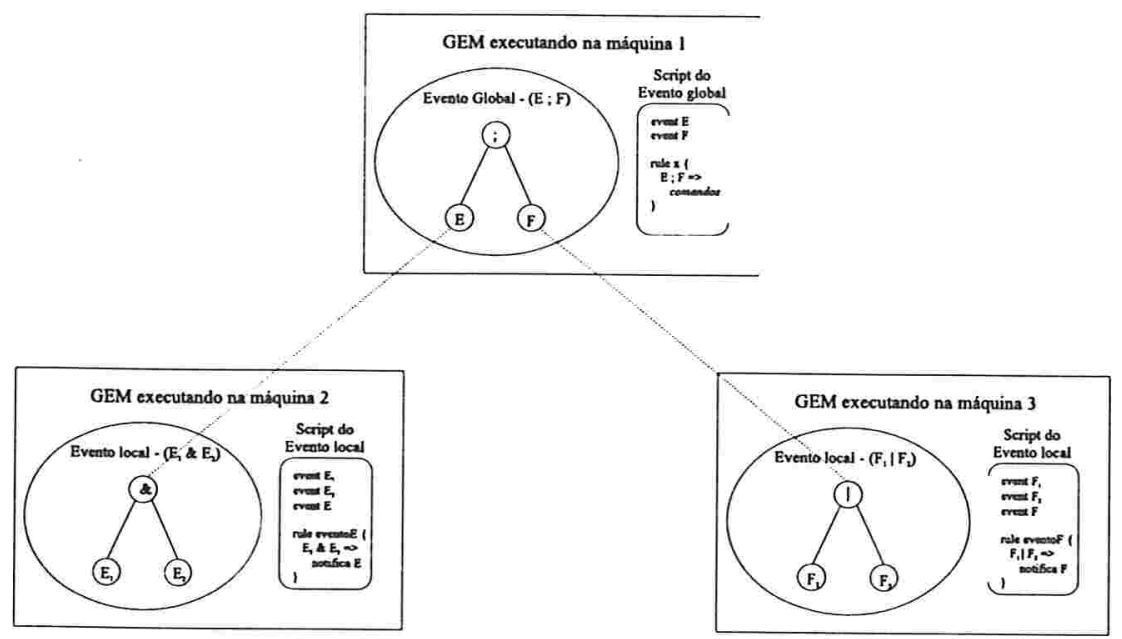

Figura 2.4: Definição de um evento composto distribuído. 


\subsection{Comparando os Monitores}

Todos os trabalhos que foram discutidos possuem algumas características em comum, tais como: todos tratam eventos de tempo (absolutos, relativos e periódicos); possuem um conjunto básico de operadores e permitem que o monitor processe eventos externos (definidos pelos processos de aplicação e/ou usuários).

O conjunto básico de operadores é listado abaixo. Os três primeiros são operadores binários e o quarto é um operador unário.

Conjunção: este operador indica que foram geradas instâncias de dois eventos mas não impõem nenhuma restrição em relação a ordem em que foram geradas;

Disjunção: considerando os eventos como operandos, este operador informa que uma instância de qualquer um dos operandos foi gerada. Este operador não está disponível nos monitores do projeto Ode $[13,12,11]$ e do projeto Eve [14];

Seqüência : este operador é uma especialização do operador conjunção. Além de informar que as instâncias de dois eventos foram geradas, impõem que a instância do segundo evento tenha sido gerada após a instância do primeiro evento. A notação mais utilizada é $\left(E_{1} ; E_{2}\right)$;

Negação: este operador informa que determinado evento não ocorreu. Como é impossível afirmar que um evento não ocorreu, considerando um tempo infinito, todos os trabalhos definem, de alguma maneira, um intervalo de tempo no qual se possa verificar a geração ou não de uma determinada instância de evento. A forma mais comum da definição de tal intervalo é especificar um evento que determina o início do intervalo e um evento que determina o fim do mesmo.

A Tabela 2.2 enfatiza quais são as diferenças e semelhanças entre os monitores, mostrando as características que os diferenciam, entre elas: o mecanismos de processamento adotado, a área de atuação dos monitores e o ambiente onde o monitor estará sendo executado. Considerando estas características não havia um monitor capaz de combinar um mecanismo eficiente de processamento (árvores agregadas) com uma vasta área de atuação (monitores genéricos) e, ainda, que estivesse preparado para tratar de problemas decorrentes de ambientes distribuídos. Em vista disso, construiu-se o EPS. 


\begin{tabular}{|c|c|c|c|c|c|c|}
\hline $\begin{array}{l}\text { Sistema } \\
\text { x Carac- } \\
\text { teristica }\end{array}$ & $\begin{array}{l}\text { Eventos } \\
\text { Primiti- } \\
\text { vos }\end{array}$ & $\begin{array}{l}\text { Eventos } \\
\text { compos- } \\
\text { tos }\end{array}$ & $\begin{array}{l}\text { Parâmetros } \\
\text { de con- } \\
\text { texto }\end{array}$ & $\begin{array}{l}\text { Mecanismo } \\
\text { do pro- } \\
\text { cessa- } \\
\text { mento }\end{array}$ & $\begin{array}{l}\text { Área de } \\
\text { Atuação }\end{array}$ & Outros \\
\hline Samos & $\begin{array}{l}\text { Externos, } \\
\text { Temporais } \\
\text { e Internos } \\
\text { (BD) }\end{array}$ & $\begin{array}{l}\text { Disjunção, } \\
\text { Conjunção, } \\
\text { Seqüência, } \\
\text { Times e } \\
\text { Not }\end{array}$ & não & $\begin{array}{l}\text { Redes de } \\
\text { Petri }\end{array}$ & $\begin{array}{l}\text { Banco de } \\
\text { Dados } \\
\text { Ativo }\end{array}$ & $\begin{array}{l}\text { Ambiente } \\
\text { Centraliza- } \\
\text { do }\end{array}$ \\
\hline Ode & $\begin{array}{l}\text { Externos, } \\
\text { Temporais } \\
\text { e Internos } \\
\text { (BD) }\end{array}$ & $\begin{array}{l}\text { Disjunção, } \\
\text { Negação, } \\
\text { Relative e } \\
\text { Relative+ }\end{array}$ & não & $\begin{array}{l}\text { Autômatos } \\
\text { finitos }\end{array}$ & $\begin{array}{l}\text { Banco de } \\
\text { Dados } \\
\text { Ativo }\end{array}$ & $\begin{array}{l}\text { Ambiente } \\
\text { Centraliza- } \\
\text { do }\end{array}$ \\
\hline Sentinel & $\begin{array}{l}\text { Externos, } \\
\text { Temporais } \\
\text { e Internos } \\
\text { (BD) }\end{array}$ & $\begin{array}{l}\text { Or, And, } \\
\text { Seqüência, } \\
\text { Any, Not, } \\
\text { Periódicos } \\
\text { e Ape- } \\
\text { riódicos }\end{array}$ & $\begin{array}{l}\text { Recente, } \\
\text { Cro- } \\
\text { nológico, } \\
\text { Contínuo e } \\
\text { Acumulati- } \\
\text { vo }\end{array}$ & $\begin{array}{l}\text { Árvores } \\
\text { Agregadas }\end{array}$ & $\begin{array}{l}\text { Banco de } \\
\text { Dados } \\
\text { Ativo }\end{array}$ & $\begin{array}{l}\text { Ambiente } \\
\text { Centraliza- } \\
\text { do }\end{array}$ \\
\hline Eve & $\begin{array}{l}\text { Temporais } \\
\text { e Internos }\end{array}$ & $\begin{array}{l}\text { Seqüência, } \\
\text { Conjunção, } \\
\text { Repetição, } \\
\text { Negação } \\
\text { e Con- } \\
\text { corrência }\end{array}$ & nāo & $\begin{array}{l}\text { Árvores } \\
\text { Simples }\end{array}$ & Workflow & $\begin{array}{l}\text { Ambiente } \\
\text { Distribuído }\end{array}$ \\
\hline Gem & $\begin{array}{l}\text { Temporais } \\
\text { e Externos }\end{array}$ & $\begin{array}{l}\text { Conjunção, } \\
\text { Disjunção, } \\
\text { Seqüência } \\
\text { e Negação }\end{array}$ & nāo & $\begin{array}{l}\text { Árvores } \\
\text { Simples }\end{array}$ & Genérico & $\begin{array}{l}\text { Ambiente } \\
\text { Distribuído }\end{array}$ \\
\hline EPS & $\begin{array}{l}\text { Temporais } \\
\text { e Externos }\end{array}$ & $\begin{array}{l}\text { Conjunção, } \\
\text { Disjunção, } \\
\text { Seqüência e } \\
\text { Repetição }\end{array}$ & não & $\begin{array}{l}\text { Árvores } \\
\text { Agregadas }\end{array}$ & Genérico & $\begin{array}{l}\text { Ambiente } \\
\text { Distribuído }\end{array}$ \\
\hline
\end{tabular}

Tabela 2.2: Quadro Comparativo entre os trabalhos analisados. 


\section{Capítulo 3}

\section{Serviço de Processamento de Eventos - EPS}

Neste Capítulo apresentamos o serviço de processamento de eventos (EPS) desenvolvido neste trabalho. Este serviço tem como finalidade automatizar a notificação de eventos para as aplicações. Para isso, as aplicações enviam um Pedido-de-Notificação para o EPS e este as avisa assim que o evento de interesse for gerado. Nas Seções seguintes descreveremos a estrutura e o funcionamento deste serviço.

\subsection{Interface}

O EPS interage com os processos das aplicações que o utilizam através de duas interfaces. Uma das interfaces é usada durante a operação do serviço. Esta interface é utilizada na troca de informações com os processos da aplicação, isto é, para receber Pedidos-de-Notificação, para receber avisos de geração de instâncias de evento e para enviar notificações aos processos da aplicação (maiores detalhes na Seção 3.3). A outra interface diz respeito à configuração do EPS. A interface de configuração é utilizada apenas na inicialização do EPS. Essa configuração determina parâmetros globais do processamento de eventos, os quais são válidos para todos os processos de aplicação que utilizarem o EPS. Os parâmetros de configuração do EPS são: Janela de Deteç̧ão (JD), Tempo de Escalonamento (TE) (vide Seção 3.5), Tempo de Concorrência (TC) e Tipos de eventos primitivos (Event).

Cada tipo de evento primitivo é definido por uma palavra-chave e uma 
lista de nomes de atributos cujos valores são atribuídos pelos "sensores" responsáveis pela detecção de eventos primitivos específicos da aplicação.

O parâmetro Tempo de Concorrência indica ao processador de eventos quando duas instâncias devem ser consideradas concorrentes (simultâneas). Duas instâncias são ditas concorrentes se a diferença entre as marcas de tempo das duas instâncias é inferior ao valor deste parâmetro. A figura 3.1 mostra as interfaces do EPS.

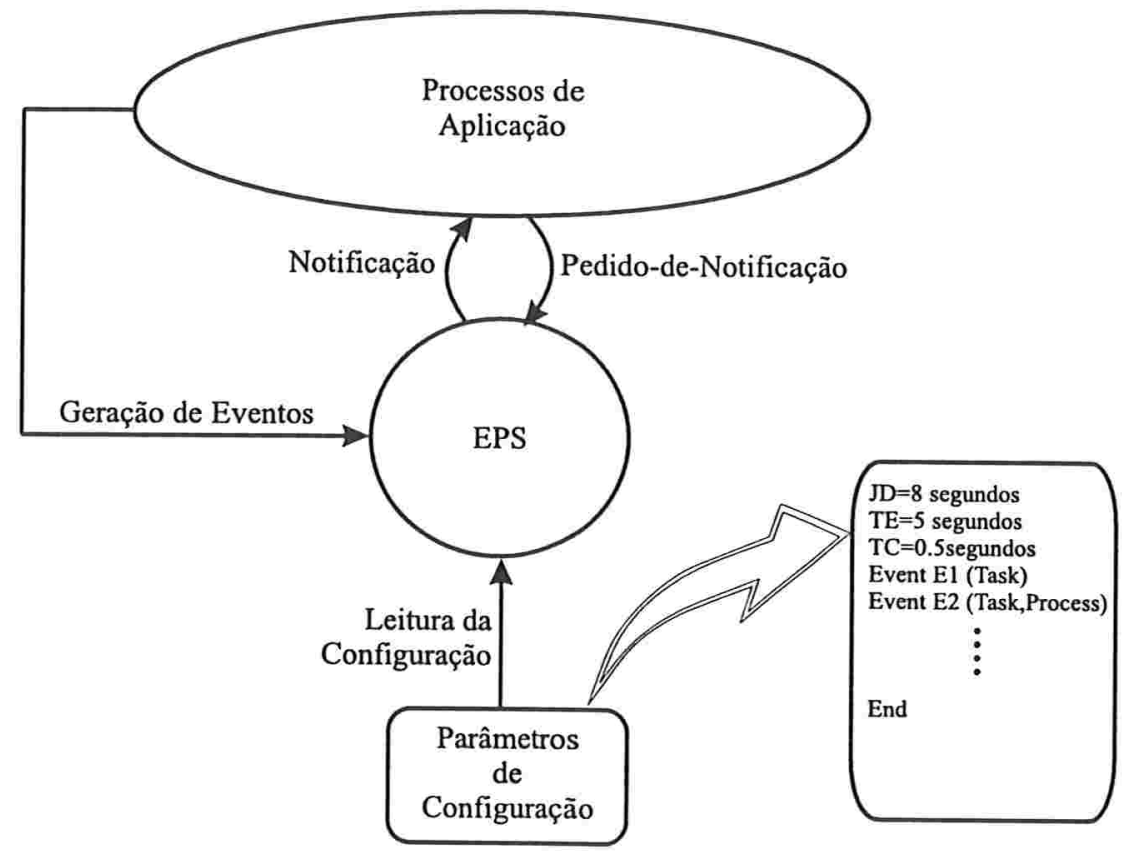

Figura 3.1: Esquema da interface do EPS com os processos de aplicação

\subsection{Arquitetura}

Os principais componentes do EPS são o Gerenciador de Interesse e o Monitor de Eventos, conforme pode ser visto na figura 3.2. O Gerenciador de Interesse é responsável por receber as mensagens do tipo Pedido-de-Notificação. Mensagens deste tipo podem requisitar o registro de interesse em um evento ou cancelar tal registro de interesse. Ao receber um registro de interesse, o gerenciador irá construir a árvore correspondente ao evento (primitivo ou composto) de interesse e tentará combinar esta árvore com as 
existentes. A construção da árvore é discutida em detalhes seção 3.6. Caso o evento de interesse da aplicação seja um evento de tempo periódico ou absoluto, nenhuma árvore será construída, mas será realizado um agendamento deste interesse com o Timer, que por sua vez é uma unidade do monitor (vide figura 3.2). No caso de eventos de tempo relativo, constrói-se a árvore correspondente ao evento e quando uma instância deste evento for gerada realiza-se o agendamento com o Timer. O instante de tempo a ser agendado é igual à marca de tempo da instância do evento somado ao tempo especificado no Pedido-de-Notificação fornecido pelo processo de aplicação.

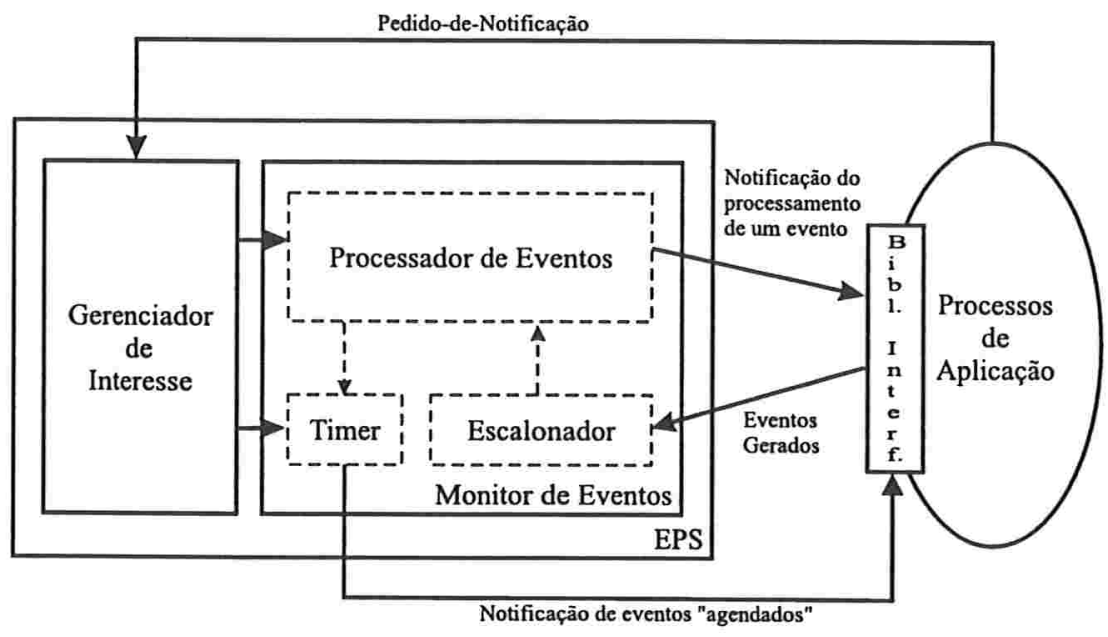

Figura 3.2: Arquitetura do EPS

O Monitor de Eventos do EPS é constituído das unidades Timer, Processador de Eventos e Escalonador. O Timer é responsável pela notificação dos processos de aplicação no instante determinado pelo agendamento. O agendamento pode ser feito pelo gerenciador de interesse (para os eventos de tempo absolutos ou periódicos) ou pelo processador de eventos (para os eventos relativos). O Processador de Eventos é o responsável pelo processamento das instâncias de evento na árvore. Toda vez que o processamento atingir uma raiz da árvore, uma notificação é enviada ao processo de aplicação associado à raiz atingida. As instâncias de evento primitivo são passadas ao processador de eventos pela unidade Escalonador. Esta unidade tem por função ordenar e liberar, uma a uma, as instâncias de evento primitivo geradas pelos sensores dos processos de aplicação. 


\subsection{Pedido-de-Notificação}

As mensagens de Pedido-de-Notificação enviadas ao EPS pelos processos de aplicação consistem de três elementos e baseiam-se no paradigma $E C A$ (Evento-Condição-Ação) $[4,8]$. Cada elemento desta tripla tem a seguinte função:

Evento: informar qual o evento ou expressão de evento de interesse;

Condição: fornecer uma condição a ser satisfeita pelos valores dos atributos das instâncias de evento que compõem o evento de interesse;

Ação: informar qual é a função a ser executada quando uma instância do evento requisitado for gerada.

Para cada mensagem contendo um registro de interesse, um identificador único é gerado pelo monitor de eventos e enviado ao processo de aplicação. De posse deste identificador o processo de aplicação pode, posteriormente, cancelar o registro de interesse neste evento.

Ao registrar interesse em um evento, o processo de aplicação fornece uma expressão contendo a condição que a instância do evento deverá satisfazer. As expressões definindo a condição devem ser construídas de acordo com a seguinte gramática:

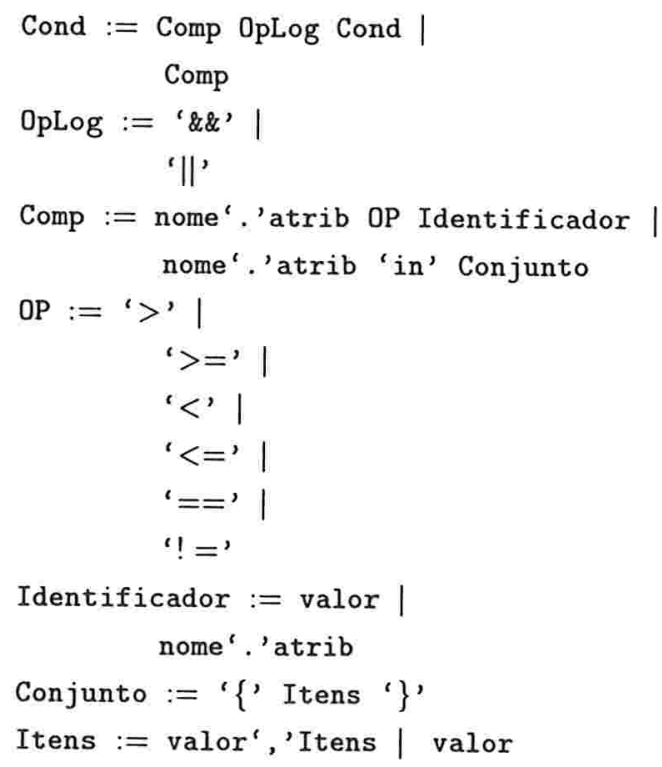


onde:

valor é uma seqüência de caracteres;

atrib é o nome de um atributo de evento. Os possíveis nomes são: TIPO, ORIGEM, TIMESTAMP mais os nomes declarados nos parâmetros de configuração do EPS. Vale lembrar que os atributos referenciados em uma condição são sempre os atributos das instâncias de eventos primitivos e nunca de instâncias de eventos compostos;

nome é uma seqüência de caracteres que representa um rótulo associado a uma instância de um tipo de evento na expressão de eventos (conforme será descrito na seção 3.4.3.

Não há precedência entre os operadores lógicos (\&\& e \|) e a sua associatividade é sempre da esquerda para a direita, ou seja $A \& \& B \| C$ é equivalente a $(A \& \& B) \| C$.

\subsection{Expressão de Eventos}

Nesta seção descreveremos os operadores que podem ser usados para criar uma expressão de eventos que caracteriza a estrutura de um evento composto baseado em eventos primitivos. Tal expressão de eventos é a primeira componente de um Pedido-de-Notificação.

\subsubsection{Eventos Compostos}

Os eventos compostos no EPS podem ser construídos utilizando-se os seguintes operadores de composição de eventos:

G : Este operador de eventos representa a conjunção $\left(E_{1} \& E_{2}\right)$ de dois tipos de evento $E_{1}$ e $E_{2}$. Uma instância deste tipo de evento será gerada quando tiverem sido geradas instâncias dos tipos de evento $E_{1}$ e $E_{2}$, independente da ordem de geração.

| : Este operador de eventos representa a disjunção $\left(E_{1} \mid E_{2}\right)$ de dois tipos de evento $E_{1}$ e $E_{2}$. Uma instância deste tipo de evento será gerada quando uma instância do tipo de evento $E_{1}$ ou uma instância do tipo de evento $E_{2}$ tiver sido gerada. 
; : Este operador de eventos representa a seqüência $\left(E_{1} ; E_{2}\right)$ de dois tipos de evento $E_{1}$ e $E_{2}$. Uma instância deste tipo de evento será gerada quando tiverem sido geradas instância dos tipos de evento $E_{1}$ e $E_{2}$, nesta ordem. Além disso, essas instâncias não podem ser concorrentes.

TimesEq : Este operador de eventos representa $n$ repetições de um mesmo tipo de evento $E$ (notação: Times $E q(E, n, a t r i b)$ ). Uma instância deste tipo de evento será gerada quando $n$ instâncias do tipo de evento $E$ tiverem sido geradas e todas elas tiverem o mesmo valor para o atributo atrib.

TimesDf : Este operador de eventos também representa $n$ repetições de um mesmo tipo de evento $E$, mas com valores diferentes para o atributo (notação: TimesD $(E, n, a t r i b)$ ). Uma instância deste tipo de evento será gerada quando $n$ instâncias do tipo de evento $E$ tiverem sido geradas e não existir, entre as $n$ instâncias de $E$, duas instâncias com o mesmos valor para o atributo atrib.

Em certas aplicações os operadores TimesEq e TimesDf podem ser úteis para detectar a geração de múltiplas instâncias de um mesmo tipo de evento, como por exemplo a notificação de timeout na comunicação com um mesmo nó da rede. Um exemplo mais detalhado da utilização destes operadores para uma aplicação tolerante a falhas é apresentado no Capítulo 5.

As instâncias de eventos compostos definidas pelos operadores acima têm como único atributo a marca de tempo (o nome deste atributo referenciado na gramática de eventos e na gramática da condição é TIMESTAMP), o qual informa quando a instância do evento composto foi gerada. Em todos os casos a marca de tempo corresponde a marca de tempo mais recente dentre as marcas de tempo das instâncias componentes. Para que uma instância de evento composto seja gerada todas as instâncias componentes devem pertencer a mesma janela de deteç̧ão.

\subsubsection{Eventos de Tempo}

O EPS disponibiliza três tipos de eventos de tempo: eventos absolutos, eventos periódicos e eventos relativos. Os eventos absolutos especificam um instante exato no tempo. Os Pedidos-de-Notificação para eventos deste tipo informam o ano, mês, dia, hora, minuto e segundo no qual o evento deve ser agendado. Os eventos periódicos permitem um escalonamento ("programação") de tarefas a serem repetidas ao se completar um determinado 
período de tempo. Os Pedidos-de-Notificação para eventos periódicos utilizam os símbolos $+\mathrm{e} *$ para definir a freqüência com que o evento deverá ser agendado. $\mathrm{O}$ símbolo ' + ' deve ser seguido de um número $n$ que informa qual é o incremento de tempo a ser usado a partir do último agendamento. Este incremento depende da posição em que o símbolo aparece na fórmula de uma data. Por exemplo, 1998/03/+3,+2:00:00 indica que o evento será gerado a cada 3 dias e 2 horas do mês de março do ano de 1998. Já o símbolo '*' funciona com uma máscara para a posição especificada e determina um incremento unitário apenas no ' $*$ ' mais a direita. Por exemplo, 1998/05/*,*:*:0 indica o agendamento do evento em todo minuto do mês de maio.

Quando um processo de aplicação registra interesse em um evento relativo, ele fornece o evento (primitivo ou composto) de interesse e o tempo a ser esperado após a geração de uma instância deste evento usando, para isto, a mesma notação acima exceto pelos símbolos.

\subsubsection{Gramática de Eventos}

As expressões de eventos são construídas de acordo com a seguinte gramática:

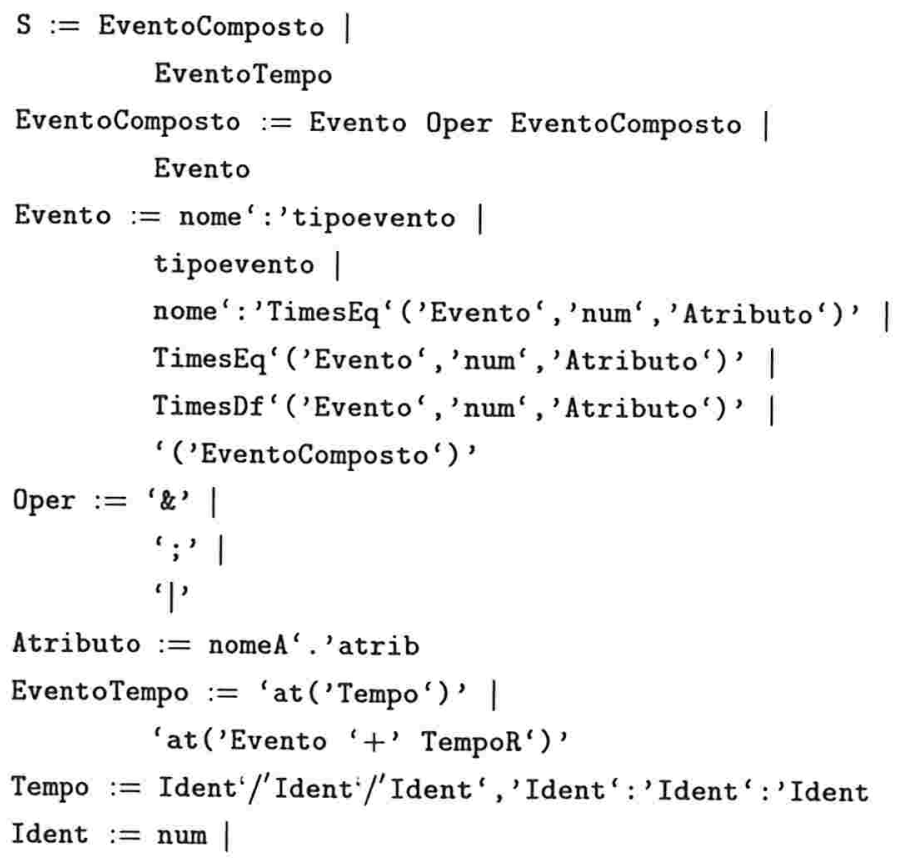


'+'num |
'*'
TempoR := num'/'num'/'num', 'num': 'num': 'num

onde:

num é uma seqüência de dígitos;

atrib é o nome de um atributo de evento. Os possíveis nomes são: TIPO, ORIGEM, TIMESTAMP mais os nomes declarados nos parâmetros de configuração do EPS. Vale lembrar que os atributos referenciados em uma condição são sempre os atributos das instâncias de eventos primitivos e nunca de instâncias de eventos compostos;

nome é uma seqüência de caracteres que define um rótulo para o tipo de evento que segue este nome;

nomeA é uma seqüência de caracteres que representa um tipo de evento, ou seja, este nome corresponde ao rótulo de algum tipo de evento;

tipoevento é o identificador de um tipo de evento primitivo.

\subsection{Trabalhando com Atrasos}

Em ambientes distribuídos a comunicação entre dois processos leva um tempo não constante. Como conseqüência, o instante de geração de uma instância por um sensor normalmente difere do instante em que esta mesma instância é recebida pelo EPS. Além disso, as instâncias de evento primitivo geradas podem chegar no EPS fora de ordem, ou seja, as instâncias podem chegar em uma ordem diferente da que foram geradas. Essas características de ambientes distribuídos tornam o processamento de eventos mais complexo.

Se utilizarmos as técnicas de ambientes centralizados para processar eventos, poderemos processar eventos inválidos (eventos muito antigos), gerar eventos compostos que não deveríamos ou deixar de gerar eventos que deveríamos.

$\mathrm{Na}$ figura 3.3 vemos um exemplo de um processamento utilizando-se as técnicas de ambientes centralizados. Neste exemplo, há interesse no evento composto $\left(E_{1} ; E_{2}\right)$. São geradas, nesta ordem, as seguintes instâncias: 


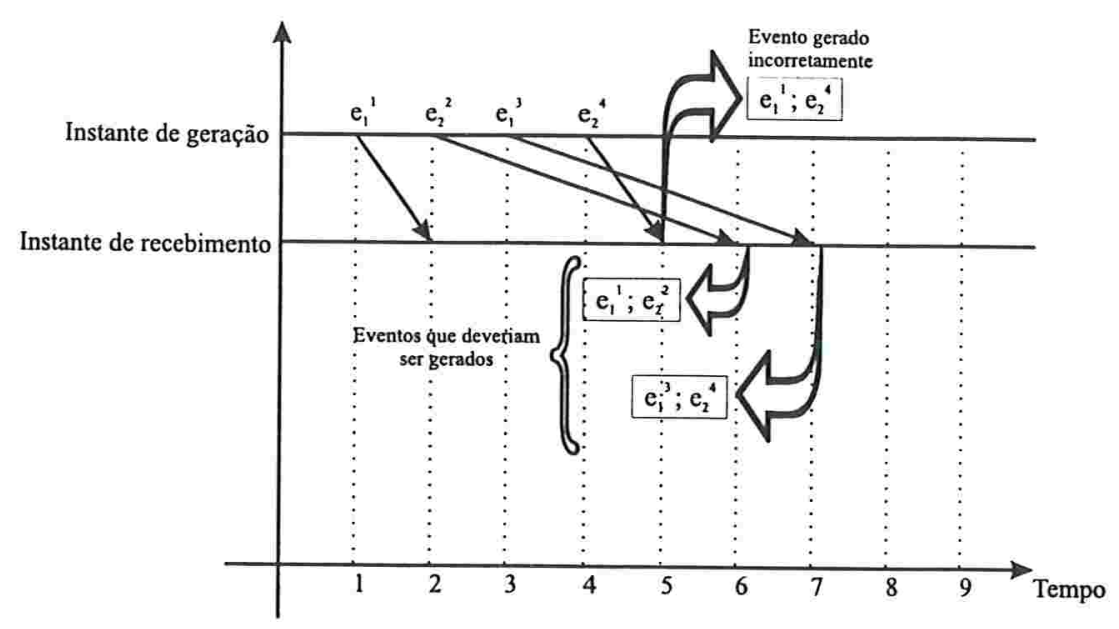

Figura 3.3: Problemas de processamento de eventos distribuídos usando técnicas de ambientes centralizados.

$e_{1}^{1}, e_{2}^{2}, e_{1}^{3}$ e $e_{2}^{4}$, mas devido a atrasos na comunicação, o EPS recebe estas instâncias na seguinte ordem: $e_{1}^{1}, e_{2}^{4}, e_{2}^{2}$ e $e_{1}^{3}$. Pela ordem em que as instâncias foram geradas deveríamos ter gerado as seguintes instâncias do evento composto: $\left(e_{1}^{1} ; e_{2}^{2}\right)$ e $\left(e_{1}^{3} ; e_{2}^{4}\right)$. Porém, se as instâncias forem processadas na ordem de chegada, haverá a geração incorreta da instância: $\left(e_{1}^{1} ; e_{2}^{4}\right)$.

No EPS estes problemas são tratados pelo monitor de eventos usando os seguintes conceitos:

Janela de Detecção: Indica um período de tempo dentro do qual uma instância de evento pode ser tratada, ou seja, uma vez que a instância de evento é gerada ela tem o tempo determinado pela Janela de Detecção para ser processada. Passado este tempo a instância é descartada, ou seja, a janela de deteç̧ão determina um prazo de validade de um instância. Uma instância de evento é válida se a diferença entre o instante atual e sua marca de tempo for inferior ao intervalo de uma janela de detecção. A figura 3.4 exemplifica o uso da janela de detecção para o recebimento de novas instâncias;

Tempo de Escalonamento: Indica um tempo de espera antes do processamento de uma instância de evento primitivo. Este parâmetro é utilizado pelo Escalonador para determinar o momento de liberação das instâncias de evento primitivo para o Processador de eventos do EPS. A figura 3.5 mostra um exemplo da utilização do tempo de escalonamento. Neste exemplo, o EPS recebe a instância $e_{2}^{4}$ antes das instâncias 


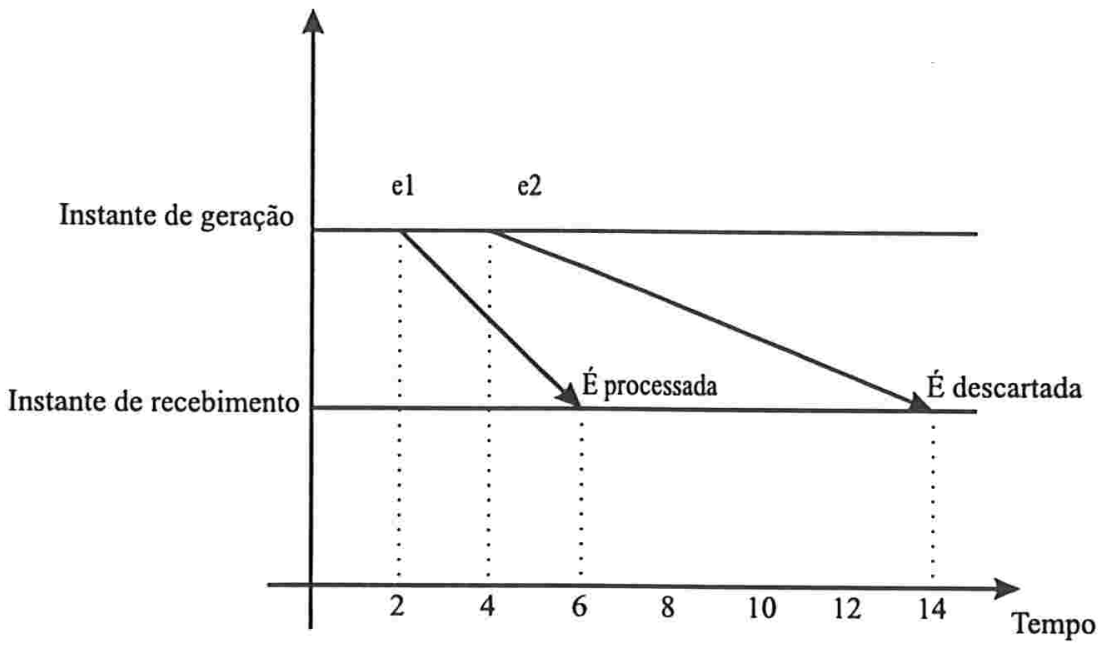

Figura 3.4: Exemplo da utilização da janela de detecção de 8 unidades.

$e_{1}^{3}$ e $e_{2}^{2}$, mas o escalonador retém a instância $e_{2}^{4}$, possibilitando o recebimento das outras duas instâncias. Com esta retenção temporária as instâncias são passadas ao processador de eventos na ordem correta.

Para funcionar corretamente, o tempo de escalonamento depende de uma estimativa do tempo máximo de atraso entre a geração e o recebimento de uma instância de evento. Por exemplo, se este tempo máximo for de 10 unidades de tempo e o tempo de escalonamento for de 8 unidades, haverá a possibilidade de instâncias serem tratadas fora de ordem gerando um processamento incorreto. Além disso, a parametrização do tempo de escalonamento deve ser feita com muito cuidado.

Todo o processamento de eventos realizado no EPS depende do instante de geração das instâncias. Esse instante é determinado pelos sensores das aplicações no momento em que uma instância é gerada. Estes sensores estão espalhados pela rede e, portanto, é necessário que exista um sincronismo entre os relógios dos diversos nós da rede. Para tal, no nosso trabalho assumimos a existência de um protocolo para a sincronização de relógios das máquinas que estão sendo utilizadas pelos sensores da aplicação.

\subsection{Processamento de Eventos}

O processador de eventos do EPS utiliza árvores para representar os 


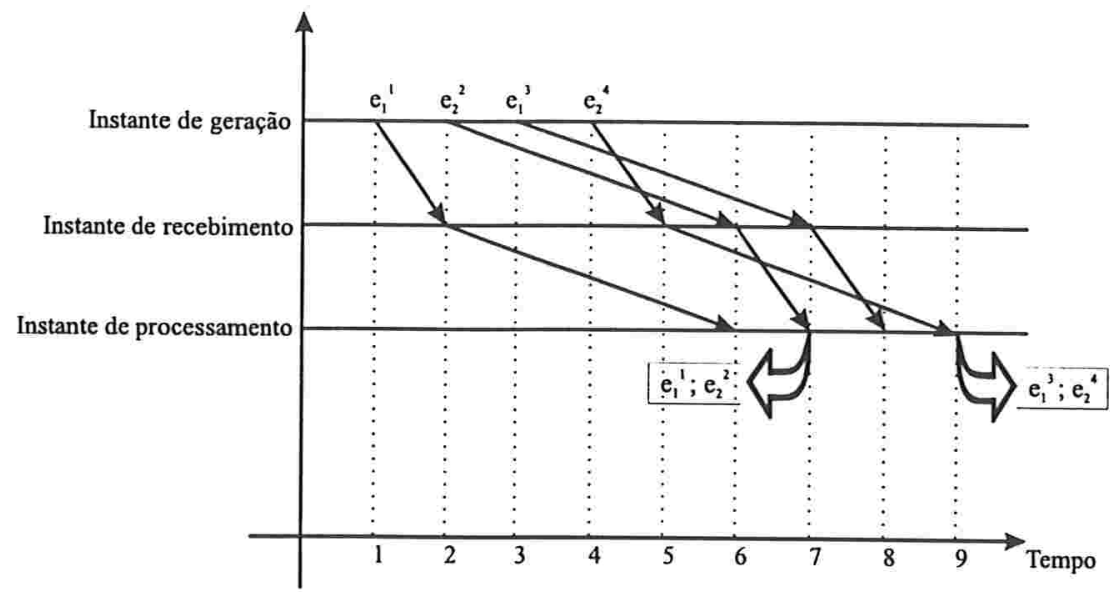

Figura 3.5: Exemplo mostrando a utilização do escalonamento de instâncias de eventos que chegam ao EPS. O Tempo de Escalonamento utilizado é de 5 unidades.

eventos compostos. Esta abordagem é comum e é encontrada também em outros trabalhos $[17,21,14,18]$. Uma árvore corresponde a um evento composto onde os tipos de eventos primitivos são representados por folhas, cada nó interno representa um tipo de evento composto, associado ao operador de composição de eventos correspondente, e os nós raízes representam os Pedidos-de-Notificação enviados pelos processos de aplicação. A condição e a ação a ser executada pelo EPS são mantidas nos nós raízes da árvore (maiores detalhes no Capítulo 4).

É possível que eventos compostos distintos tenham subexpressões em comum ou que um evento composto seja requerido por diversos processos de aplicação. Nestes casos, a abordagem comumente encontrada na literatura $[17,14]$ é manter árvores replicadas e independentes para cada evento composto de interesse.

Para evitar a redundância de espaço e processamento associados a esta replicação, optamos por um compartilhamento de subárvores comuns, criando o que chamamos de árvores agregadas. Agregando as árvores aumentamos a eficiência no processamento das instâncias de eventos e agilizamos também a notificação aos processos de aplicação.

O processamento de uma instância de evento primitivo começa pelas folhas das árvores. Caso não exista uma folha correspondente ao tipo da instância de evento gerada, não há processos de aplicação interessados neste evento e assim a instância é descartada. Ao encontrar a folha com o tipo cor- 
respondente ao tipo da instância de evento gerada, os atributos da instância de evento são armazenados e todos os nós pais desta folha são avisados da existência desta nova instância. Ao ser avisado, o nó pai verifica se pode gerar uma nova instância do evento composto correspondente ao seu operador. Se uma nova instância puder ser gerada, esta instância é armazenada na lista de instâncias do nó e um aviso de sua geração é passado para todos os respectivos pais deste nó. Enquanto novas instâncias puderem ser geradas continuamos subindo na árvore até que eventualmente sejam atingidos os nós raízes, quando os atributos das instâncias envolvidas serão utilizados para verificar a satisfação da condição.

No exemplo da Figura 3.6 vemos um exemplo do processamento das instâncias: $e_{1}^{1}, e_{2}^{2}, e_{3}^{3}, e_{2}^{4}, e_{3}^{5}, e_{2}^{6}$ com processos de aplicação interessados nos eventos compostos $\left(E_{1} \& E_{2} ; E_{3}\right)$ e $\left(E_{1} \& E_{2}\right)$. Neste exemplo, os quadros de $(a)$ até $(d)$ mostram a geração de instâncias de eventos compostos pelo Processador de eventos do EPS (maiores detalhes no capítulo 4). No quadro $(e)$ é mostrado a situação da árvore após a notificação da geração de uma instância do evento composto $\left(E_{1} \& E_{2} ; E_{3}\right)$. Nos demais quadros, as instâncias que são recebidas pelo EPS são armazenadas para futuras utilizações. Uma exceção ocorre no quadro $(h)$, onde a instância $e_{3}^{5}$ é descartada devido a semântica do operador ';' que exige que as instâncias do filho da direita tenham sido geradas após as instâncias do filho da esquerda. 

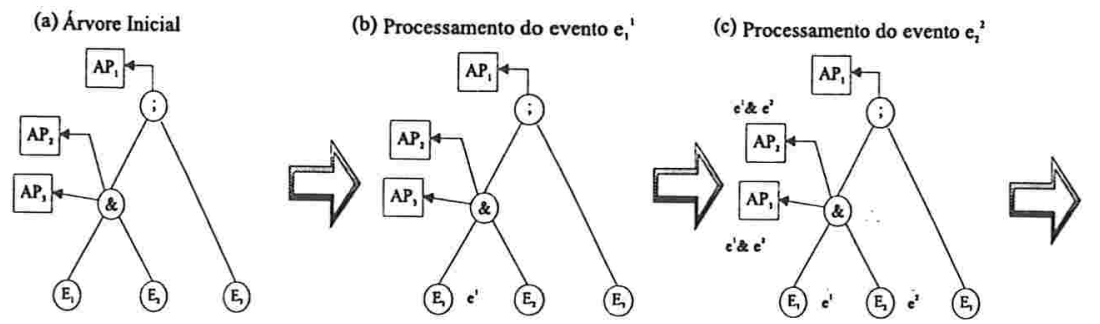

(d) Processamento do evento e,'

(e) Após o processamento do evento e, (f) Processamento do evento e $e_{3}$
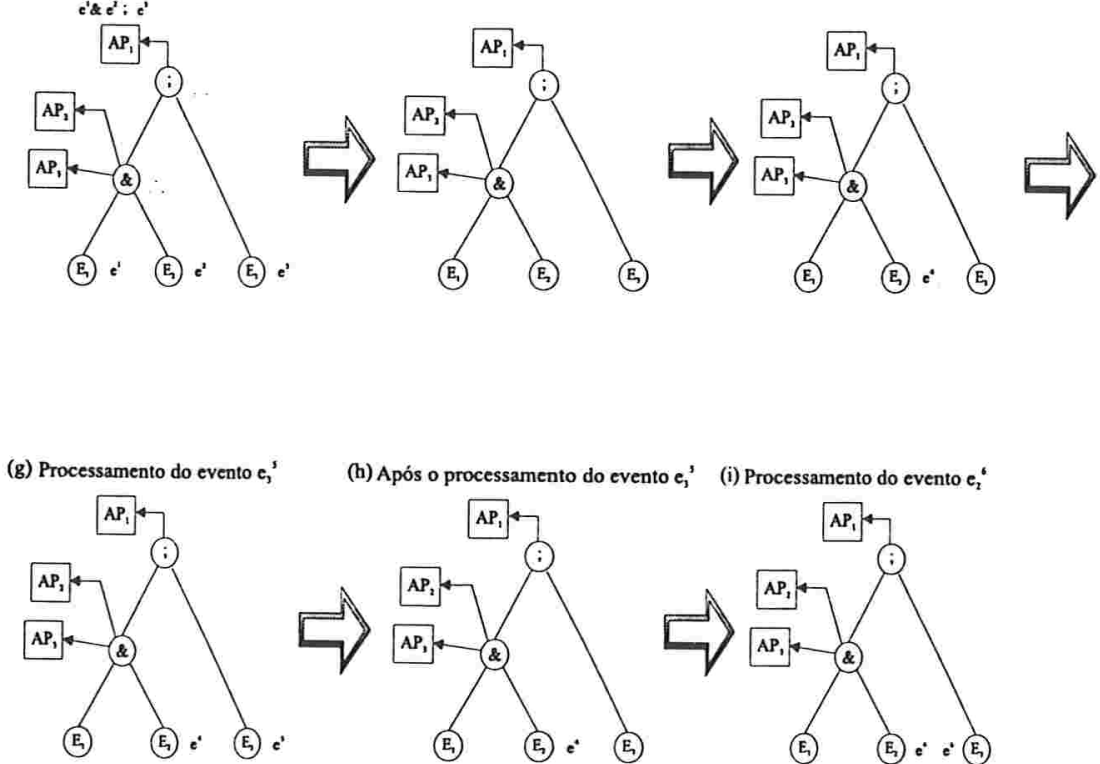

Figura 3.6: Exemplo do processamento de eventos 


\section{Capítulo 4}

\section{Processamento de Eventos}

Uma breve introdução ao processamento de eventos foi apresentada no Capítulo 3. Agora descreveremos esse processamento com maiores detalhes e com exemplos.

Para entendermos o resto do capítulo é importante conhecermos a diferença entre um nó da árvore de eventos e uma instância de evento. Um nó da árvore de eventos representa a intenção de algum processo de aplicação em saber da geração de determinado tipo de evento primitivo ou composto. Já a instância representa a geração, propriamente dita, de um evento primitivo ou composto. Embora nó e instância sejam elementos distintos, eles estão fortemente relacionados. Em todo nó da árvore de eventos existe uma lista de todas as instâncias já geradas para o tipo de evento primitivo ou composto representado pelo nó.

Para cada nova instância primitiva que for recebida pelo EPS, são realizadas todas as combinações possíveis entre esta nova instância e as instâncias já geradas, criando, assim, novas instâncias nos níveis superiores da árvore. Desta forma, construímos inúmeras árvores de instâncias (seguindo a mesma estrutura da árvore de eventos), as quais nos informarão quais eventos primitivos e compostos já foram gerados. Enquanto a árvore de eventos é criada a partir de um Pedido-de-Notificação uma "única" vez, à medida que novas instâncias vão sendo recebidas pelo EPS, árvores de instâncias vão sendo criadas, o que denominamos de processamento de eventos.

O processamento de eventos foi dividido em quatro fases, sendo que as três primeiras devem ser executadas em seqüência para cada nova instância que chegar ao EPS. Uma descrição formal das regras de cada fase encontra-se no apêndice $\mathrm{A}$, onde utilizou-se uma gramática de atributos para descrever 
o processamento para cada fase e para cada tipo de nó da árvore.

As fases do processamento são:

1. Construção das árvores de instâncias: O objetivo desta fase é construir as árvores de instâncias a partir de uma instância primitiva que foi recebida pelo EPS e, ao alcançarmos um nó raiz da árvore de eventos, executar a função associada a esta raiz (Notificar a aplicação) consumindo a instância de evento composto gerada;

2. Consumo das instâncias: Nesta fase o objetivo é marcar todas as instâncias da árvore de instâncias que participaram diretamente na formação da instância consumida no final da primeira fase;

3. Anulando as instâncias: Nesta fase pretendemos marcar todas as instâncias da árvore de instâncias que não participaram diretamente da formação da instância consumida na primeira fase, mas estão relacionadas diretamente com as instâncias marcadas na segunda fase, ou seja, pretendemos marcar todas as instâncias que possuem como componentes pelo menos uma das instâncias de evento primitiva que foram marcadas na segunda fase;

4. Coleta de lixo: Ao terminar as três primeiras fases, muitas instâncias foram criadas sendo que várias poderiam ser eliminadas. Nesta fase estaremos removendo estas instâncias. A coleta de lixo tem início em qualquer nó raiz e, a partir deste nó, desce-se na árvore até atingir os nós folhas ou até verificar-se que não há mais instâncias a serem removidas nos níveis inferiores.

Nos exemplos utilizados para exemplificar as quatro fases do processamento, adotamos círculos para representar os nós da árvore de eventos e linhas grossas indicarão a estrutura da árvore de eventos. As instâncias são representadas por retângulos e linhas finas indicarão como as instâncias estão relacionadas. Nos retângulos, os dois conjuntos status e users, descritos na seção seguinte, estarão representados na parte superior e inferior, respectivamente.

\subsection{Atributos internos}

Além dos atributos comuns a todos os tipos de eventos, tais como: TIMESTAMP, ORIGEM, TIPO, e outros específicos de cada tipo do evento, 
temos dois outros atributos para cada instância, os quais são utilizados apenas no processamento de eventos para guardar informações a respeito da utilização de uma instância pelos diversos nós raízes.

Os dois atributos são:

users: Este conjunto contém a identificação dos nós raízes que já utilizaram a instância, ou seja, devido ao consumo direto ou devido a anulação.

status: É uma lista onde cada posição $i$ fornece a informação da utilização desta instância pelo i-ésimo pai do nó a qual esta instância está associada. Cada posição pode assumir um dos seguintes valores (em ordem decrescente de precisão no conhecimento do estado desta instância):

C: Indica que esta instância foi consumida pelo nó pai correspondente;

U: Indica que todos os nós nos níveis superiores, a partir do nó pai correspondente, já utilizaram por completo esta instância;

A: Só uma instância associada a um nó raiz pode ter este estado, o qual é atingido se pelo menos uma de suas instâncias componentes foi utilizada por este nó raiz, ou seja, o estado de uma das instâncias componentes deve ser $C, P U$ ou $U$ e a identificação deste nó raiz deve pertencer ao seu conjunto users;

PU: Uma instância está parcialmente utilizada enquanto existirem nós raízes da árvore de eventos que ainda não utilizaram esta instância;

PA: Este estado só pode ser atingido durante a terceira fase do processamento e indica que esta instância eventualmente poderá ser cancelada, mas como não sabemos se há ou não nós raízes nos níveis superiores que ainda não a utilizaram ou a anularam, dizemos que esta instância está parcialmente anulada;

SU: Este é o estado inicial de utilização pelos nós pais para todas as novas instâncias. $\mathrm{O}$ mesmo indica que nada se sabe a respeito de sua utilização pelos nós pais.

Nas próximas Seções serão apresentadas as quatro fases do processamento de eventos. Para explicar o princípio de funcionamento de cada fase, utilizamos um exemplo simples. A árvore utilizada no exemplo é a representação dos seguintes eventos compostos: $A p l_{1}=E_{1}$ \& Times $E q\left(E_{2}, 2\right.$, "atributo1") e $A p l_{2}=$ TimesE $q\left(E_{2}, 2\right.$, "atributo1") ; $E_{3}$. 


\subsection{Primeira fase}

A primeira fase é iniciada toda vez que uma nova instância é recebida pelo processador de eventos. Inicialmente, esta instância é associada ao nó folha correspondente ao seu tipo de evento e sua chegada é propagada árvore acima. A cada nível que se sobe na árvore, novas instâncias são criadas. A quantidade de novas instâncias e como estas novas instâncias serão criadas depende do operador de composição de eventos e das instâncias filhas associadas aos nós filhos deste operador.

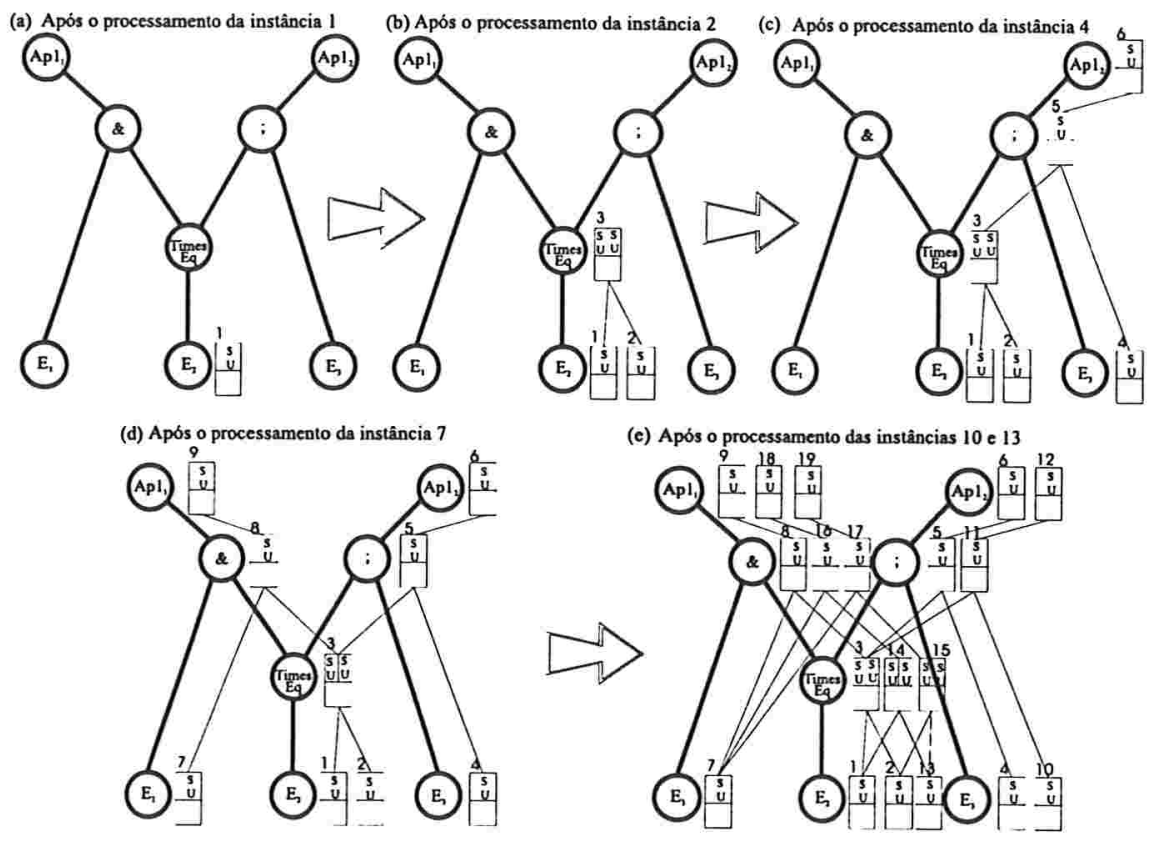

Figura 4.1: Processamento da primeira fase para 6 novas instâncias.

Na figura 4.1 vemos como os conjuntos de instâncias de cada nó vão sendo construídos durante esta fase. Por exemplo, o operador de conjunção ('\&') constrói o seu conjunto de instâncias a partir do produto cartesiano dos conjuntos de instâncias associados aos nós filhos ( $E_{1}$ e TimesEq). O operador de seqüência (';') é um caso particular do operador ' $\&$ ', pois o conjunto de instâncias do operador ';' só contém os pares do produto cartesiano em que a instância associada ao nó filho da direita do operador tem a marca de tempo mais recente do que a instância que está associada ao nó filho da esquerda. Podemos ver isso na etapa (e) do exemplo da figura 4.1 onde a 
instância 10 do nó $E_{3}$ só forma par com a instância 3 do nó TimesEq (no exemplo o operador TimesEq tem $n=2$ como o número de repetições).

O operador de disjunção ('l'), embora não o tenhamos na figura, constrói o seu conjunto de instâncias a partir da união entre os conjuntos de instâncias associadas aos seus nós filhos.

Para os operadores de repetição TimesEq e TimesDf, o conjunto de instâncias criado por estes operadores corresponde a todas as combinações possíveis das instâncias associadas ao nó filho (conjunto L) em grupos de $N$, ou seja, a cardinalidade máxima deste conjunto é:

$$
\left(\begin{array}{c}
\operatorname{card}(L) \\
N
\end{array}\right)
$$

A cardinalidade, no entanto, pode ser menor dependendo dos valores dos atributos das instâncias do nó filho e da restrição imposta pelo operador sobre a igualdade ou desigualdade dos valores destes atributos.

Esta fase necessariamente termina ao atingirmos um nó raiz, mas se em algum nó intermediário nenhuma nova instância for criada, o processamento pára neste nó. Sempre que nesta fase alcançarmos um nó raiz terminamos esta fase e iniciamos diretamente a segunda fase.

Embora a quantidade de instâncias possa explodir (estamos fazendo o produto cartesiano) e tornar o processamento muito demorado, há dois mecanismos implementados no monitor que procuram amenizar este problema. Um desses mecanismos é a janela de detecção. Esse mecanismo faz com que uma instância só participe dos produtos cartesianos enquanto ela for válida. Outro mecanismo é a Quarta fase, que será explicada na Seção 4.4. Esse mecanismo faz com que a árvore de instâncias encolha com a mesma rapidez com que cresceu. Portanto, com esses dois mecanismos, a árvore de instâncias poderá crescer rapidamente apenas dentro de uma janela de detecção e, ainda, ela tende a encolher tão rapidamente quanto cresceu.

\subsection{Segunda e Terceira fases}

Nestas duas fases iremos descer (segunda fase) e subir (terceira fase) na árvore de eventos para marcar todas as instâncias que foram consumidas ou que não poderão mais fazer parte das futuras novas instâncias de eventos dos níveis superiores.

Como estas duas fases são intrinsecamente relacionadas e são sempre executadas em seqüência, optamos por descrevê-las juntas em uma única 
seção.

A tarefa da segunda fase é propagar a informação de consumo de uma instância por um nó raiz para todas as instâncias folhas que fazem parte da instância consumida. Essa propagação é realizada através do envio de uma mensagem $m$, contendo o estado da instância no nível $i$, para todas as instâncias filhas do nível $i-1$. O estado da instância a ser enviado na mensagem $m$ é obtido pela aplicação de uma das três regras abaixo:

1. Se todos os elementos da lista status tiverem valor $C$, então, $m=C$;

2. Se existir algum valor $P A$ ou $P U$ ou $S U$ na lista status, então, $m=$ $P U$;

3. Se nenhuma das regras acima puderem ser aplicadas, então, $m=U$.

Em outras palavras, a regra 1 nos diz que se uma instância foi consumida por todos os seus nós pais, seu estado é consumida ('C') e, consequentemente, as instâncias filhas também devem ser consumidas. A regra 2 nos diz que se existir um nó raiz da árvore que ainda não utilizou a instância, esta instância está parcialmente utilizada e, portanto, a mensagem a ser enviada é parcialmente utilizada. A regra $3 \mathrm{diz}$ que se todos os nós pais já utilizaram ou cancelaram a instância, esta instância foi totalmente utilizada por seus pais e as instâncias filhas também devem ser marcadas como totalmente utilizadas para este pai.

\begin{tabular}{|c|c|c|c|c|c|c|}
\hline MSG x Estado & C & U & A & PU & PA & SU \\
\hline C & C & C & C & C & C & C \\
\hline U & C & U & U & $*$ & $*$ & $*$ \\
\hline PU & C & U & A & PU & PU & PU \\
\hline A & C & U & A & PU & PA & $* *$ \\
\hline
\end{tabular}

Tabela 4.1: Tabela de transformação dos estados dos elementos de status.

Ao receber a mensagem $m$, de um de seus nós pais, digamos o j-ésimo pai, o novo estado de (status $[j]$ ) será calculado de acordo com a tabela 4.1. Nesta tabela o asterisco simples $\left({ }^{*}\right)$ indica que o novo estado da instância com relação ao $j$-ésimo pai depende também dos conjuntos users.

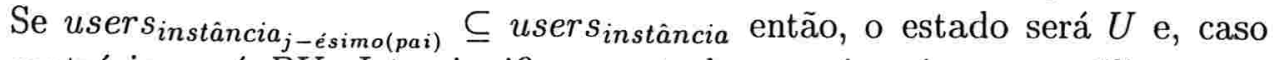
contrário, será $P U$. Isto significa que todos os nós raízes que utilizaram a instância pai associada ao j-ésimo pai, também utilizaram a instância em 
questão e então podemos dizer que a instância em questão foi totalmente utilizada.

A última linha da tabela 4.1 corresponde ao envio de mensagens durante a terceira fase. Nesta fase a mensagem a ser enviada é sempre $m=A$. $\mathrm{O}$ asterisco duplo $\left({ }^{* *}\right)$ indica que o estado da instância só será $A$ se esta instância pertencer ao conjunto de instâncias de um nó raiz. Caso contrário, seu estado será $P A$.
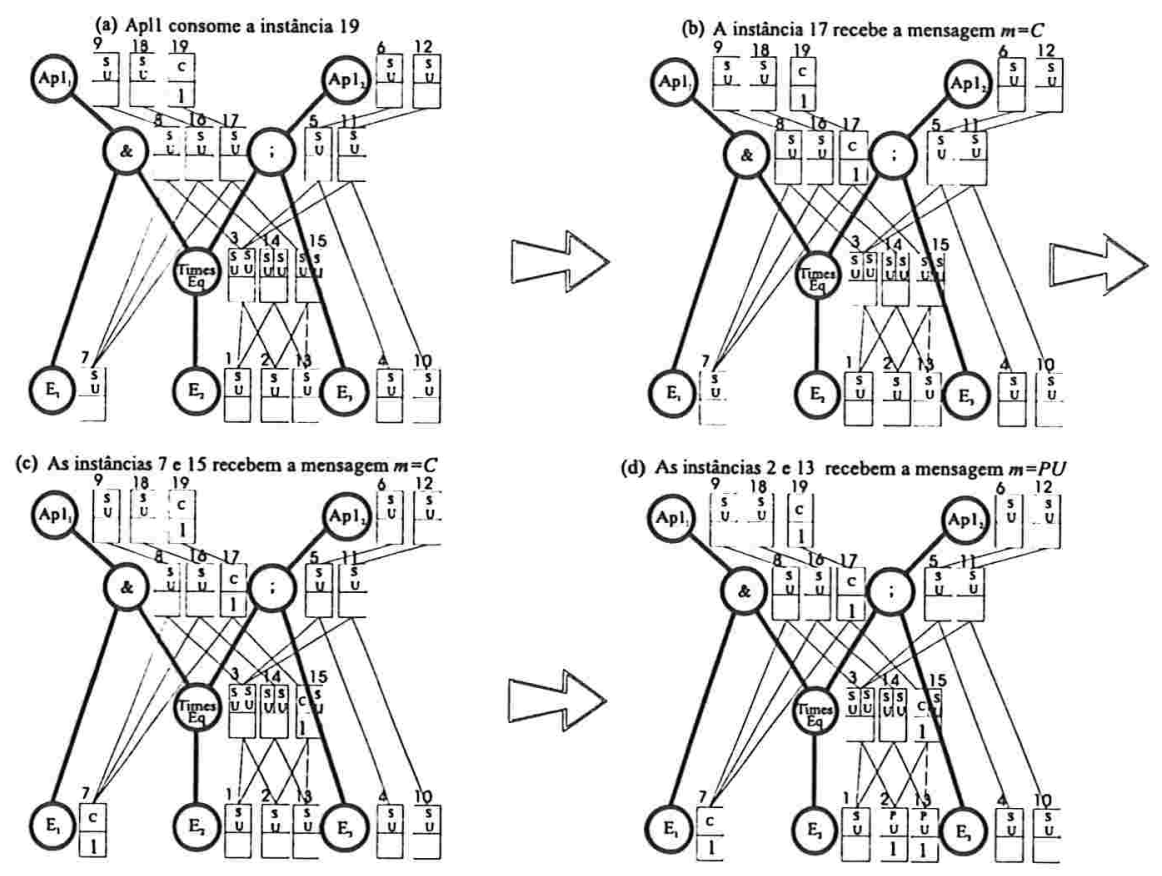

Figura 4.2: Processamento da segunda fase para o consumo da instância 19.

Na figura 4.2 temos um exemplo do processamento da segunda fase envolvendo 4 passos. No exemplo, a aplicação $A p l_{1}$ consome a instância 19. Esta instância atualiza sua lista status e aplica a regra 1 para obter a mensagem a ser enviada para as instâncias filhas, ou seja a instância 17 (etapa(a)). Recebendo a mensagem $m=C$ a instância 17 atualiza seu status para $C$ e, novamente, aplica a regra 1 para obter a nova mensagem a ser enviada as suas filhas, as instâncias 7 e 15 (etapa(b)). A instância 7 atualiza seu status para $C$ e termina o processamento por ser uma folha, enquanto que a instância 15 atualiza o seu status correspondente ao pai que enviou a mensagem $m$ e aplica a regra 2 para obter a nova mensagem a ser enviada as sua filhas, as instâncias 2 e 13 (etapa(c)). Ao receberem a mensagem 
$m=P U$ estas atualizam o seu status para $P U$ e finalizam o processamento da segunda fase (etapa(d)). Todas as instâncias envolvidas na descida, as instâncias 19, 17, 7, 15, 2 e 13, tiveram seus conjuntos users modificados. Este conjunto passou a ter a identificação do nó raiz $(i d=1)$, justamente o nó que iniciou a segunda fase.

Durante o processamento da segunda fase foi marcado o estado das instâncias que são componentes da instância consumida. Na terceira fase iremos atualizar os estados das instâncias que estão relacionadas com as instâncias componentes da instância consumida e, devido a isso, não podem mais serem utilizadas. Começamos a subir na árvore de eventos a partir dos nós folhas atingidos na segunda fase. Estes nós folhas enviam, para os nós pais percorridos na segunda fase, a mensagem $m=A$. A mensagem $m$ caminhará na árvore de eventos pelo mesmo caminho percorrido na segunda fase, só que no sentido oposto, e todas as instâncias associadas aos nós que receberem esta mensagem terão seu estado alterado de acordo com a tabela 4.1, desde que a instância tenha como componente a instância que iniciou a terceira fase.

A figura 4.3 mostra os passos executados durante a terceira fase. No primeiro passo (etapa (a)) as instâncias 2 e 13 enviam a mensagem $m=A$ para o nó pai (TimesEq) e este procura por instâncias que tenham como componente as instâncias 2 e 13. As instâncias encontradas (3, 14 e 15) atualizam o seu estado e enviam para o nó pai (\&) a mensagem $m=A$ (etapa(b)). O nó pai (\&) ao receber a mensagem $m=A$ vinda das instâncias $7,3,14$ e 15, procura por instâncias que tenham como componentes uma destas. As instâncias encontradas $(8,16$ e 17) tem seus estados atualizados e enviam uma mensagem $m=A$ para o nó pai (nó raiz $A p l_{1}$ ) (etapa(c)). Recebendo a mensagem, o nó raiz atualiza o estado das instâncias 9 e 18 como sendo anuladas, devido ao fato de terem como componentes a instância primitiva (7) consumida pela instância 19, e finaliza o processamento da terceira fase. 


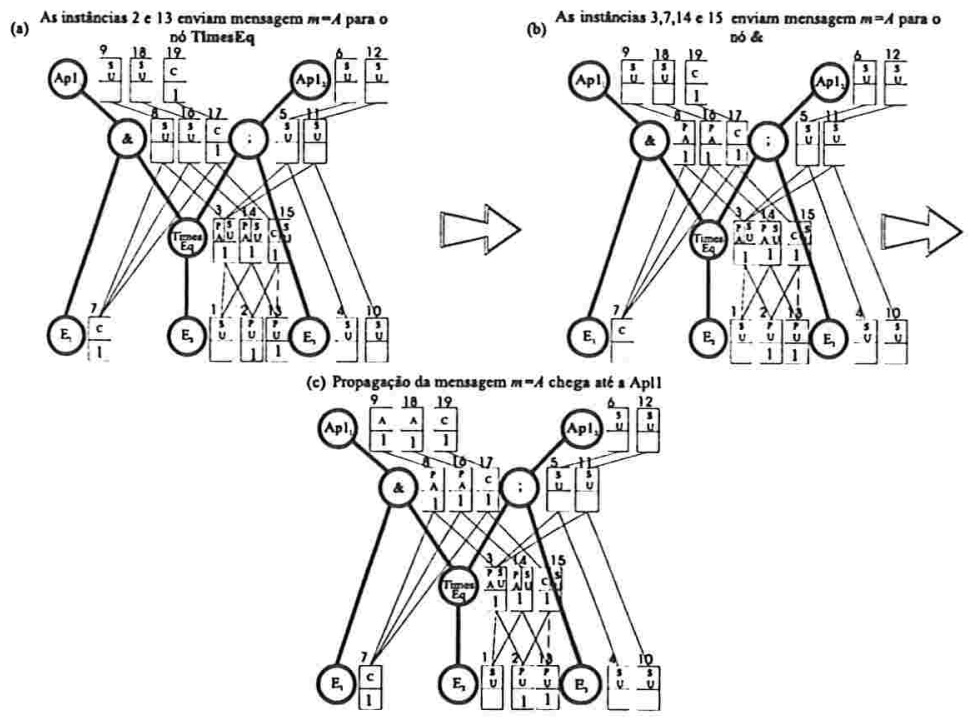

Figura 4.3: Processamento da terceira fase.

\subsection{Quarta fase}

Durante a primeira fase criamos várias instâncias e nas duas fases seguintes apenas marcamos as instâncias que não são mais úteis. Na quarta fase estas instâncias são, então, eliminadas como uma forma de coleta de lixo.

O processo de eliminação das instâncias "inúteis" começa por um nó raiz, geralmente o mesmo que iniciou a segunda fase. Assim, há uma grande possibilidade de eliminarmos várias instâncias. Neste nó raiz, procuramos pelas instâncias aptas a serem eliminadas, ou seja, as instâncias que já foram consumidas (estado $C$ ), anuladas (estado $A$ ) ou utilizadas (estado $U$ ) por todos os nós pais. No processo de eliminação, também enviamos uma mensagem $m=U$ para todos os nós filhos e nestes nós, atualizamos o estado das instâncias que são instâncias filhas de uma das instâncias que foram eli- 
minadas do nó pai. Após atualizarmos o estado, selecionamos as instâncias que só contenham em status os seguintes estados: $C, A$ ou $U$. A seleção das instâncias a serem eliminadas e o envio de mensagens, descritos acima, são repetidos recursivamente até chegarmos nos nós folhas ou até que não existiam mais instâncias que possam ser eliminadas.

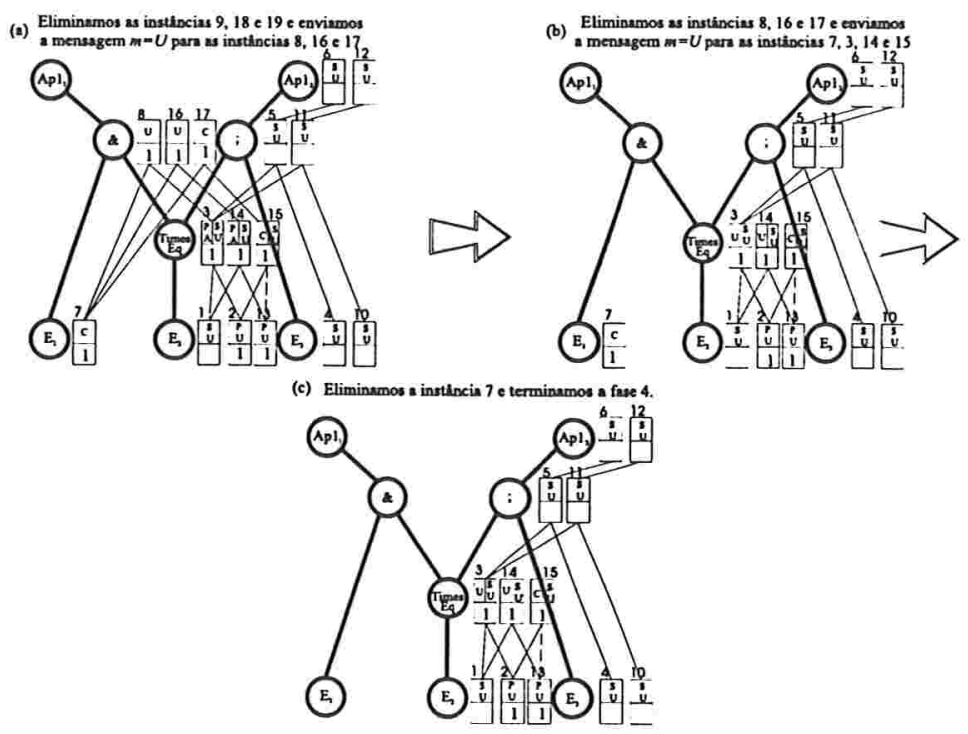

Figura 4.4: Processamento da quarta fase.

Na figura 4.4 vemos a quarta fase sendo executada em três passos. Primeiro, são eliminadas as instâncias 9,18 e 19 por terem os estados $A, A$ e $C$, respectivamente, e uma mensagem $m=U$ é enviada para as instâncias 8,16 e 17 (etapa(a)). Estas, ao receberem a mensagem, passam a ter os novos estados $U, U, C$. No próximo passo, essas três instâncias são eliminadas e as instâncias 7,3,14 e 15 recebem a mensagem $m=U$ e modificam o estado correspondente ao nó pai \& (etapa(b)). Finalmente, removemos a instância 7 por ser a única que tem cada elemento da sua lista status pertencendo ao conjunto $\{C, U, A\}$ (etapa(c)). 


\subsection{Limpeza da árvore}

Além da coleta de lixo realizada pela quarta fase, a cada vez que uma instância é consumida, é interessante eliminar, também, as instâncias cuja permanência no EPS tenha ultrapassado o limite de tempo determinado pela janela de deteç̧ão.

A limpeza por marca de tempo (atributo TIMESTAMP) consiste em analisar todas as instâncias existentes e, para cada uma, verificar a sua validade e se não há nenhuma instância, em níveis superiores da árvore, ainda válida que a esteja utilizando. Esta análise é feita árvore abaixo a partir dos nós raízes (top-down). Inicialmente, o conjunto de instâncias a ser analisado é composto pela união dos conjuntos de instâncias de todos os nós raízes da árvore de eventos. Ao término deste conjunto, o próximo conjunto a ser analisado é o conjunto formado pela união dos conjuntos de instâncias de todos os nós filhos dos nós analisados. E assim, sucessivamente, descemos na árvore até atingirmos os nós folhas.

Considerando que gostaríamos de eliminar o maior número possível de instâncias, o intervalo mínimo entre duas limpezas consecutivas deve ser de uma janela de deteç̧ão. Quanto maior o intervalo, maior a quantidade de instâncias que iremos eliminar mas, em compensação, teremos uma árvore sobrecarregada por mais tempo.

$\mathrm{Na}$ figura 4.5 ilustramos o funcionamento desta coleta de lixo por marca de tempo. Para este exemplo, consideramos que a janela detecção é de 14 unidades de tempo e o instante em que a limpeza geral está sendo realizada é o instante 25. Nesta figura 4.5, ao contrário das figuras 4.1,4.2,4.3 e 4.4, representamos as marcas de tempo das instâncias na parte inferior de sua representação, no lugar do conjunto users. 

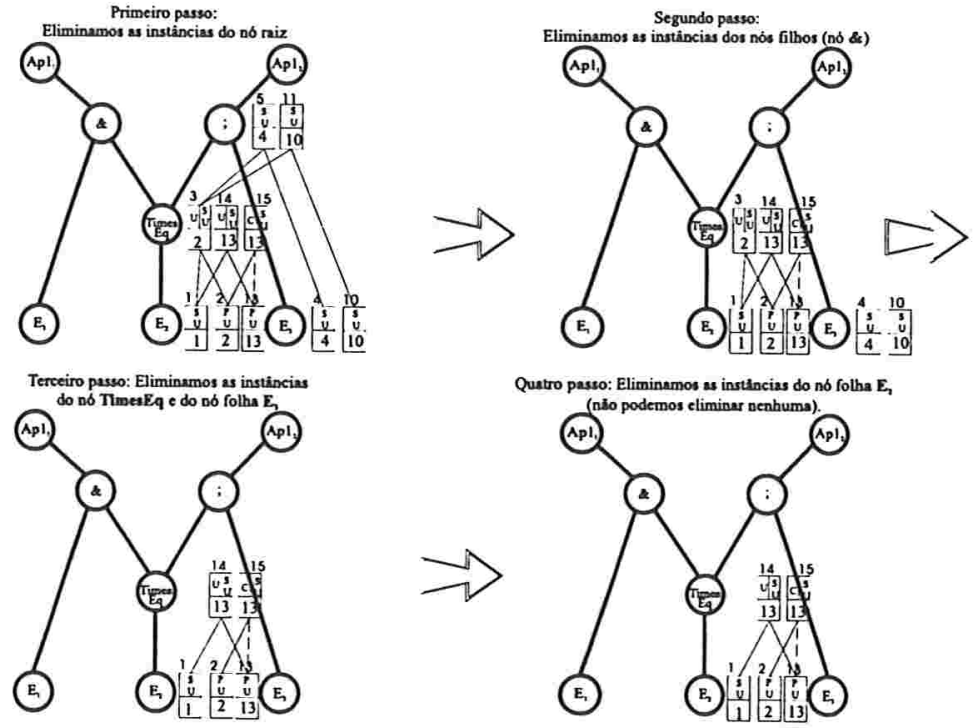

Figura 4.5: Processamento da limpeza geral da árvore. 


\section{Capítulo 5}

\section{Exemplos}

Neste capítulo apresentaremos algumas situações reais onde o serviço de processamento de eventos pode ser muito útil.

Nos exemplos utilizaremos a seguinte notação: evento.atributo indicando um atributo da instância do evento. Como em capítulos anteriores, utilizamos letras maiúsculas para indicar tipos de eventos e letras minúsculas para indicar instâncias de eventos. Além disso, os Pedidos-de-Notificação utilizados nesta seção seguem a sintaxe vista na seção 3.3 (evento, condição,ação).

\subsection{Tolerância a Falhas}

Consideremos uma aplicação distribuída com requisitos de tolerância a falhas que esteja executando em uma rede de computadores com $n$ máquinas $\left(m_{1}, m_{2}, \ldots, m_{n}\right)$, e suponhamos que existam sensores capazes de detectar e gerar os eventos primitivos abaixo. Neste caso, em particular, os sensores responsáveis por detectar e gerar os eventos poderiam ser os próprios processos de aplicação, que usariam, por exemplo, timeouts para detectar eventuais problemas na comunicação com outros processos e nós da rede. Os tipo de eventos primitivos seriam:

- NO(Node Overload): Indica sobrecarga de um nó e tem como atributos a identificação do nó (NodeId);

- PO(Process Overload): Indica a sobrecarga de um processo e tem como atributos a identificação do nó (NodeId) e a identificação do processo (ProcessId); 
- NC(Node Crash): Indica a falha de um nó e tem como atributo a identificação do nó (NodeId);

- PC(Process Crash): Indica a falha de um processo e tem como atributos a identificação do nó (NodeId) e a identificação do processo (ProcessId);

- NT(Node Timeout): Indica que um nó não está respondendo ou demorando a confirmar o recebimento de mensagens de controle de operação (Are You Alive? - AYA). Tem como atributo o identificação do nó (NodeId);

- PT(Process Timeout): Indica que um processo não está respondendo ou demorando a confirmar o recebimento de mensagens de controle de operação (Are You Alive? - AYA). Tem como atributos a identificação do nó (NodeId) e a identificação do processo (ProcessId);

- ST(Send Task): Indica a delegação de uma tarefa de um processo a outro e tem como atributos a identificação do processo (ProcessId), a identificação do processo destino (ProcessDest) e a identificação da tarefa (TaskId);

- RT(Receive Task): Indica o recebimento de uma tarefa de outro processo e tem como atributos a identificação do processo (ProcessId), a identificação do processo remetente (ProcessSource) e a identificação da tarefa (TaskId).

Uma possível situação indesejável para esta aplicação seria a quebra de um nó ou a falha de comunicação com um nó da rede $\left(m_{i}\right)$. Para que um processo supervisor da aplicação pudesse reestruturar os demais processos da aplicação em um novo conjunto de nós seria necessário, primeiro, tomar conhecimento da quebra ou falha de comunicação com um nó. Isso poderia ser realizado com a ajuda do EPS e de sensores monitorando a rede. Estes, ao perceberem que o nó $m_{i}$ estivesse quebrado ou que ninguém conseguisse comunicar-se com ele, enviariam ao EPS instâncias de evento informando da quebra $\left(\mathbf{N C}\left(m_{i}\right)\right)$ ou da falha de comunicação $\left(\mathbf{N T}\left(m_{i}\right)\right)$ com o nó. Para evitar uma conclusão precipitada a respeito da falha de um nó, poder-se-ia esperar pelo recebimento de mais de uma instância do evento relacionado com o mesmo nó antes de que alguma ação fosse tomada. Por exemplo, só após receber um conjunto de três instâncias do evento para o mesmo nó $m_{i}$, o EPS avisaria o processo supervisor de que o nó $m_{i}$ não estaria disponível. 
Neste exemplo, o processo supervisor registraria interesse na geração de três instâncias do evento composto $N C \mid N T$ sem impor nenhuma condição e tendo como ação o envio de uma mensagem avisando da indisponibilidade do nó. Para isso, o Pedido-de-Notificação a ser enviado ao EPS seria o seguinte:

- ("TimesEq(NC|NT,3,nodeId)",", "Nó não disponível").

A figura 5.1 mostra as mensagens trocadas entre a rede, o EPS e o supervisor.

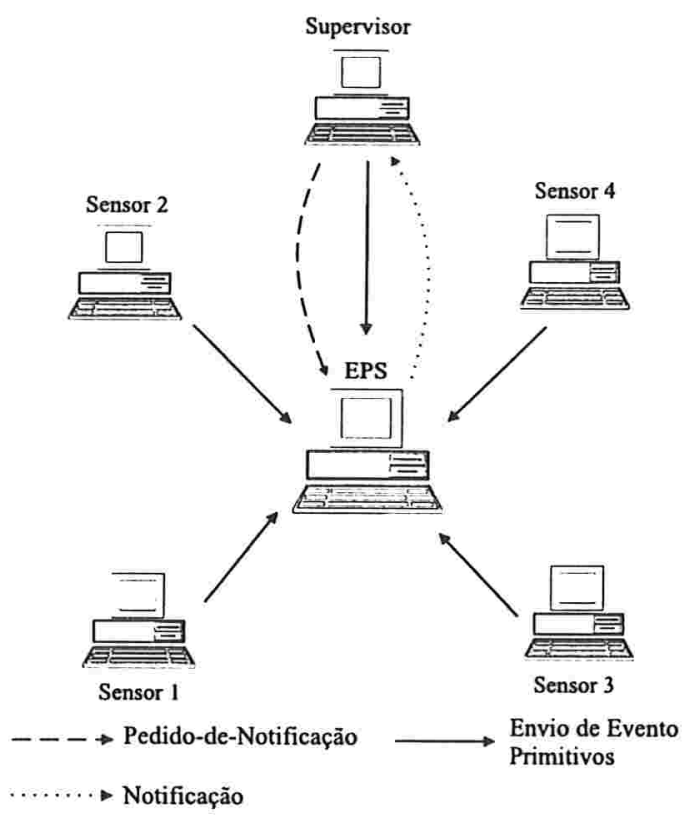

Figura 5.1: Exemplo da utilização do EPS por uma aplicação com requisitos de tolerância à falha.

No exemplo a seguir veremos a utilidade da condição em um Pedido-deNotificação.

Em outra aplicação possivelmente seja desejável a deteç̧ão de ciclos na delegação de tarefas entre servidores. Vamos supor que existam três servidores: $p_{1}, p_{2}$ e $p_{3}$. O servidor $p_{1}$, por estar sobrecarregado, delegaria a tarefa $x_{1}$ para o servidor $p_{2}$, este por sua vez a delegaria ao servidor $p_{3}$ e este tornaria a delegá-la ao servidor $p_{2}$ formando um ciclo (conforme figura $5.2)$.

Ciclos deste tipo poderiam ser identificados quando um servidor delegasse uma tarefa para outro e após algum tempo esta mesma tarefa fosse dele- 
gada a ele novamente. Tal delegação cíclica poderia ser formulada em termos de eventos compostos usando os tipos de eventos $S T$ e $R T$ e a seguinte condição: (ST.ProcessId == RT.ProcessId \&\& ST.TaskId $==$ RT.TaskId). Para detectar tal ciclo, o processo supervisor enviaria o seguinte Pedido-deNotificação ao EPS, que contém o registro de interesse no geração do evento $S T$ seguido do evento $R T$ com a condição mencionada anteriormente:

- ("(ST ; RT)", "ST.ProcessId == RT.ProcessId \&\& ST.TaskId== RT.TaskId", "Foi verificado um ciclo na delegação de tarefas").

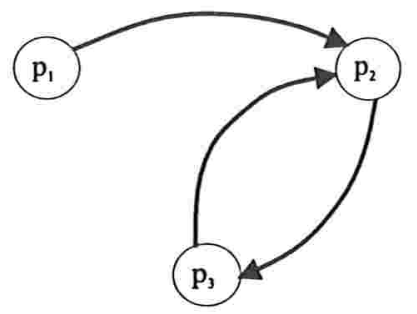

Figura 5.2: Ciclo na delegação de tarefas.

\subsection{Automação Industrial}

O controle de processos na automação industrial é essencialmente baseado em eventos, onde cada evento carrega informações sobre a posição e/ou características físicas dos objetos sendo processados ou das ferramentas em operação.

Vejamos um exemplo da indústria química e consideremos um processo de produção totalmente controlado por computadores. Digamos que um dos equipamentos seja um reator usado na reação de duas substâncias ( $A$ e $B$ ). A reação entre as substâncias $A$ e $B$ só se iniciaria quando o reator estivesse cheio e a temperatura interna fosse superior a $250^{\circ} \mathrm{C}$. Atingida a temperatura, a reação demoraria 5 minutos para ser concluída. Finalizada a reação, o reator seria esvaziado para que uma nova reação pudesse ser processada.

O controle de tal reação seria baseado nos seguintes eventos primitivos:

- cheio(ReatorId,capac): indica que o reator está cheio. Seus atributos são o identificador do reator (ReatorId) e a capacidade, em $\mathrm{m}^{3}$, do reator (capac) 
- vazio(ReatorId): indica que o reator está vazio. Seu único atributo é o identificador do reator (ReatorId);

- TempMud(ReatorId,temp): Indica que a temperatura interna do reator sofreu alguma variação positiva, isto é, subiu. Seus atributos são: o identificador do reator (ReatorId) e o valor da temperatura atual do reator (temp);

Com esses eventos primitivos, o processo de aplicação responsável pelo controle do reator poderia registrar interesse junto ao EPS enviando os seguintes Pedidos-de-Notificação:

1. ("at ((x:cheio \& y:TempMud $)+0 / 0 / 0,0: 5: 0)$ ", "x.ReatorId == y.ReatorId $\& \&$ y.temp $>250$ ", "Abra registro 3 e desliga aquecedor")

2. ("vazio", "'", "Abra registros 1 e 2 e fecha registro 3")

3. ("cheio", "'", "Fecha registros 1 e 2 e liga aquecedor")

Esses pedidos correspondem exatamente aos eventos que caracterizam as mudanças de fase no controle da reação mostrada na figura 5.3.

Note-se no pedido número 1 o uso do evento de tempo relativo ao evento cheio \& TempMud.

\subsection{Fluxo de Informação}

O exemplo a seguir mostra a utilidade de se usar eventos para a coordenação de tarefas executadas de forma descentralizada e onde o processador de eventos do EPS desempenha uma função central.

Outra área de aplicação que emprega o processamento de eventos é a área de controle de fluxo de informação (Workflow). Imagine uma empresa de assistência médica que possui vários escritórios espalhados por todo o estado. Para processar um pedido de reembolso feito em um dos escritórios por um segurado seria necessário a realização das seguintes etapas:

1. O segurado apresenta o diagnóstico médico, o tratamento recomendado e o seu custo;

2. A assistência médica verifica se o seguro saúde não está vencido; 

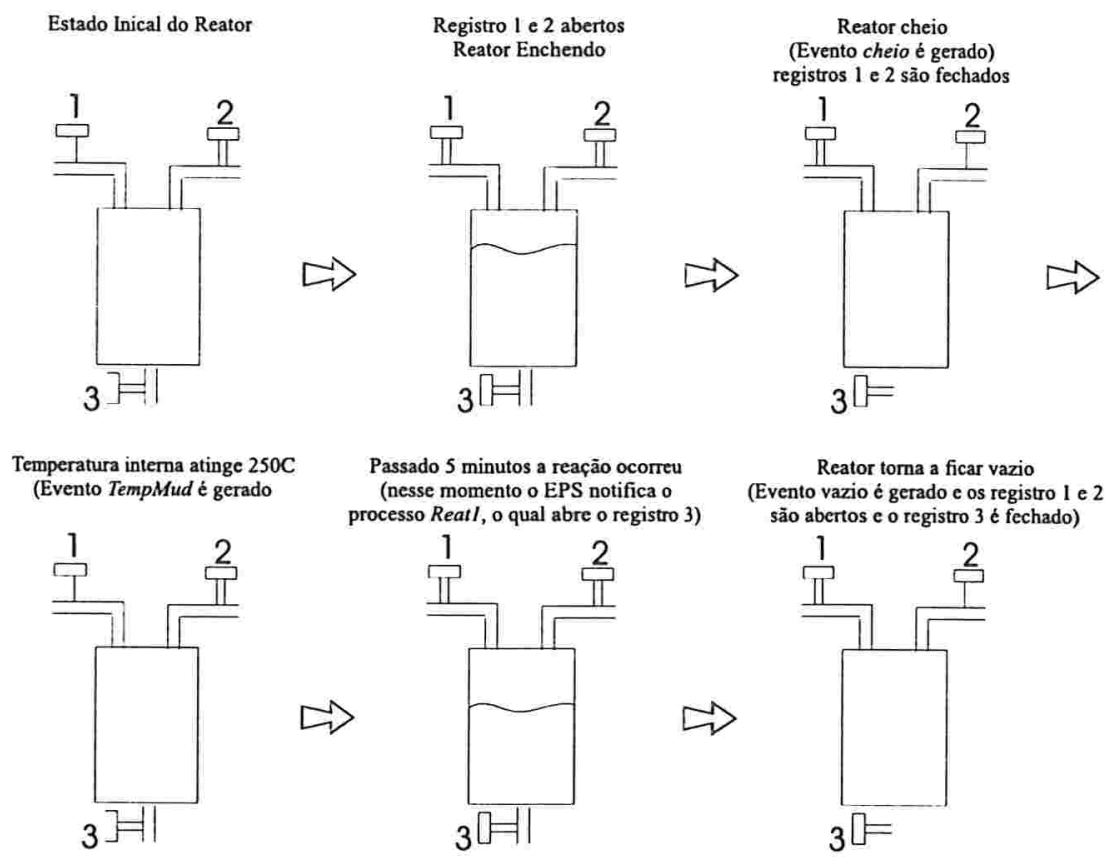

Figura 5.3: Exemplo da utilização do EPS dentro de uma indústria.

3. A assistência médica verifica se o tratamento é coberto pelo plano de saúde e qual o valor máximo permitido para o reembolso;

4. O reembolso é pago.

Para modelar esta situação os seguintes eventos primitivos poderiam ser usados:

ReqReem (Trat,Diag,Custo,userId): Este evento determinaria a existência de uma requisição de reembolso. Seus atributos são o tratamento (Trat), o diagnóstico (Diag), o custo do tratamento (Custo) e o número de identificação do segurado (userId);

PlanoOk (dataVenc,userId): Este evento determinaria a validade de um plano de saúde. Seus atributos são a data em que este plano vence (dataVenc) e a identificação do segurado (userId);

TratCob (userId,Trat,ValorMax): Este evento determinaria que um tratamento está coberto pelo plano e o valor máximo que poderia ser reembolsado por este tratamento. Seus atributos são a identificação 
do segurado (userId), o tratamento coberto pelo plano (Trat) e o valor máximo que poderia ser reembolsado (ValorMax).

Para processar o fluxo de informação poderíamos ter três processos de aplicação (verificaValidade, verificaCobertura e efetuaPagamento). Os dois primeiros estariam interessados no evento ReqReem. O primeiro processo de aplicação (verif caValidade) teria como finalidade verificar a validade do plano de saúde e gerar ou não uma instância do evento PlanoOk. O segundo processo de aplicação (verificaCobertura) teria como finalidade verificar a cobertura do tratamento e gerar ou não uma instância do evento TratCob. O terceiro processo (efetuaPagamento) seria responsável pelo reembolso propriamente dito e efetuaria o pagamento quando fosse gerado o seguinte evento: (ReqReem \& PlanoOk \& TratCob). Os Pedidos-deNotificação enviados ao EPS por estes três processos seriam:

- verificaValidade: ("ReqReem", "", "Pedido de reembolso");

- verificaCobertura: ("ReqReem", "”, "Pedido de reembolso").

- efetuaPagamento : "x:ReqReem \& y:PlanoOk \& z:TratCob", "x.userId $==$.userId \&\& x.userId $==$ z.userId \&\& x.custo $<=$ z.ValorMax", "Pague o reembolso").

A figura 5.4 mostra a interação entre os processos, o EPS e o usuário, e suas respectivas gerações de eventos. 


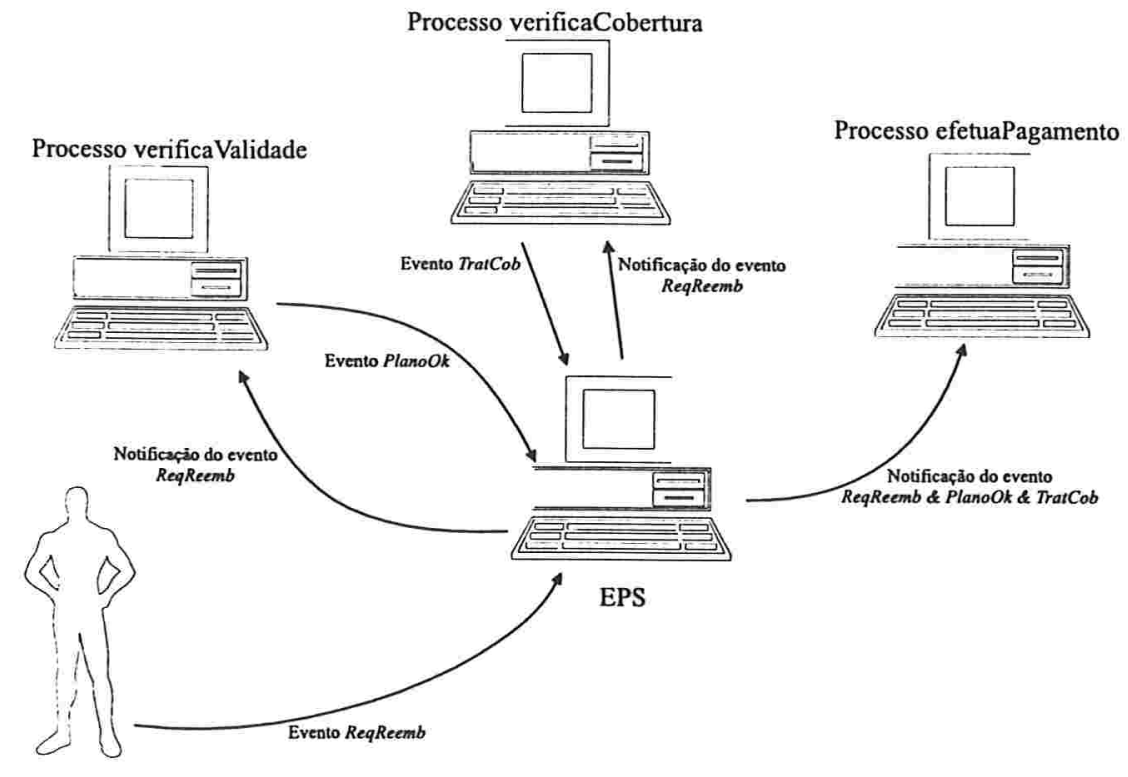

Figura 5.4: Exemplo da utilização do EPS no gerenciamento de fluxo de informação. 


\section{Capítulo 6}

\section{Implementação}

Os seguintes requisitos foram impostos ao ambiente de programação para a implementação do EPS:

- A possibilidade de implementar threads, ou seja, várias linhas de controle de execução dentro do EPS;

- Disponibilizar mecanismos de comunicação entre processos;

- Dispor de mecanismos de sincronização na utilização de objetos compartilhados.

Para satisfazer essas exigências escolhemos a linguagem de programação Java [7] e seu ambiente de programação jdk 1.1.4 que, além dessas características, possibilita a execução do EPS em várias plataformas (Sistemas Operacionais). Uma descrição breve de cada módulo é apresentada abaixo.

\subsection{Módulos do EPS}

A implementação do EPS foi dividida em 5 módulos: Eps, Eps.Timer, Eps.Display, Eps.ManagerTree e Eps.ProcessTree. Essa divisão foi baseada na arquitetura do EPS. A figura 6.1 mostra a hierarquia de diretórios nos quais as classes java correspondentes foram implementadas. Cada diretório corresponde a um módulo da implementação do EPS e contém diversas classes. 


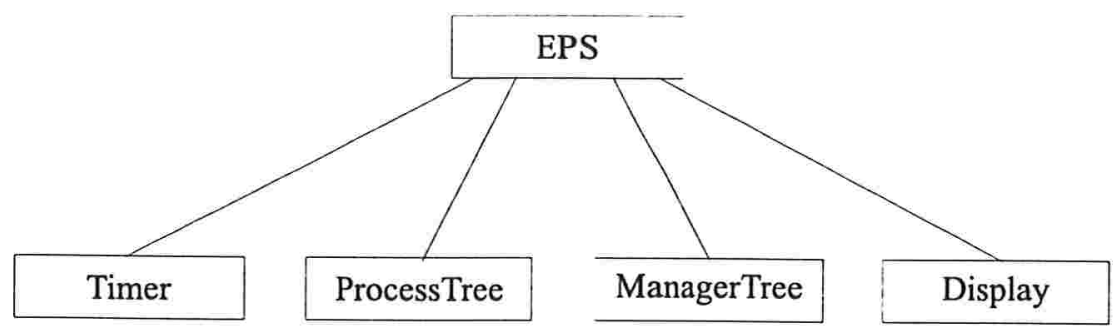

Figura 6.1: Hierarquia das componentes

EPS: Neste módulo encontramos a classe FuncGen que define os parâmetros do EPS utilizados pelas demais classes, as funções de uso genérico e constantes. Além dessa classe, encontramos a classe responsável por inicializar o EPS: EpsMain.

EPS.Display: Aqui encontramos a classe responsável por gerar ou não um $\log$ das operações do EPS (ou de quem a estiver utilizando). A escolha de gerar ou não o log é tomada quando o EPS é ativado, por meio da linha de comando.

EPS.Timer: Esta componente é responsável por controlar o "relógio" do EPS. Duas classes são utilizadas para controlar o relógio. Uma delas (Relogio.java) implementa uma thread (em loop infinito) que fica verificando a existência de um evento de tempo pronto para ser "acordado". A outra thread (EventoDeTempo.java) tem por função escalonar o próximo agendamento do evento.

EPS.ManagerTree: Todo o gerenciamento das funções do EPS é realizado pelas classes contidas neste módulo. O gerenciamento consiste de controlar a concorrência no acesso à árvore de processamento, de receber e processar Pedidos-de-Notificação em eventos compostos bem como receber as mensagens de geração de instâncias de eventos primitivos enviadas pelos sensores da aplicação. A classe responsável por implementar o escalonador também se encontra neste módulo. Além disso, é implementada neste módulo a classe responsável pela limpeza geral da árvore.

EPS.ProcessTree: As quatro fases do processamento nas árvores descritas no capítulo 4 são implementadas nesta componente. 


\subsection{Comunicação entre processos}

Em Java a comunicação entre processos pode ser feita de duas maneiras: utilizando-se o RMI (Remote Method Invocation) [7] ou sockets. Adotamos o RMI como método de comunicação entre processos por ser mais fácil e simples de usar. A única restrição imposta por esta escolha é a de que todos os processos que forem utilizar o EPS precisam ser implementados em java.

\subsubsection{RMI - Remote Method Invocation}

A comunicação entre processos implementada no EPS utilizando o RMI da linguagem Java baseou-se no fato de que há processos oferecendo serviços (servidores) e processos necessitando de serviços (clientes).

Para utilizar a estrutura cliente/servidor com RMI, o processo servidor deve criar um servidor RMI, que será controlado pela linguagem java, e registrar o serviço que estará sendo disponibilizado, a porta na qual o serviço estará recebendo os pedidos remotos e o servidor no qual o serviço estará funcionando.

Já o processo cliente necessita conhecer a interface deste serviço, o nome deste serviço, a porta e o servidor no qual o serviço está funcionando. Com estes dados a chamada do método é simples, basta obter junto ao servidor RMI remoto a permissão de execução. Com a permissão obtida, a chamada remota é feita como se fosse uma chamada local.

A interface do serviço remoto é constituída dos métodos disponibilizados por este serviço e que podem ser chamados pelo processo cliente.

O serviço remoto registrado no servidor RMI é um objeto java (instância de alguma classe java) com métodos e variáveis membros, dos quais uma parte (especificada na interface) é disponibilizada para acessos remotos.

\subsubsection{Utilização do RMI pelo EPS}

A comunicação entre processos é utilizada no EPS em três momentos:

1. No Pedido-de-Notificação por uma aplicação junto ao EPS;

2. No aviso da geração de uma instância de evento primitivo por um sensor de aplicação; 
3. Na notificação da geração de um evento composto pelo EPS a uma aplicação.

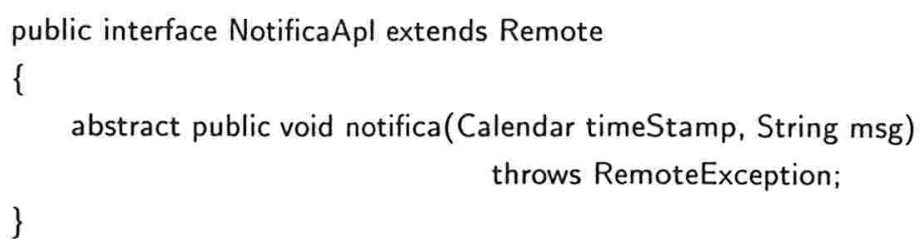

Figura 6.2: Interface utilizada pelo EPS no acesso ao serviço remoto do processo de aplicação.

Nos itens 1 e 2 o EPS faz o papel do servidor de serviços remotos enquanto que no item 3 faz o papel de cliente.

No papel de servidor o EPS cria um servidor de RMI na máquina em que estiver executando e registra dois serviços: ControlePedidos e ControleEventos, que correspondem aos serviços relacionados nos itens 1 e 2 acima, respectivamente.

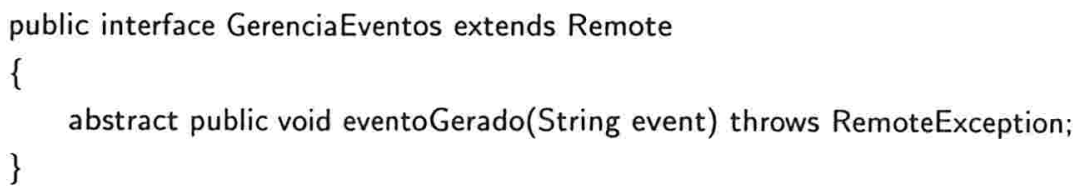

Figura 6.3: Interface utilizada pelos processos de aplicação que estão gerando as instâncias de eventos primitivos.

No papel de cliente, o EPS vai procurar no servidor RMI remoto, criado pelo processo de aplicação, o serviço (método) do processo de aplicação responsável pelo tratamento da notificação e executá-lo.

As interfaces dos serviços remotos do EPS são mostradas nas figuras 6.2, 6.3 e 6.4. A figura 6.2 mostra a interface (NotificaApl) correspondente ao serviço remoto que todos os processos de aplicação devem implementar para serem notificados pelo EPS quando instâncias dos eventos de interesse destes processos forem geradas. As figuras 6.3 e 6.4 mostram as interfaces (GerenciaPedidos e GerenciaEventos) correspondentes aos serviços remotos do EPS. 


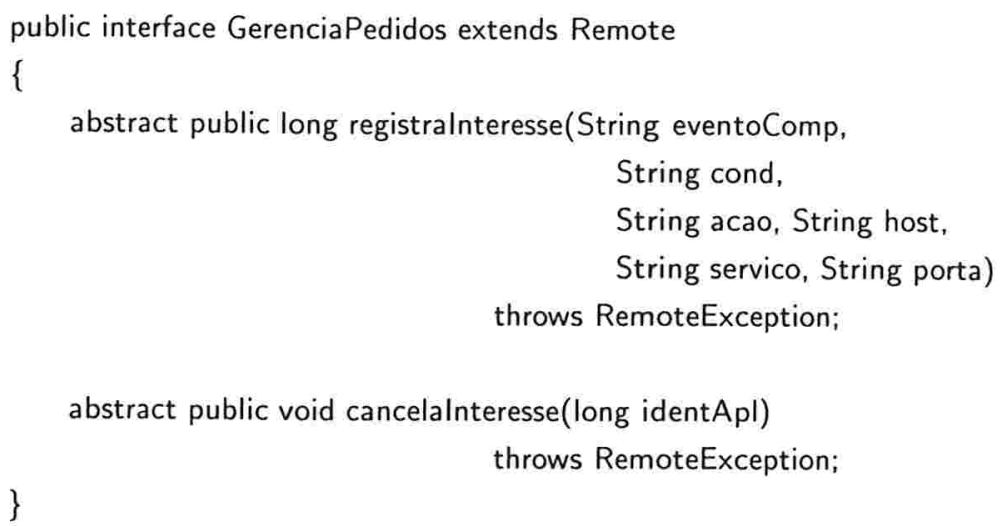

Figura 6.4: Interface utilizada pelos processos de aplicação para os Pedidosde-Notificação em eventos compostos.

\subsection{Funcionamento do EPS}

Ao ativar o EPS, a classe EpsMain, contida na módulo EPS, inicializa duas threads (schedule e clock), cria o servidor RMI e registra os dois serviços remotos: ControleEventos e ControlePedidos. O serviço ControleEventos é responsável por receber os avisos remotos de geração de instâncias de eventos primitivos e iniciar o processamento dos mesmos. O serviço ControlePedidos tem a finalidade de processar os Pedidos-de-Notificação em eventos compostos feitos pelos processos de aplicação.

\subsubsection{Principais Threads}

As principais threads são criadas pela classe EpsMain e executam loops infinitos que verificam a existência de instâncias de eventos primitivos (thread schedule) e instâncias de eventos de tempo (thread clock) prontos para serem tratadas. Só existirão tais instâncias se o serviço controleEventos (interface GerenciaEventos) tiver recebido algum aviso de geração de instâncias de eventos ou se o serviço ControlePedidos (interface GerenciaPedidos) tiver recebido algum Pedido-de-Notificação para eventos de tempo.

Outra thread importante é a thread responsável por notificar a geração 
de instâncias de evento aos processos de aplicação. Essa thread é criada toda vez que uma instância de evento primitivo relativa a um registro de interesse é gerada. Assim que a notificação termina, a thread é finalizada. Dessa forma, o bloqueio da aplicação não bloqueia o EPS e, ainda, proporciona um serviço de notificação mais ágil, possibilitando que várias notificações sejam processadas concorrentemente.

Além dessas threads, toda vez que Pedido-de-Notificação ou um aviso de geração de instâncias de eventos primitivos chegar ao EPS, uma nova thread é criada automaticamente (pelo próprio mecanismo de RMI) para tratar tal aviso ou pedido.

\subsubsection{Controle de Concorrência}

Devido a existência de múltiplas threads faz-se necessário um controle de concorrência na utilização de alguns objetos do EPS que são compartilhados pelas threads. Os objetos: listas de eventos de tempo e listas de instâncias de eventos primitivos bem como a árvore de processamento não podem ter mais de uma thread as utilizando ao mesmo tempo. Por exemplo, no caso da árvore de processamento garante-se a exclusão mútua entre o processamento de um Pedido-de-Notificação e o processamento de uma instância de evento. No caso da lista de instâncias de eventos primitivos garante-se a exclusão mútua entre a inclusão de uma nova instância e a procura por uma instância pronta. No caso da lista de eventos de tempo garante-se a exclusão mútua entre um agendando de um novo evento de tempo e a procura por um evento de tempo pronto para ser "acordado".

Em java este controle de concorrência é obtido através do uso do modificador de acesso synchronized. Por exemplo, para a árvore de processamento temos uma classe responsável por coordenar os três tipos de acesso a árvore, a saber, o processamento de evento, o registro de interesse e o cancelamento de interesse. Esta classe chamada de Sincronizador.java (ver figura 6.5) centraliza todas as requisições de acesso à árvore através de três métodos, todos com o modificador synchronized. Portanto, executa sempre uma requisição por vez.

\subsubsection{Construção da árvore agregada}

Outro aspecto da implementação que vale a pena ser comentado é como as árvores são construídas e agregadas. 
public class Sincronizador

\{

synchronized static public void novasInstancias(Instancia inst)

synchronized static public long registralnteresse(String eventoComp,

String cond, String acao,

String host, String servico,

String porta)

synchronized static public void cancelalnteresse(long identApl)

\}

Figura 6.5: Classe Sincronizador e seus métodos.

A construção e agregação das árvores depende de como as expressões de eventos compostos são escritas. No EPS, uma árvore é criada percorrendose a expressão da esquerda para a direita. Como, no entanto, expressões equivalentes podem ser escritas apenas alterando-se a ordem dos operandos (os tipos de eventos primitivos) isto implica que pode-se ter árvores com estruturas bem distintas para expressões equivalentes. Isto, por sua vez, tem implicações profundas na estrutura das árvores agregadas correspondentes que eventualmente não serão minimais no número de nós intermediários (ver figura 6.6). Ou seja, idealmente seria necessário um processamento adicional sobre a expressão de eventos, antes de efetuar o agregamento de árvores. No entanto, como o objetivo do trabalho é o processamento de eventos em um contexto mais geral, tal otimização da construção e agregamento não foi tratada no presente trabalho. No EPS, portanto, não é feita qualquer transformação sobre a estrutura da expressão a fim de otimizar o agregamento das árvores.

\subsection{Calculando as Condições}

A última etapa do processamento de um evento antes de notificarmos o processo de aplicação é a avaliação da condição associada ao evento. Esta avaliação pode ser dividida em duas etapas: obtenção dos valores dos atributos especificados na condição e a avaliação da expressão sobre estes atributos. Iremos abordar apenas a obtenção dos atributos, visto que avaliar uma condição contendo apenas constantes (estado atingido após a obtenção 
Apl $_{1}$ interessada em: $E_{1}$ \& $E_{2}$ \& $E_{3} \quad A_{p l}$ interessada em: $E_{3}$ \& $E_{1}$ \& $E_{2}$
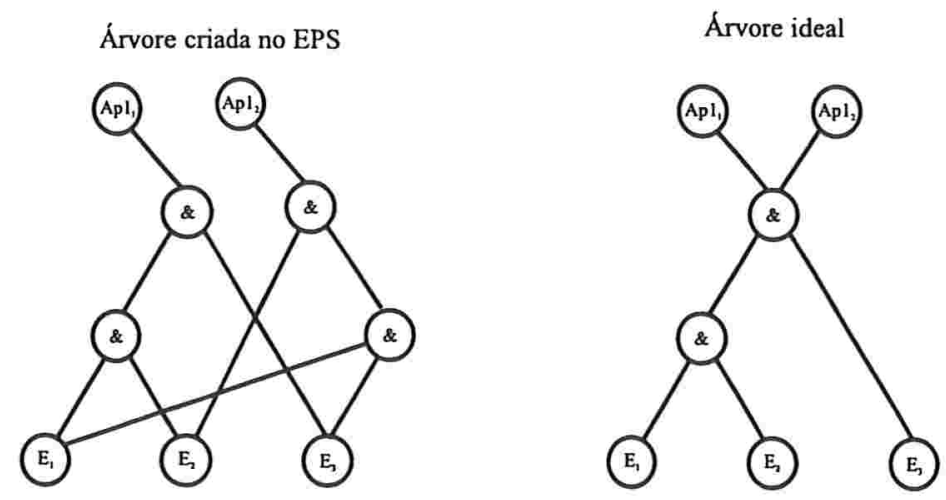

Figura 6.6: Exemplos de agregação distinta para expressões equivalentes.

de todos os atributos) é simples.

Os valores dos atributos de uma instância de evento primitivo são fornecidos nos avisos de geração de uma instância de evento primitivo enviados pelos sensores da aplicação. Durante o processamento da instância de evento primitivo, separamos todos os valores de atributos do evento e os guardamos em uma lista "global", a qual todas as instâncias da árvore têm acesso. Para que cada instância saiba em qual posição da lista "global" estão os atributos procurados, cada instância possui uma lista "local" com as posições dos respectivos atributos na lista "global". Se a instância é uma folha, sua lista "local" tem apenas uma posição. Se for uma instância de um nó não-folha sua lista "local" será a concatenação das listas "locais" de seus filhos, vindo primeiro a lista do filho da esquerda e depois a lista do filho da direita (ver figura 6.7).

Como discutido na seção 3.4 , a condição de um evento composto utiliza nomes para os eventos, e com estes nomes referenciamos os atributos do evento. Assim, no nó raiz (associado a um processo de aplicação) temos uma lista de símbolos que nos indica em qual posição da lista "local" deveremos procurar pelo atributo especificado. Conforme o exemplo da figura 6.7 para um Pedido-de-Notificação com a expressão de evento: $x: E_{1} \& E_{2}$ e a condição $x . N u m==25$, o nó raiz correspondente terá uma lista de símbolos contendo o par (símbolo,posição), ou seja, $(x, 0)$. Quando uma instância chegar até este nó, esta instância terá uma lista "local" contendo $(i, j)$. Para descobrir qual o valor do atributo $N u m$ de $E_{1}$, procuramos pelo símbolo $x$ na lista de símbolos do nó aplicação e encontramos a posição 0 . O próximo 


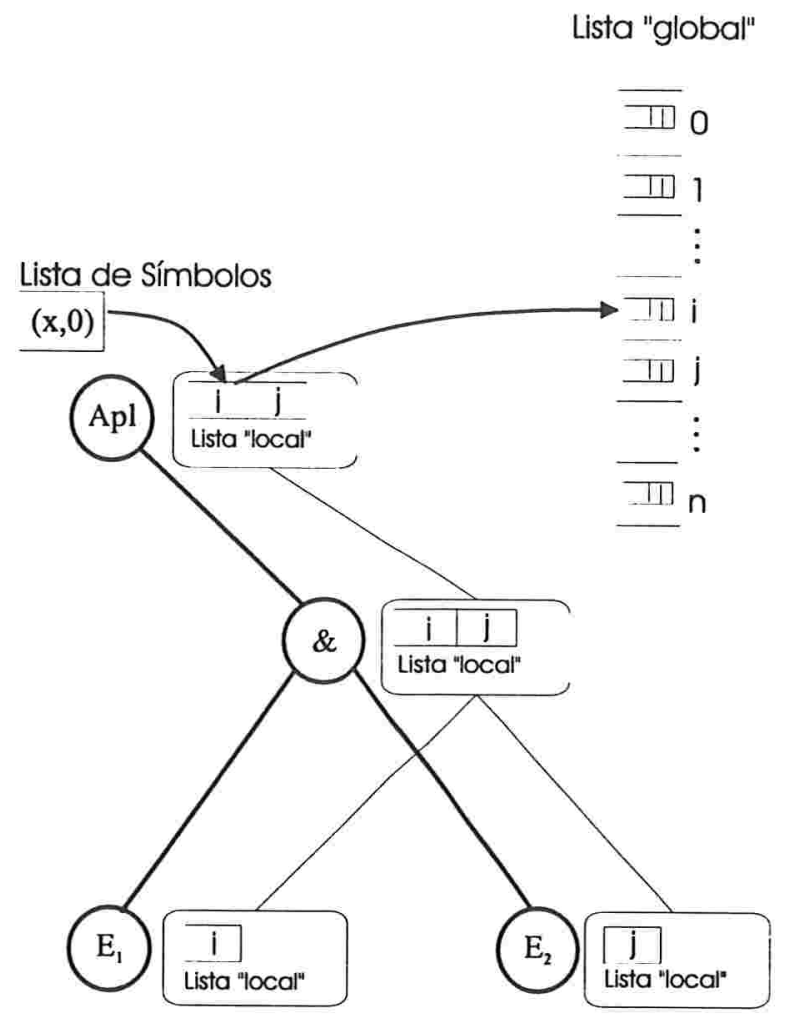

Figura 6.7: Exemplo de como obter o valor de um atributo.

passo é obter da lista "local", na posição 0, a posição na lista "global", no caso a posição é $i$. O último passo é procurar, na lista "global" na posição $i$ encontrada, e o atributo e substituí-lo por seu valor. Substituídos todos os atributos, a condição é avaliada e é decidido se o processo de aplicação deve ou não ser notificado. 


\subsection{Testando o EPS}

Para avaliar o desempenho do EPS, foram realizados testes que mediram o tempo de duração de três itens:

- Processamento completo;

- Processamento da primeira fase;

- Processamento da segunda e terceira fases

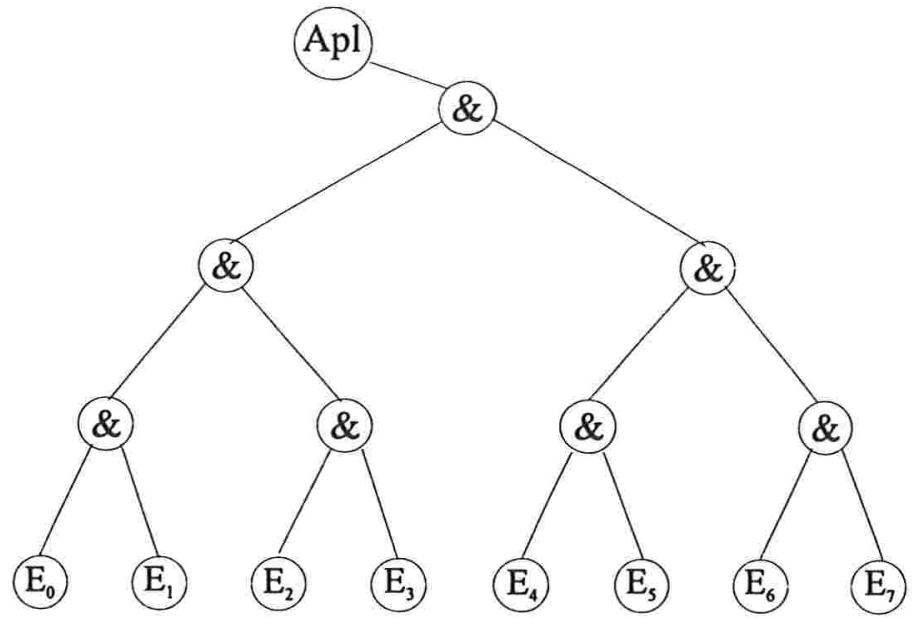

Figura 6.8: Árvore balanceada utilizada nos teste de desempenho do EPS.

As medições de tempo foram feitas para dois tipos de árvores, cada uma com uma distribuição diferente dos nós. Uma das árvores era binária e balanceada com oito nós folha, conforme figura 6.8. A outra era uma árvore coluna (árvore linear com um nó folha adicional em cada nó da linha principal) com dez nós folhas conforme a figura 6.9. Além de variarmos a distribuição dos nós da árvore, variamos, também, a quantidade de instâncias presentes na árvore toda, uma vez que esta última variável exerce uma grande influência sobre o tempo de processamento.

Para medir os tempos de processamento, acrescentamos ao código instruções que gravavam o instante no qual determinado processamento era executado. Além disso, geramos instâncias de eventos primitivos de forma que somente a última instância de evento primitivo provocasse a notificação às aplicações. Os tempos para os três itens do processamento foram obtidos da seguinte maneira: 


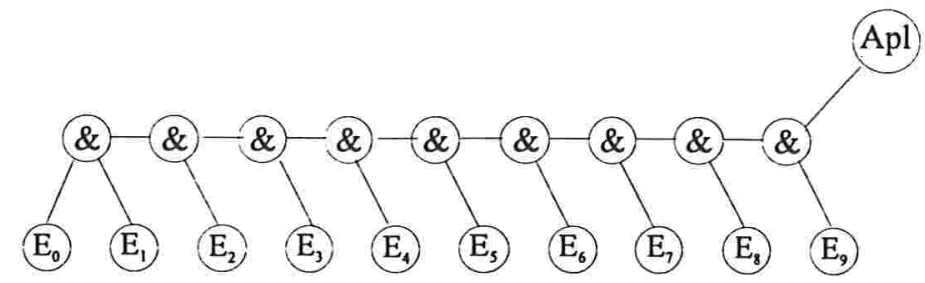

Figura 6.9: Árvore coluna utilizada nos teste de desempenho do EPS.

Processamento Completo: o tempo de duração deste item correspondeu à diferença entre os instantes de início e fim do processamento da instância que provocou a notificação às aplicações;

Processamento da primeira fase: o tempo de duração deste item correspondeu à diferença entre o instante de início do processamento da última instância gerada e o instante de notificação à aplicação;

Processamento da segunda e terceira fases: o tempo de duração destas duas fases juntas correspondeu à diferença entre o instante em que a aplicação foi notificada e o instante de fim de processamento da instância que provocou a notificação.

Todos os teste foram realizados em um computador Pentium $133 \mathrm{MHz}$ com $16 \mathrm{Mb}$ de RAM e com o jdk 1.1.4 executando sobre o sistema operacional Windows 95. Como uma mesma operação levou tempos diferentes para ser executada, os testes de medição de tempo foram realizados vinte vezes. Tomando a média destas medições, construímos então os gráficos e realizamos as análises desta seção.

\subsubsection{Desempenho do EPS}

O desempenho do EPS foi medido, para cada uma das árvores (balanceada e coluna), para sete quantidades diferentes de instâncias nas árvores.

A tabela 6.1 mostra quais foram as instâncias folhas geradas, quantas instâncias foram processadas e a quantidade de instâncias que atingiram o nó raiz para a árvore balanceada. A tabela 6.2 mostra quais foram as instâncias folhas geradas, quantas instâncias foram processadas e a quantidade de instâncias que atingiram o nó raiz para a árvore coluna.

Com essas distribuições obtivemos os resultados mostrados no gráficos $6.10,6.11$ e 6.12 . 


\begin{tabular}{|l|l|l|l|l|l|l|l|l|l|l|l|}
\hline No. & Total & $\begin{array}{l}\text { Inst. } \\
\text { Nó } \\
\text { Raiz }\end{array}$ & $\begin{array}{l}\text { Nós } \\
\text { Fo- } \\
\text { lhas }\end{array}$ & $E_{0}$ & $E_{1}$ & $E_{2}$ & $E_{3}$ & $E_{4}$ & $E_{5}$ & $E_{6}$ & $E_{7}$ \\
\hline 1 & 577 & 256 & 17 & 1 & 4 & 2 & 2 & 2 & 2 & 2 & 2 \\
\hline 2 & 1111 & 512 & 19 & 1 & 4 & 2 & 2 & 2 & 2 & 4 & 2 \\
\hline 3 & 2157 & 1024 & 21 & 1 & 4 & 4 & 2 & 2 & 2 & 4 & 2 \\
\hline 4 & 3589 & 1728 & 23 & 1 & 6 & 2 & 3 & 2 & 3 & 2 & 4 \\
\hline 5 & 4766 & 2304 & 24 & 1 & 3 & 4 & 4 & 4 & 4 & 3 & 1 \\
\hline 6 & 6312 & 3072 & 24 & 1 & 4 & 3 & 4 & 2 & 4 & 4 & 2 \\
\hline 7 & 8381 & 4096 & 25 & 1 & 4 & 4 & 4 & 4 & 2 & 4 & 2 \\
\hline
\end{tabular}

Tabela 6.1: Tabela com distribuição das instâncias na árvore balanceada.

\begin{tabular}{|l|l|l|l|l|l|l|l|l|l|l|l|l|l|}
\hline No. & Total & $\begin{array}{l}\text { Inst. } \\
\text { Nó } \\
\text { Raiz }\end{array}$ & $\begin{array}{l}\text { Nós } \\
\text { Fo- } \\
\text { lhas }\end{array}$ & $E_{0}$ & $E_{1}$ & $E_{2}$ & $E_{3}$ & $E_{4}$ & $E_{5}$ & $E_{6}$ & $E_{7}$ & $E_{8}$ & $E_{9}$ \\
\hline 1 & 591 & 128 & 17 & 1 & 2 & 2 & 2 & 2 & 2 & 2 & 1 & 2 & 1 \\
\hline 2 & 1357 & 384 & 19 & 1 & 2 & 2 & 3 & 2 & 2 & 2 & 2 & 1 & 2 \\
\hline 3 & 2018 & 576 & 20 & 1 & 2 & 2 & 3 & 3 & 2 & 2 & 2 & 1 & 2 \\
\hline 4 & 3411 & 1024 & 23 & 1 & 4 & 2 & 2 & 2 & 4 & 1 & 4 & 1 & 2 \\
\hline 5 & 4944 & 1296 & 22 & 1 & 2 & 3 & 3 & 2 & 3 & 2 & 3 & 2 & 1 \\
\hline 6 & 6624 & 1620 & 24 & 1 & 3 & 3 & 3 & 3 & 5 & 1 & 2 & 2 & 1 \\
\hline 7 & 8297 & 1728 & 25 & 1 & 4 & 3 & 4 & 3 & 4 & 1 & 3 & 1 & 1 \\
\hline
\end{tabular}

Tabela 6.2: Tabela com distribuição das instâncias na árvore coluna.

Observando-se os gráficos, verificamos que o processamento na árvore balanceada foi pior do que o processamento na árvore coluna (esperava-se o contrário). Isso ocorreu devido à distribuição diferente das instâncias nas duas árvores. Por exemplo, na medição número 7 as duas árvores processaram por volta de 8000 instâncias, mas na árvore balanceada 4096 foram processadas todas no nó raiz enquanto que na árvore coluna tivemos apenas 1728 instâncias processadas no nó raiz, ou seja, o número de instâncias no nó raiz da árvore balanceada foi cerca de $137 \%$ maior do que na árvore coluna. A medida que essa diferença foi diminuindo, os tempos de processamento também foram ficando mais próximos.

Observamos, também, que o tempo de processamento da segunda e da terceira fases juntas tende a ser de aproximadamente $80 \%$ do tempo total. 


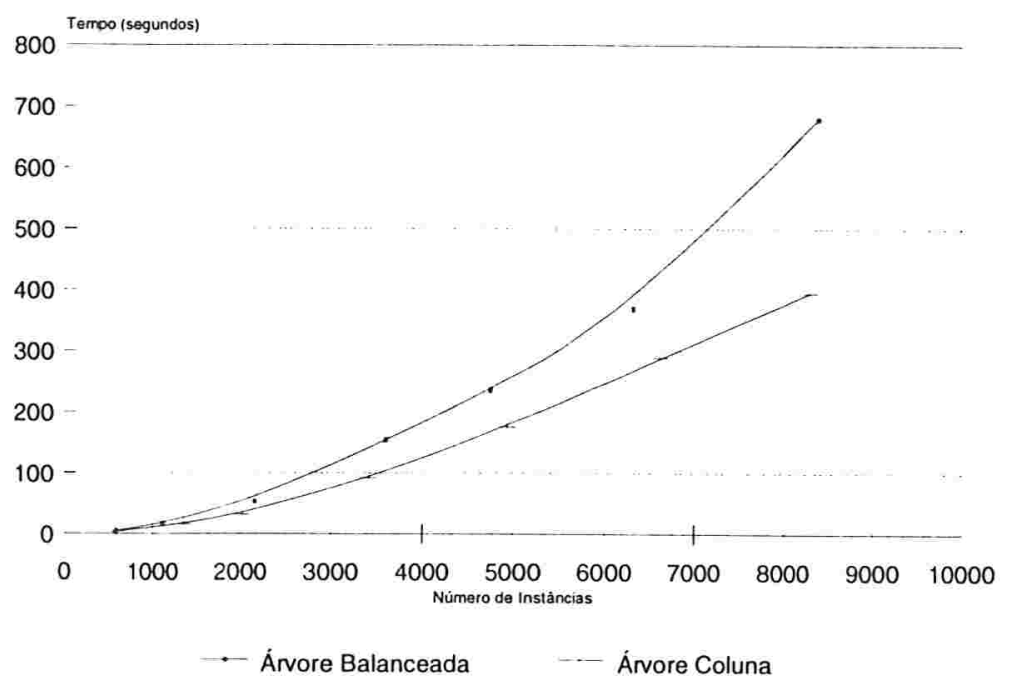

Figura 6.10: Curva de variação do tempo de processamento de acordo com número de instâncias.

O principal motivo deste fato é que na terceira fase sobe-se pela árvore de instâncias diversas vezes (uma para cada instância folha que for atingida pela segunda fase), repetindo-se algumas vezes um processamento já realizado.

A partir desses resultados pode-se concluir que os seguintes fatores são os principais determinantes do desempenho do EPS:

1. Número de instâncias total na árvore - quanto maior o número de instâncias maior é o tempo de processamento;

2. Distribuição das instâncias na árvore - quanto menor for a concentração de instâncias nos nós superiores da árvore menor será o tempo de processamento;

3. Número de nós na árvore - quanto menor o número de nós da árvore menor será o tempo de processamento.

O terceiro fator é o de menor peso no tempo de processamento dentre os três fatores apresentados acima. Isto mostra a importância da coleta de lixo de instâncias com a validade vencida. 
Tempo de Processamento da Primeira fase

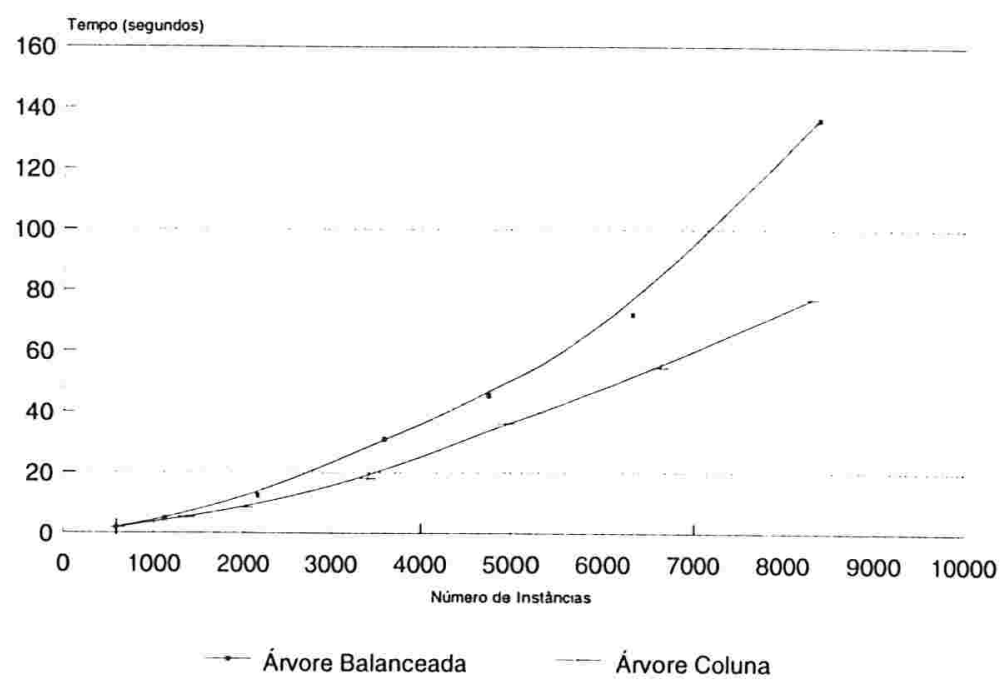

Figura 6.11: Curva de variação do tempo de processamento da primeira fase de acordo com número de instâncias. 
Tempo de Proc.da Segunda e Terceira fase

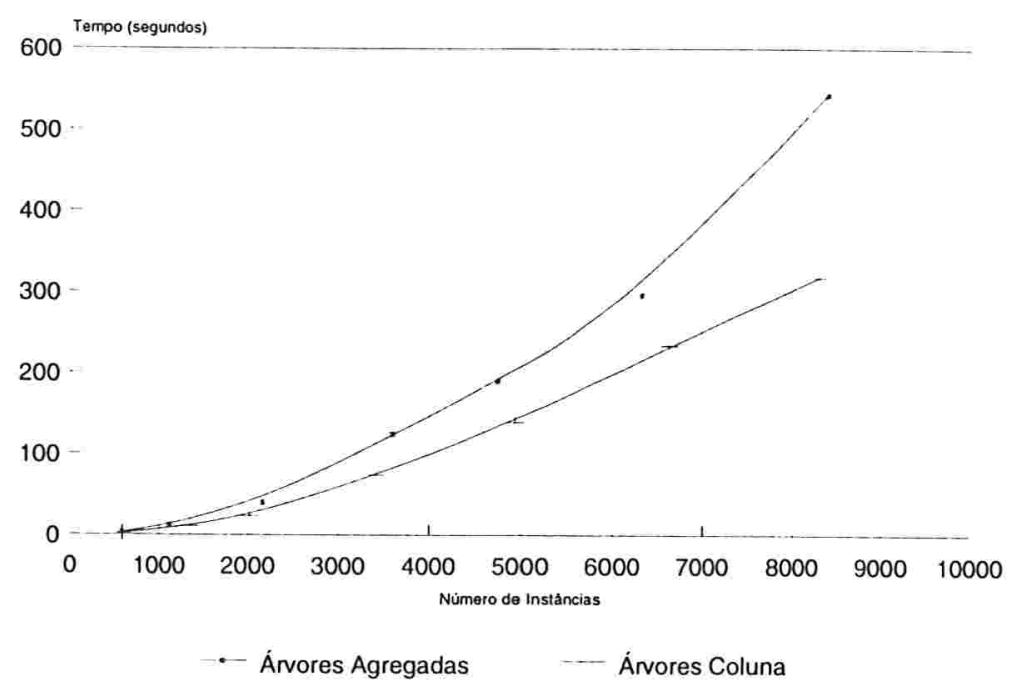

Figura 6.12: Curva de variação do tempo de processamento da segunda e terceira fases de acordo com número de instâncias. 


\subsubsection{Comparação entre árvores Agregadas e Árvores Sim- ples}

Sendo o compartilhamento de árvores a principal contribuição do EPS, fizemos também alguns testes para comparar o tempo de processamento de uma árvore compartilhada com o tempo de processamento para as árvores replicadas correspondentes a árvore compartilhada.

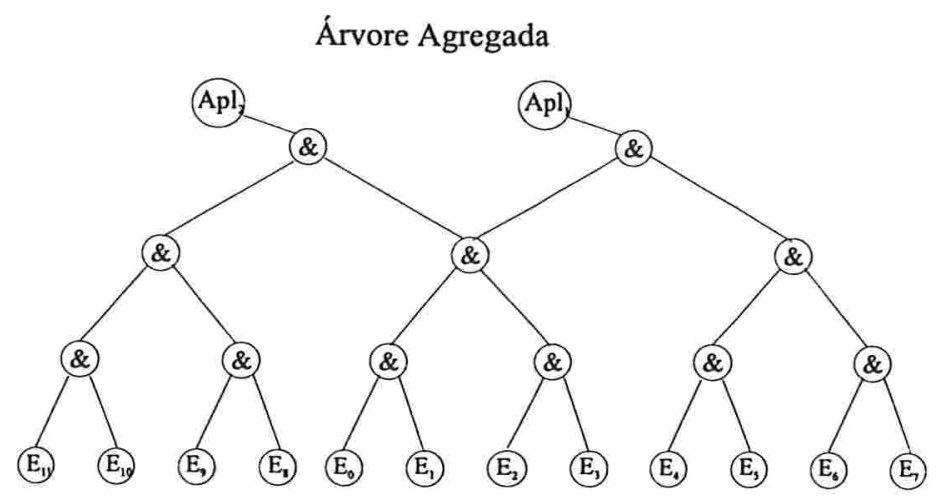

Árvores simples
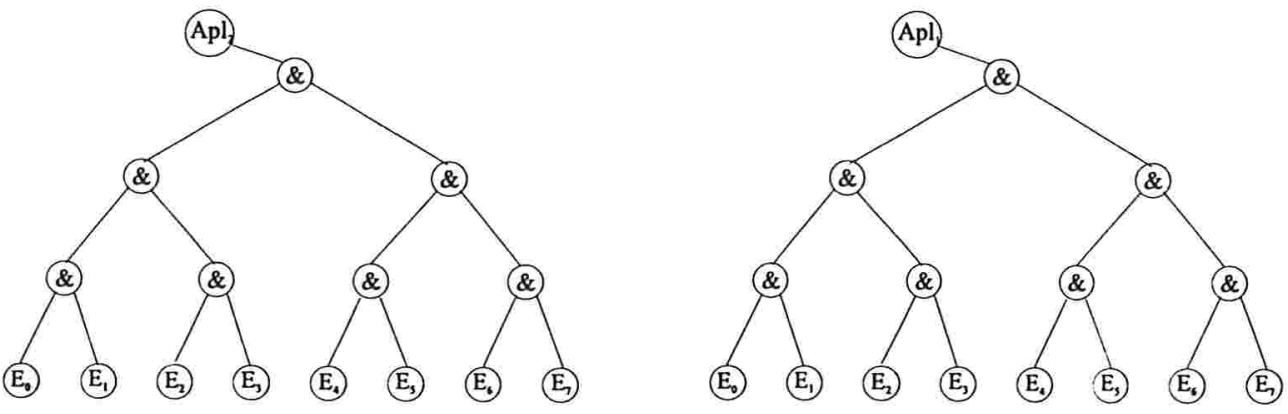

Figura 6.13: Árvore agregada e as correspondentes árvores simples utilizadas na avaliação.

Dos 5 testes realizados, quatro utilizaram árvores balanceadas, conforme a figura 6.13 , e o quinto teste utilizou uma árvore coluna, conforme a figura 6.14 .

Os testes consistiram em medir o tempo total gasto para se processar duas notificações, ou seja, calculou-se o tempo gasto desde o inicio do processamento da instância que provoca a notificação às aplicações até o fim o término da terceira fase, incluindo as duas notificações. Para computar os 
tempos deste processamento em árvores simples, calculou-se o tempo gasto para o processamento da notificação à uma aplicação e dobrou-se este tempo. Dobramos o tempo porque em árvores simples duas aplicações interessadas no mesmo evento composto gerariam duas árvores idênticas.

A distribuição de instâncias folhas utilizada em cada teste é mostrada na tabela 6.3. Os resultados dos testes são mostrados no gráfico 6.15.

\begin{tabular}{|c|c|c|c|c|c|c|c|c|c|c|c|c|}
\hline Medição & $E_{0}$ & $E_{1}$ & $E_{2}$ & $E_{3}$ & $E_{4}$ & $E_{5}$ & $E_{6}$ & $E_{7}$ & $E_{8}$ & $E_{9}$ & $E_{10}$ & $E_{11}$ \\
\hline 1 & 1 & 8 & 8 & 8 & 1 & 1 & 1 & 1 & 1 & 1 & 1 & 1 \\
\hline 2 & 1 & 9 & 9 & 9 & 1 & 1 & 1 & 1 & 1 & 1 & 1 & 1 \\
\hline 3 & 1 & 10 & 10 & 10 & 1 & 1 & 1 & 1 & 1 & 1 & 1 & 1 \\
\hline 4 & 1 & 11 & 11 & 11 & 1 & 1 & 1 & 1 & 1 & 1 & 1 & 1 \\
\hline 5 & 1 & 4 & 3 & 4 & 3 & 4 & 1 & 3 & 1 & 1 & - & - \\
\hline
\end{tabular}

Tabela 6.3: Tabela com a distribuição das instâncias folhas utilizada nos testes da comparação entre as árvores.

Com esses resultados pode-se concluir que o ganho no compartilhamento de subárvores depende de quanto do processamento é compartilhado, ou seja, quanto do processamento não é repetido. Quanto maior for a quantidade de processamento compartilhado menor será o tempo gasto no processamento total. Outro fator que interfere no tempo de processamento de árvores simples é a necessidade de procurar por novas árvores que provavelmente poderão ser processadas. Este fator não foi considerado nos teste realizados porque nossa implementação não utiliza tal busca e, ainda, não encontramos referências na literatura de como essas busca seriam realizadas pelos monitores que utilizam árvores não compartilhadas. 


\section{Árvore Agregada}

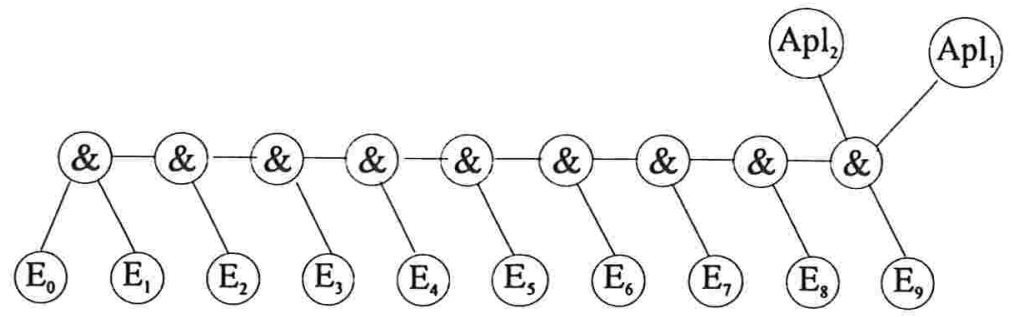

\section{Árvores Simpless}

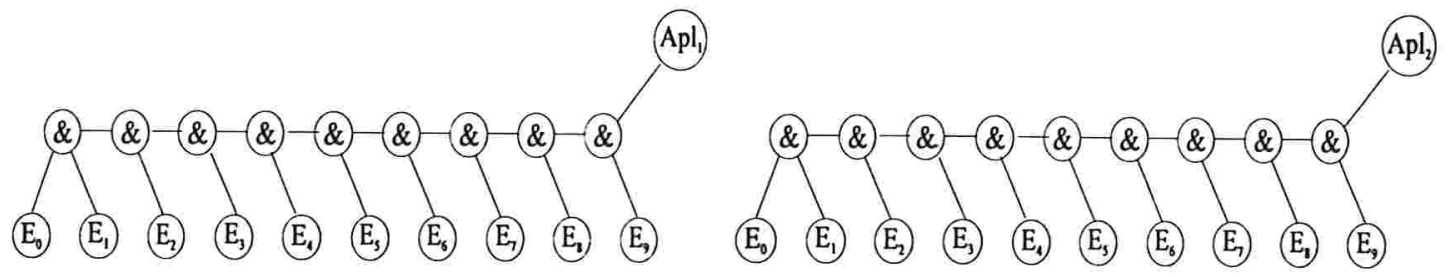

Figura 6.14: Árvore agregada e as correspondentes árvores simples utilizadas na avaliação. 
Comparação do Processamento

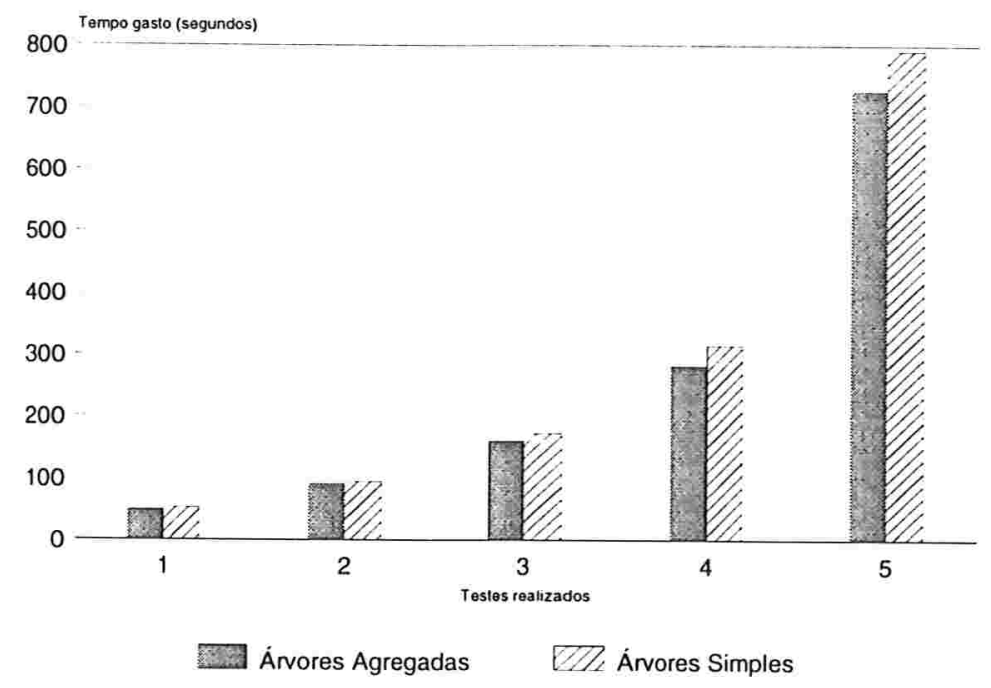

Figura 6.15: Comparativo dos tempos de processamento entre árvores agregadas e árvores simples. 


\section{Capítulo 7}

\section{Conclusão}

Processamento de eventos é uma tarefa importante que vem sendo pesquisada há vários anos na área de Banco de Dados e, mais recentemente em outras áreas tais como, sistemas distribuídos, segurança de sistemas, robótica, entre outras. Com a diversificação das áreas de interesse em processamento de eventos, processadores genéricos passaram a ser mais interessantes do que processadores exclusivos a uma área específica.

Nesta dissertação, propusemos um serviço de processamento de eventos compostos denominado EPS capaz de processar eventos em ambientes distribuídos e que pudesse, também, ser utilizado por diferentes tipos de aplicação (Banco de Dados, sistemas de segurança, etc.).

A contribuição mais importante desta dissertação é a utilização de árvores agregadas pelo processador de eventos. Sua utilização possibilita que a busca do nó folha correspondente a um tipo de evento primitivo seja reduzida significativamente. Com árvores agregadas só existe uma folha para cada tipo de evento possível. Assim, quando uma instância de evento é recebida pelo EPS, é necessário procurar apenas pela primeira e única folha deste tipo para se iniciar seu processamento.

A primeira vista, agregar árvores parece ser uma tarefa simples. Porém, quando uma mesma instância é referenciada por vários nós raízes da árvore com diferentes condições, existe uma certa complexidade para gerenciar quais nós raízes utilizaram a instância e quando esta instância pode ser eliminada. Tal gerenciamento foi possível através da divisão do processamento em quatro fases e da atribuição de um status a todas as instâncias contidas na árvore, status que representa o grau de utilização da instância com relação aos nós raízes. 
O EPS descrito nesta dissertação foi implementado integralmente em Java utilizando o RMI como base para a comunicação entre o EPS e os processos de aplicação. Essa facilidade fornecida pela linguagem java proporcionou que a implementação da comunicação fosse simples e rápida. Porém, ela restringe o conjunto de aplicações que podem usar o EPS como monitor de eventos, a saber, apenas as aplicações implementadas em Java.

\subsection{Trabalhos Futuros}

A elaboração e implementação do EPS foi baseada no fato de que o processamento dos eventos seria centralizado sendo a geração dos eventos distribuídas. Futuramente estudos poderiam ser realizados para que o processamento também fosse distribuído, garantindo uma confiabilidade maior do serviço, dado que existiriam outros locais capazes de processar eventos caso algum processador falhasse, e aumentando o seu desempenho, uma vez que vários eventos poderiam ser processados simultaneamente.

Alguns trabalhos tais como $[17,21]$ já investigaram maneiras de distribuir o processamento de eventos. Porém, todos eles só utilizam árvores simples em vez de árvores agregadas, o que se deve à maior complexidade de distribuição desta última forma de representação. Além disso, esses monitores não permitem mudanças dinâmicas na distribuição das árvores, ou seja, uma vez definida a distribuição das árvores esta não pode ser mais modificada, o que seria desejável para permitir um melhor balanceamento de carga de processamento.

Outro aspecto importante a ser observado na distribuição do processamento é de como decompor uma árvore agregada de forma a manter consistente os estados das instâncias que estarão espalhadas pelos diversos nós. Quando sugerimos a distribuição do processamento, imaginamos um serviço que garanta uma transparência de localização do processamento de eventos para as aplicações que estão utilizando o serviço.

$\mathrm{Na}$ implementação do EPS um conjunto de operadores foi implementado. Este conjunto poderia ser ampliado com o acréscimo de outros operadores proporcionando um poder bem maior de representação das situações que estariam ocorrendo. Operadores como a negação e a concorrência seriam alguns exemplos.

Outra medida para aumentar o poder de expressão dos Pedido-de-Notificação seria o acréscimo de novas funções à gramática de condições. Em particular, poderiam, também, ser adicionadas funções matemáticas às condições. 
O acréscimo destas funções permitira às aplicações a elaboração de condições mais precisas. Por exemplo, cada aplicação poderia definir seu próprio intervalo de tempo para o qual eventos são considerados concorrentes. Ou seja, cada aplicação criaria o seu próprio operador de concorrência. Para criar um operador de concorrência a aplicação poderia enviar o seguinte Pedidode-Notificação: (" $a . E_{1} \&$ b. $E_{2}$ ", "a.TIM EST AMP - b.TIMEST AMP < 500", "Evento concorrentes"), onde TIMESTAMP é um atributo dos eventos $E_{1}$ e $E_{2}$ e 500 corresponde ao tempo de concorrência (em milissegundos).

Para que o EPS tenha uma maior flexibilidade quanto a adaptação às características da rede, o parâmetro de configuração Tempo de Escalonamento, poderia ser calculado dinamicamente de acordo com o desempenho da rede. Isso permitira que em momentos de grande congestionamento na rede, o tempo que o escalonador do EPS reteria uma instância seria maior do que em momentos sem congestionamento, possibilitando um processamento mais preciso das instâncias de eventos.

Nesta dissertação, nós nos concentramos em desenvolver as funcionalidades básicas de um processador de eventos. No entanto, seria também útil desenvolver uma interface gráfica que permita a visualização de quais aplicações enviaram um Pedido-de-Notificação e quais foram os eventos compostos já gerados. 


\section{Apêndice A}

\section{Regras da Gramática de Atributos.}

Baseando-se em Gramáticas de Atributos, definiremos regras para as quatro fases do processamento de eventos descritas no capítulo 4 .

Antes de definir as regras, especificaremos os conjuntos associados a cada nó da árvore (folhas, não-terminais e raízes):

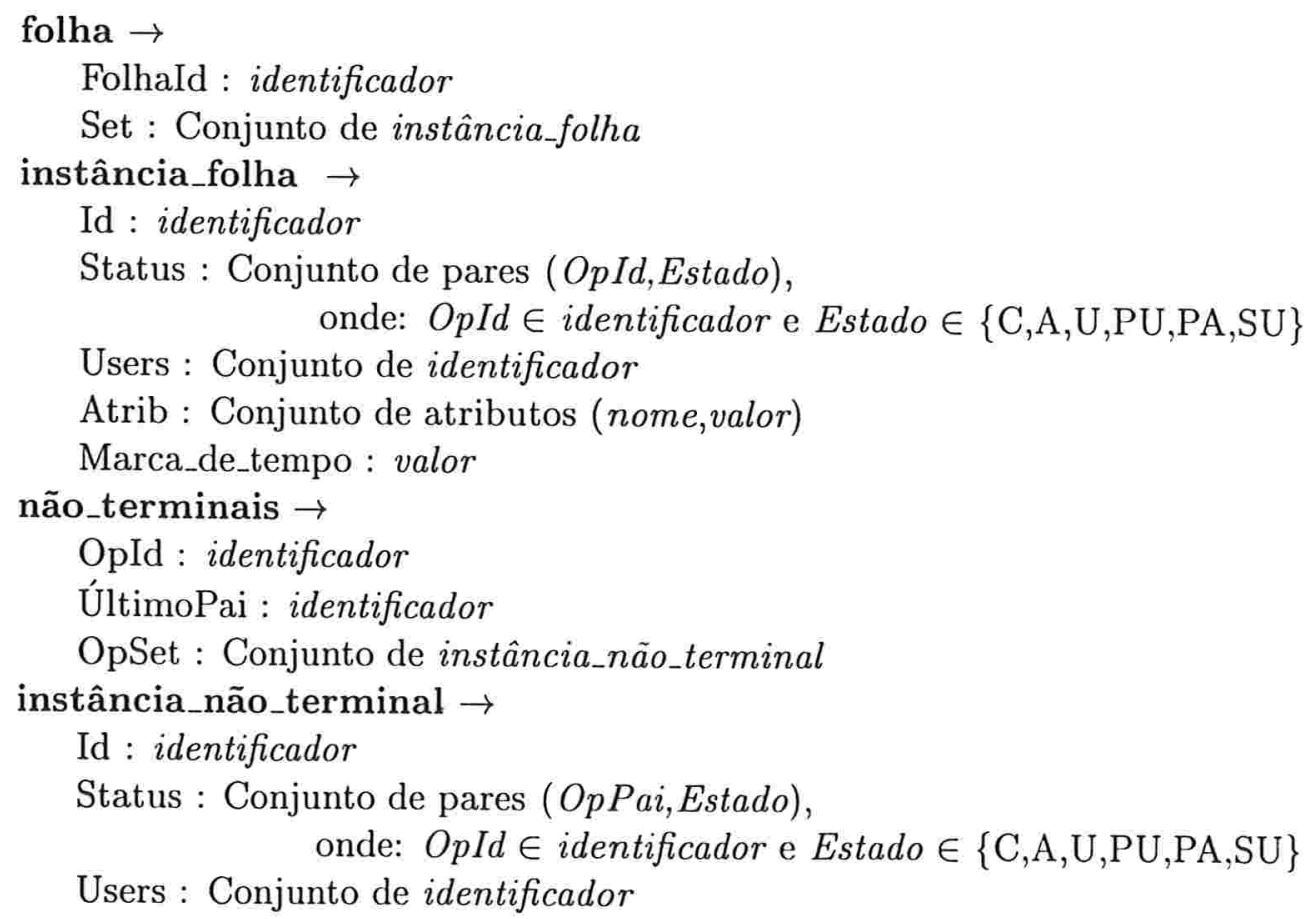


Filhos : Seqüência de identificador

Atrib : Seqüência de atributos (nome,valor)

Marca_de_tempo : valor

raízes $\rightarrow$

AplId : identificador

Cond : Expressão booleana

AplSet : Conjunto de instância_Apl

instância_Apl $\rightarrow$

Id : identificador

Status : Estado,

onde: Estado $\in\{\mathrm{C}, \mathrm{A}, \mathrm{U}, \mathrm{PU}, \mathrm{PA}, \mathrm{SU}\}$

Users : Conjunto de identificador

Filhos : Seqüência de identificador

Atrib : Seqüência de atributos (nome,valor)

Marca_de_tempo : valor

Cada fase do processamento é especificada por uma regra. Nas próximas seções, fornecemos as quatro regra. $\mathrm{Na}$ especificação das regras utilizamos p símbolo ' $>>$ ' para indicar que as ações seguintes serão efetuadas quando o "evento" que precede o símbolo ocorrer.

\section{A.1 Regras que definem a Primeira fase}

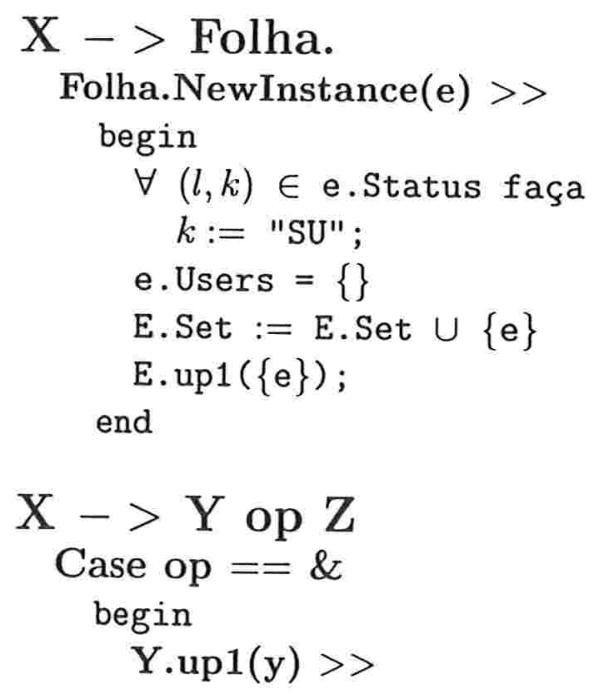



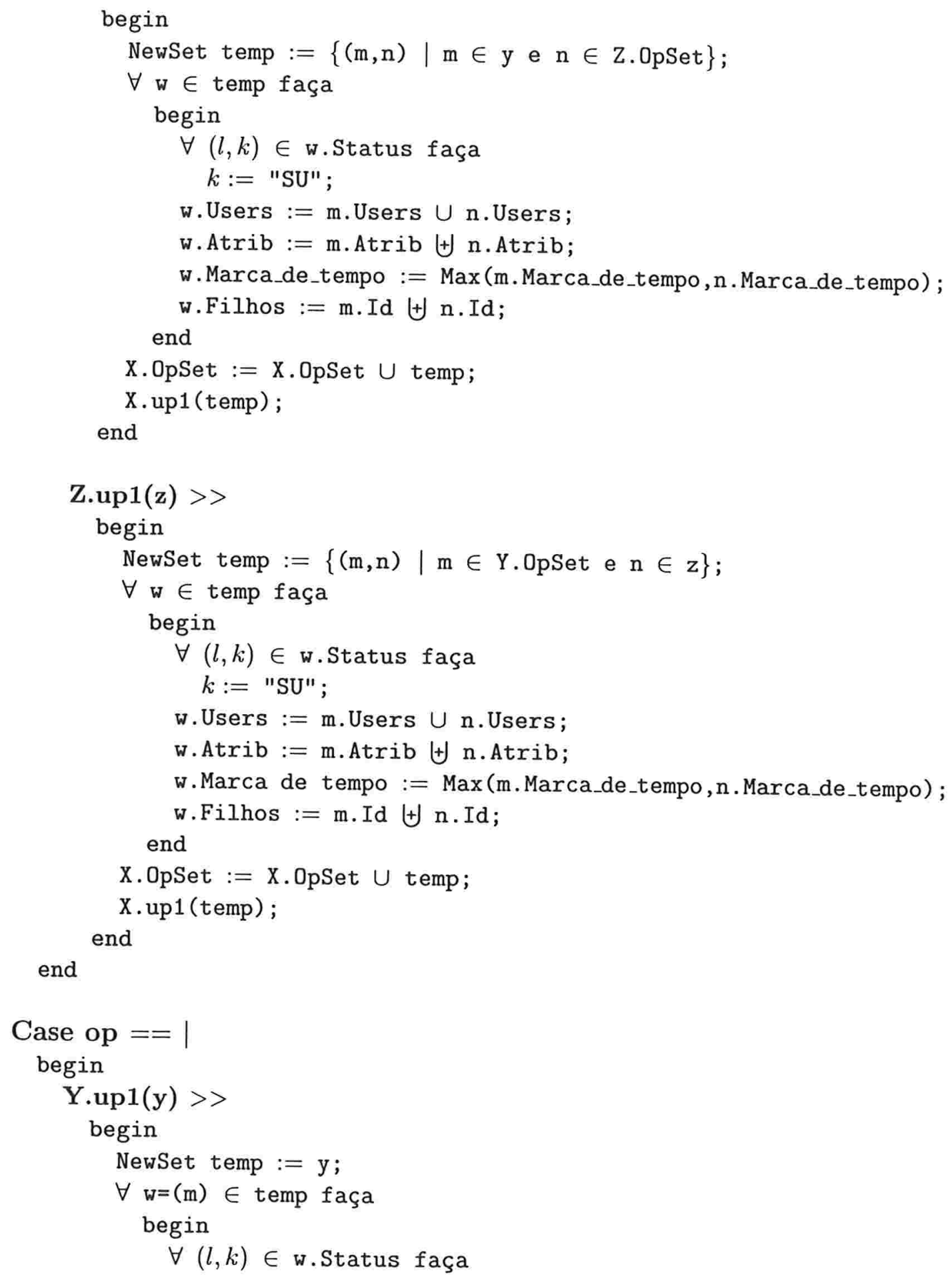


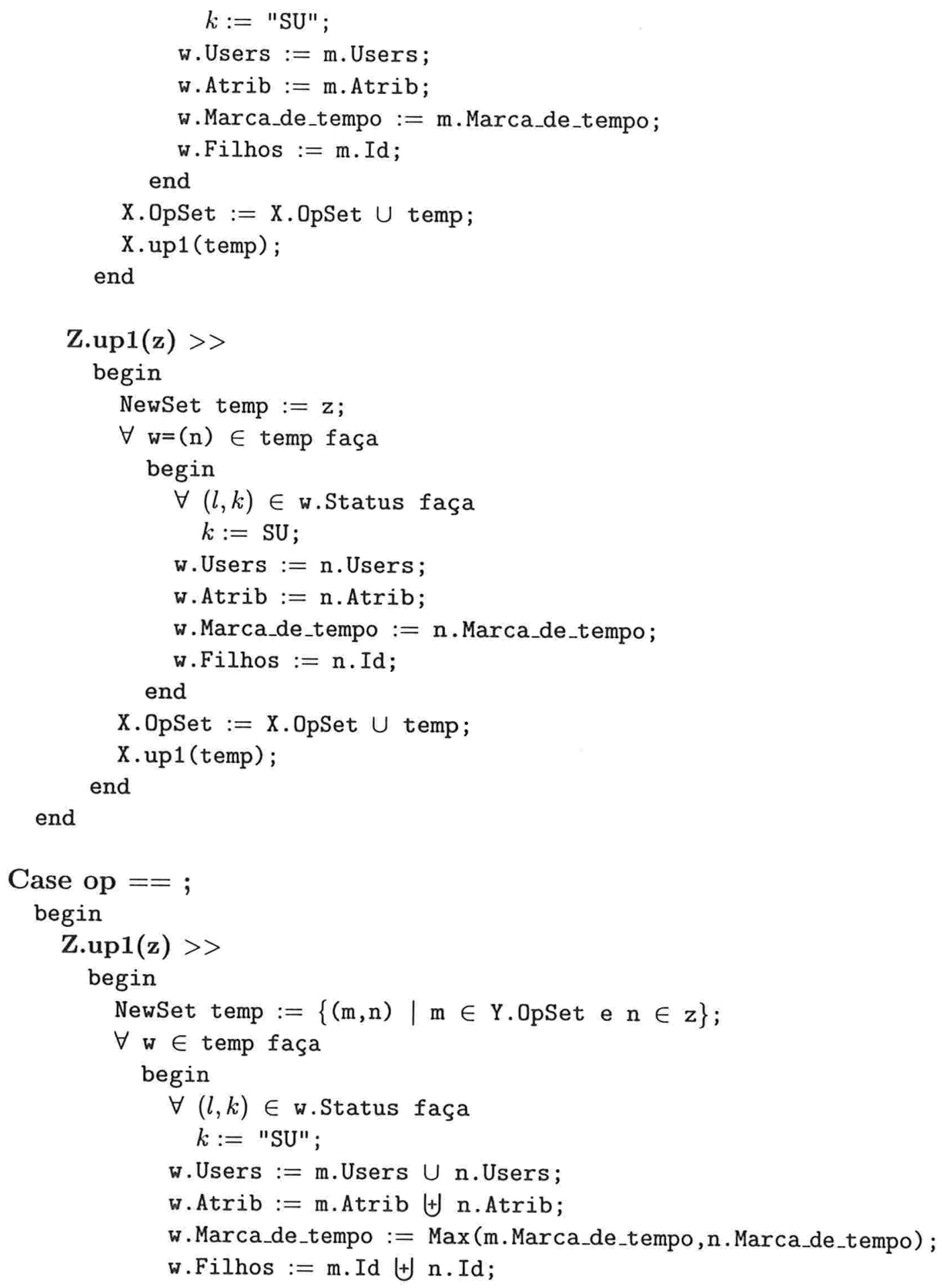




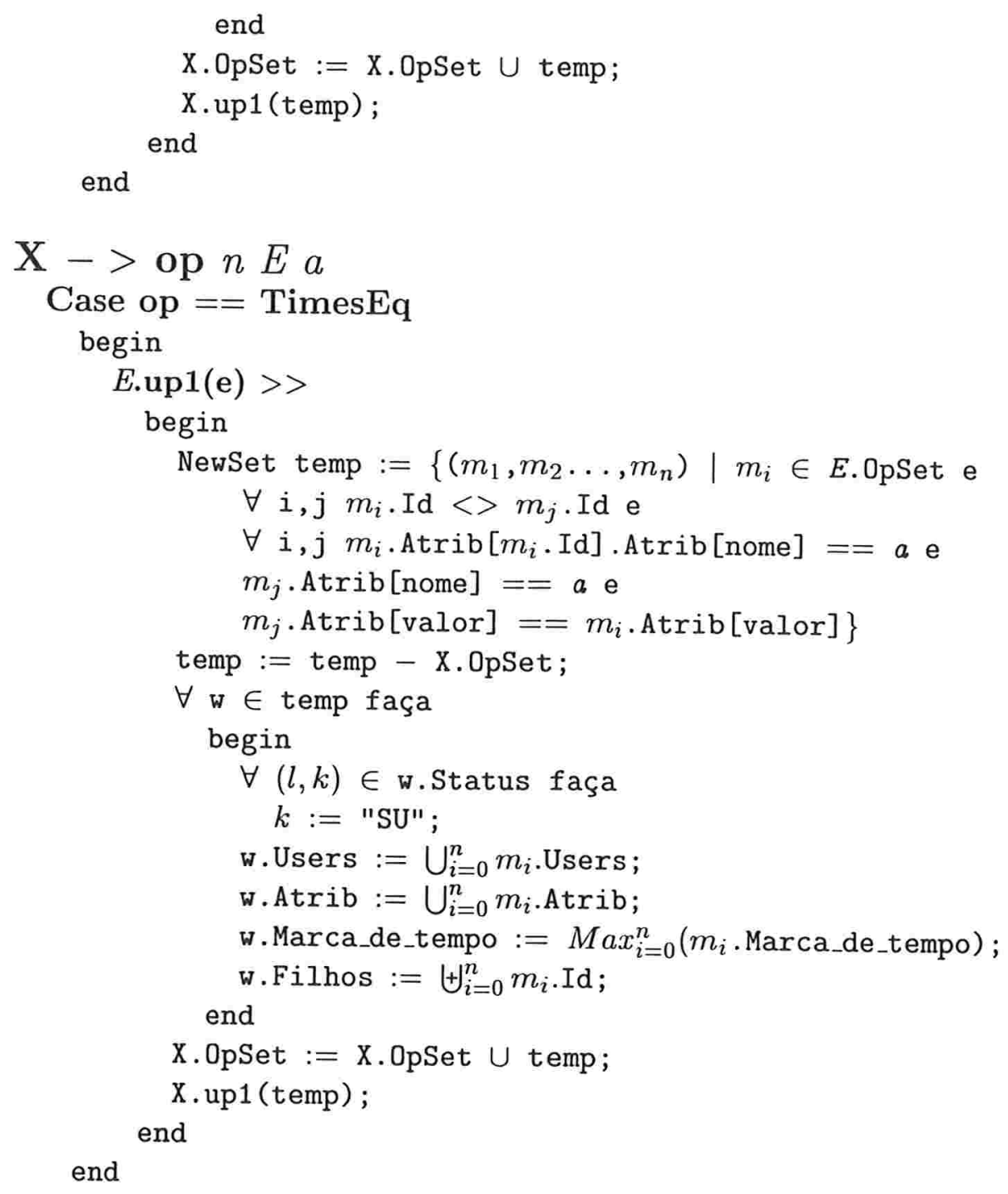




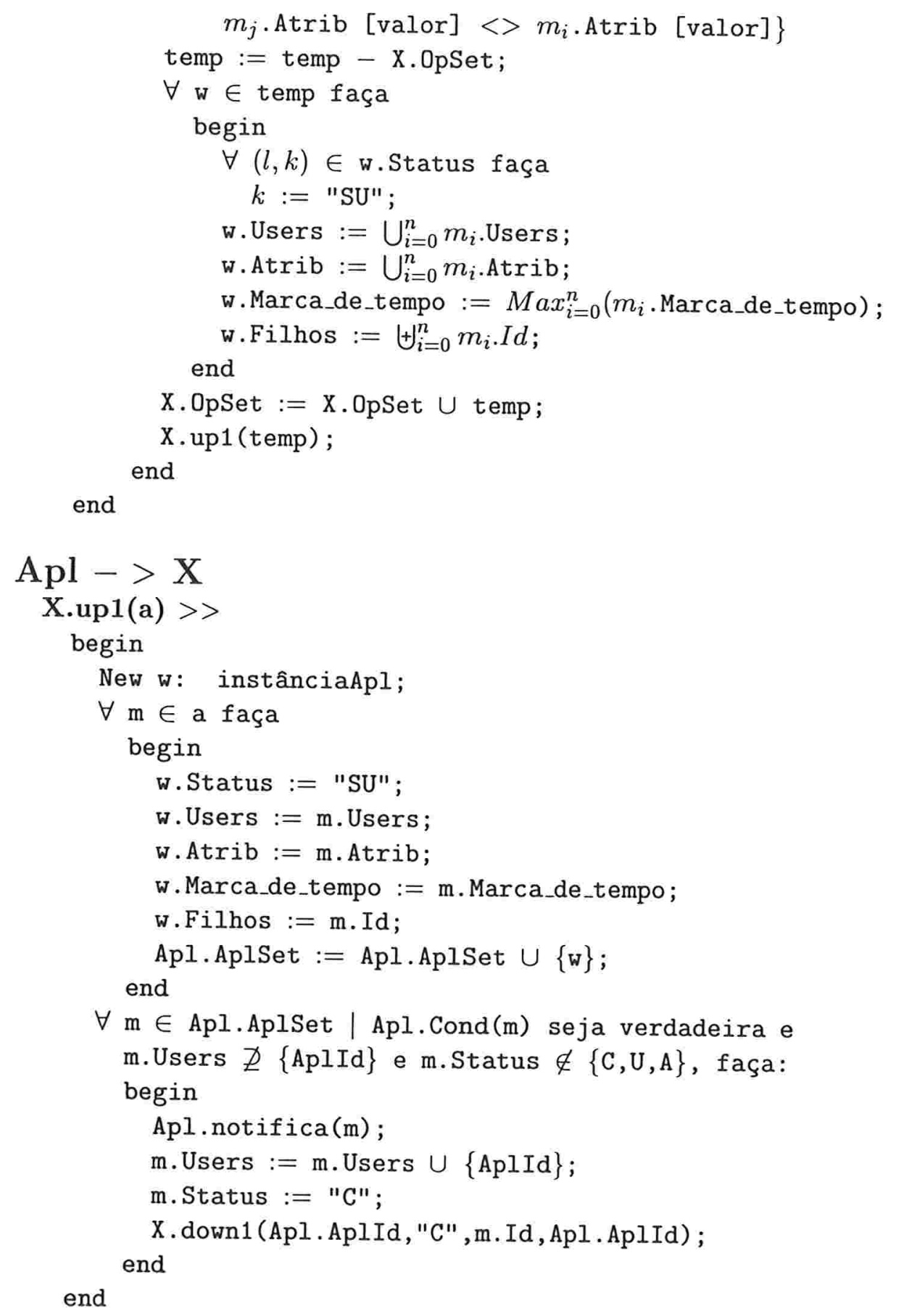




\section{A.2 Regras que definem a Segunda fase.}

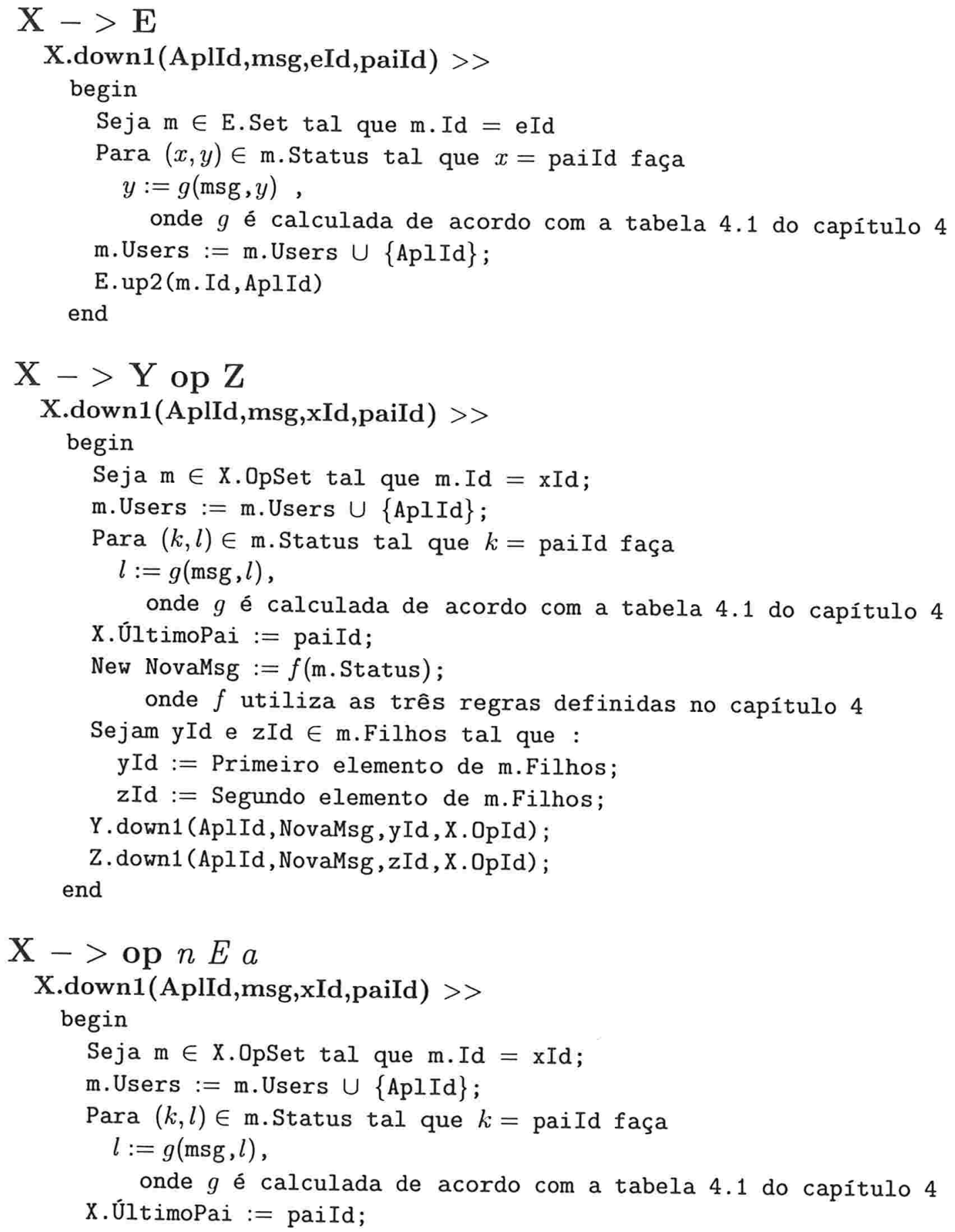




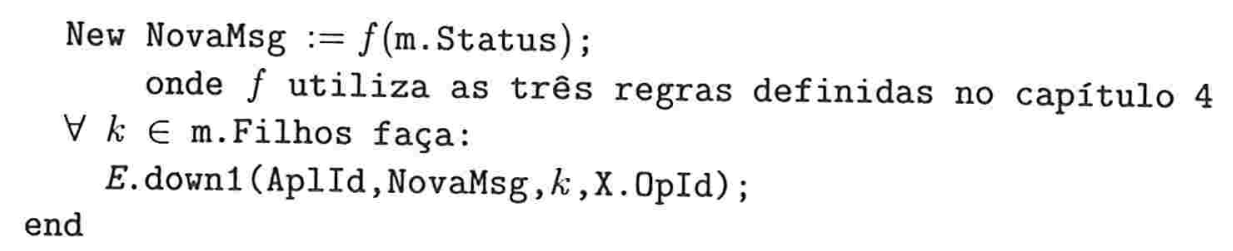

\section{A.3 Regras que definem a Terceira fase}

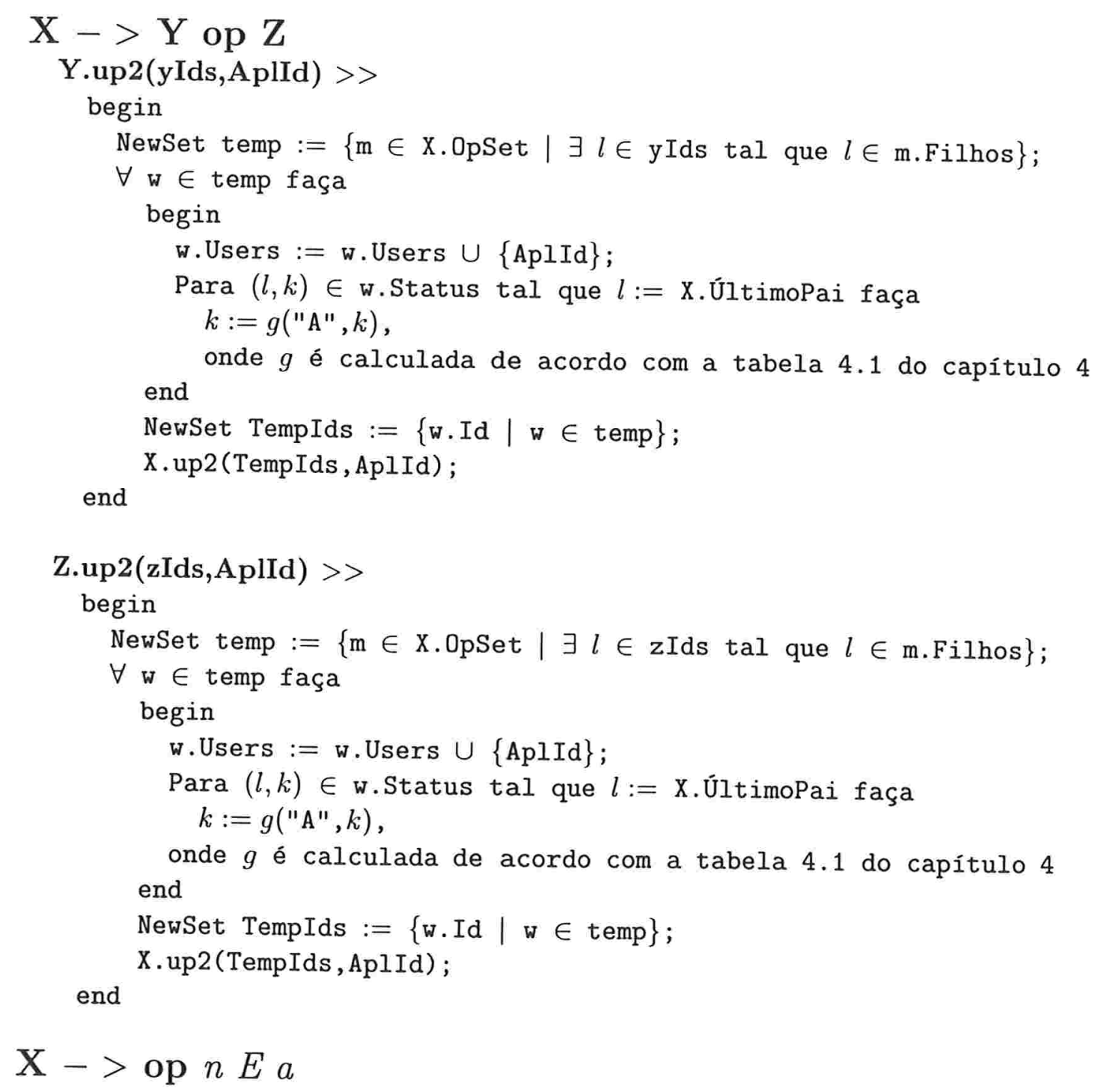




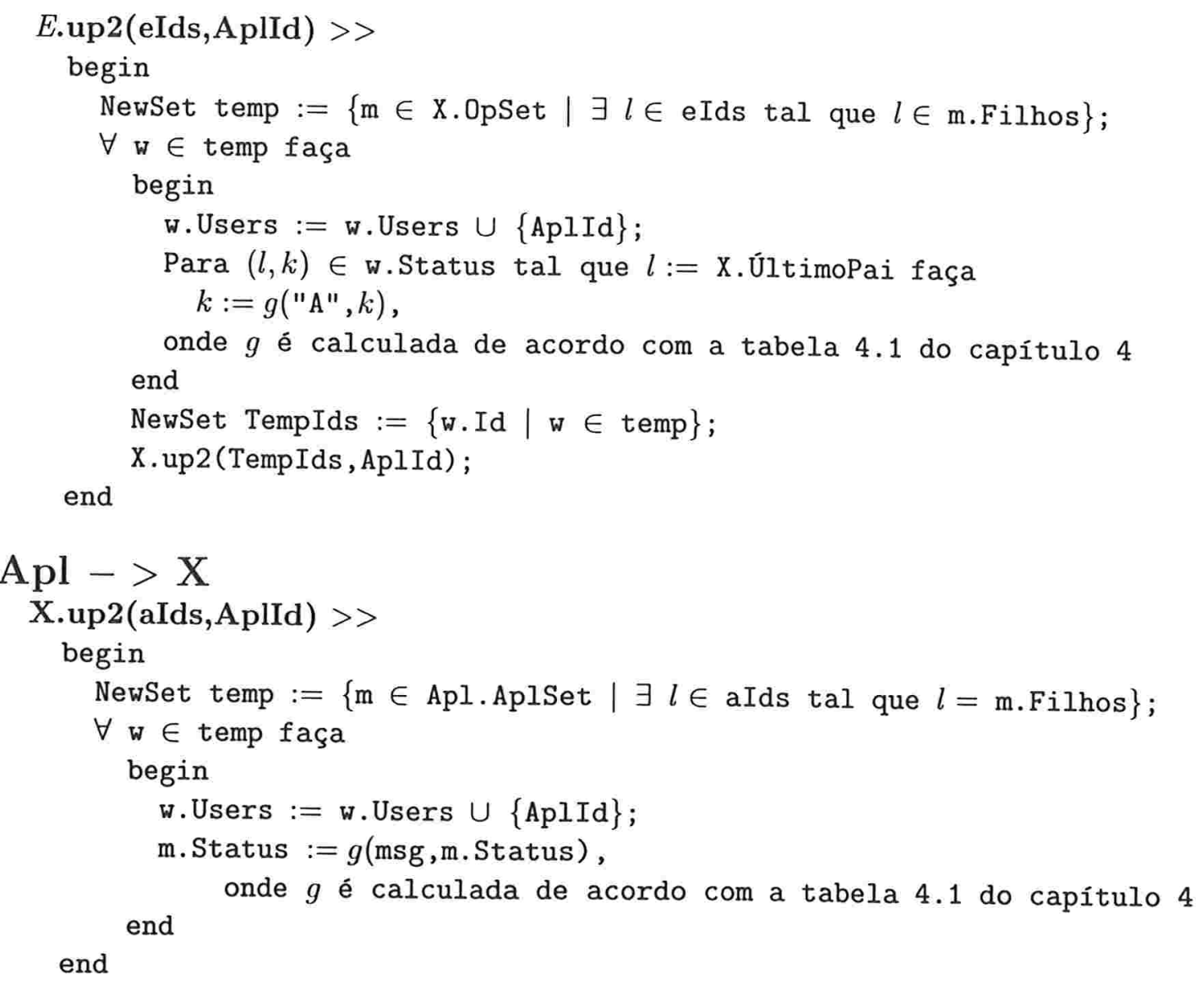

\section{A.4 Regras que definem a Quarta fase}

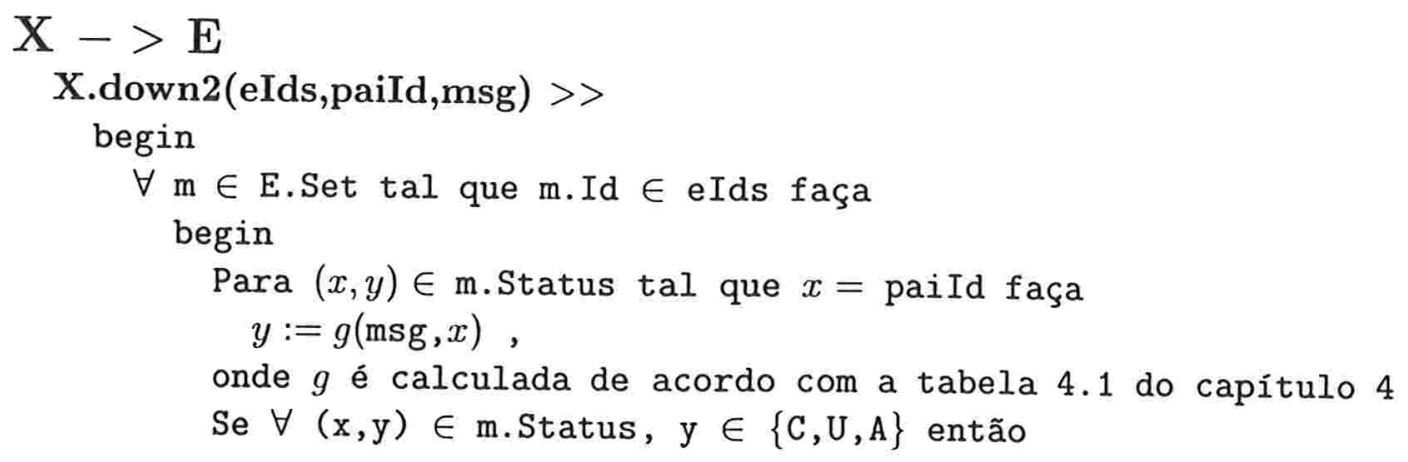




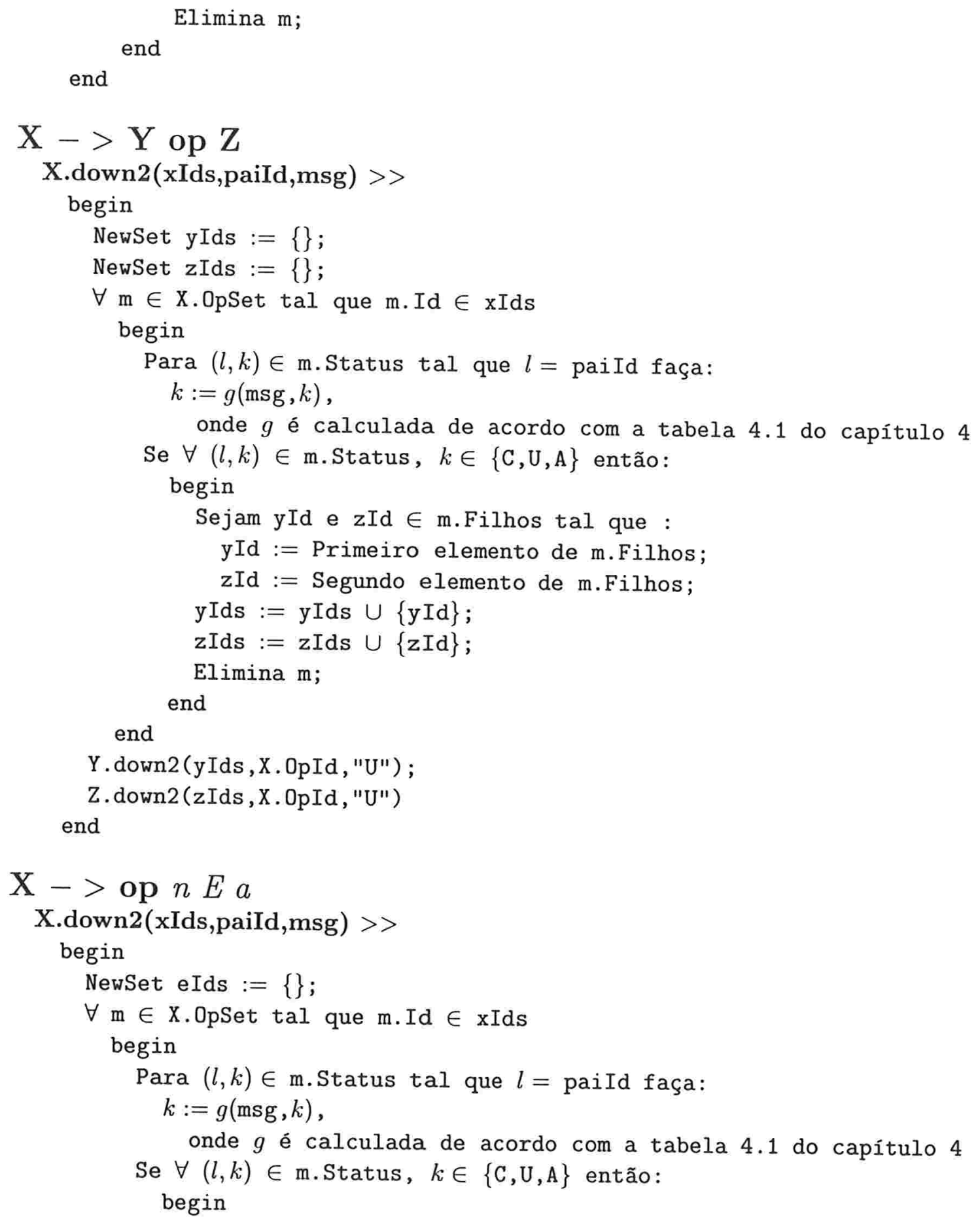




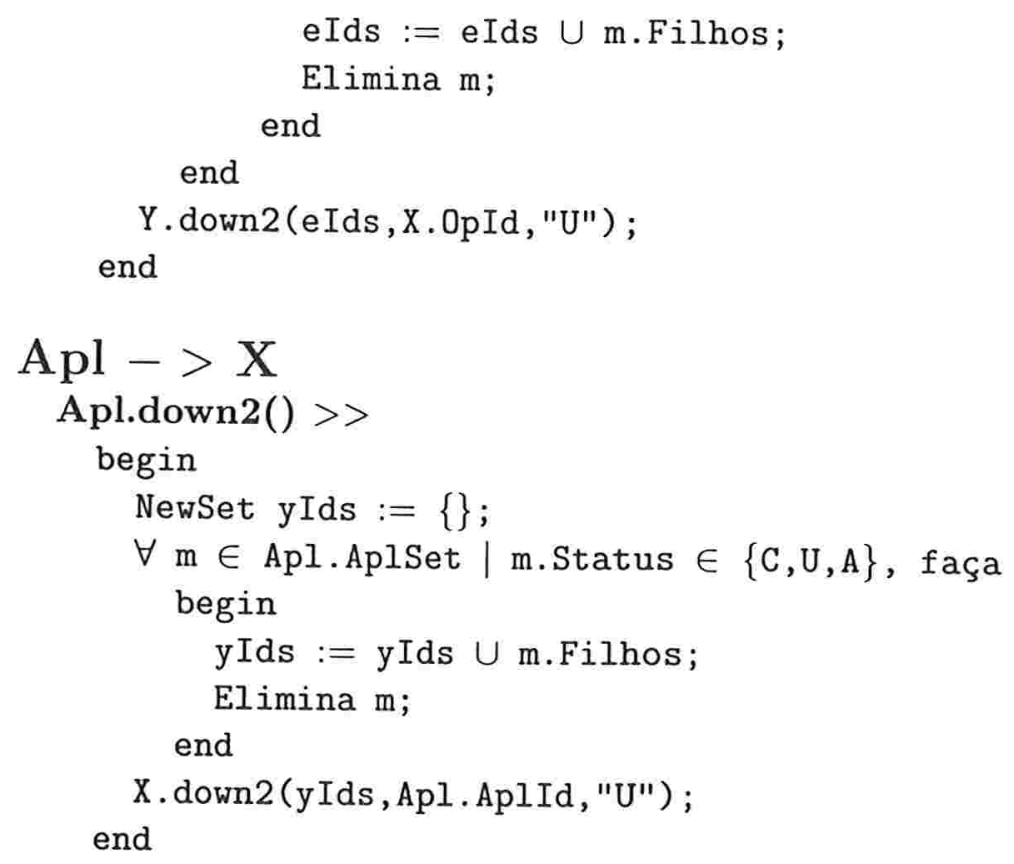




\section{Apêndice B}

\section{Diagrama de Classes do EPS}

O diagrama de classes apresentado neste apêndice é baseado na notação UML (Unified Modeling Language). Na figura B.1 é apresentado uma breve descrição dos símbolos utilizados nos diagramas deste apêndice.

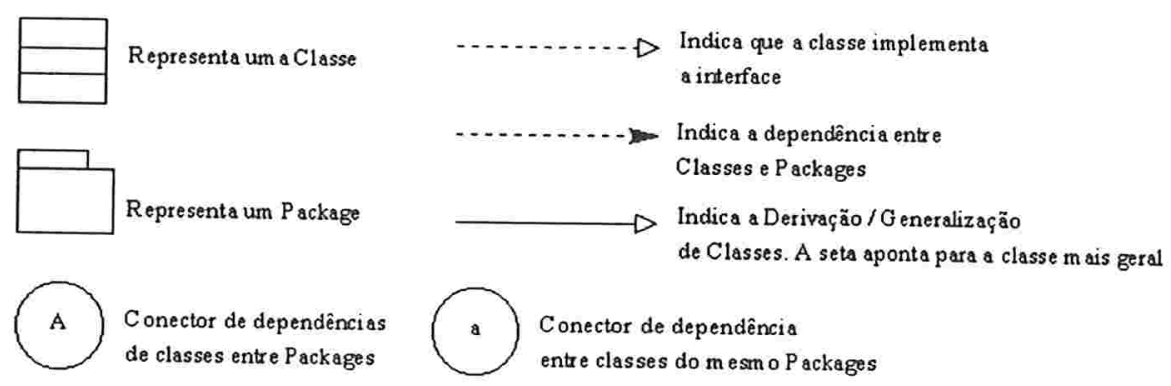

Figura B.1: Símbolos utilizados no Diagrama de Classes. 


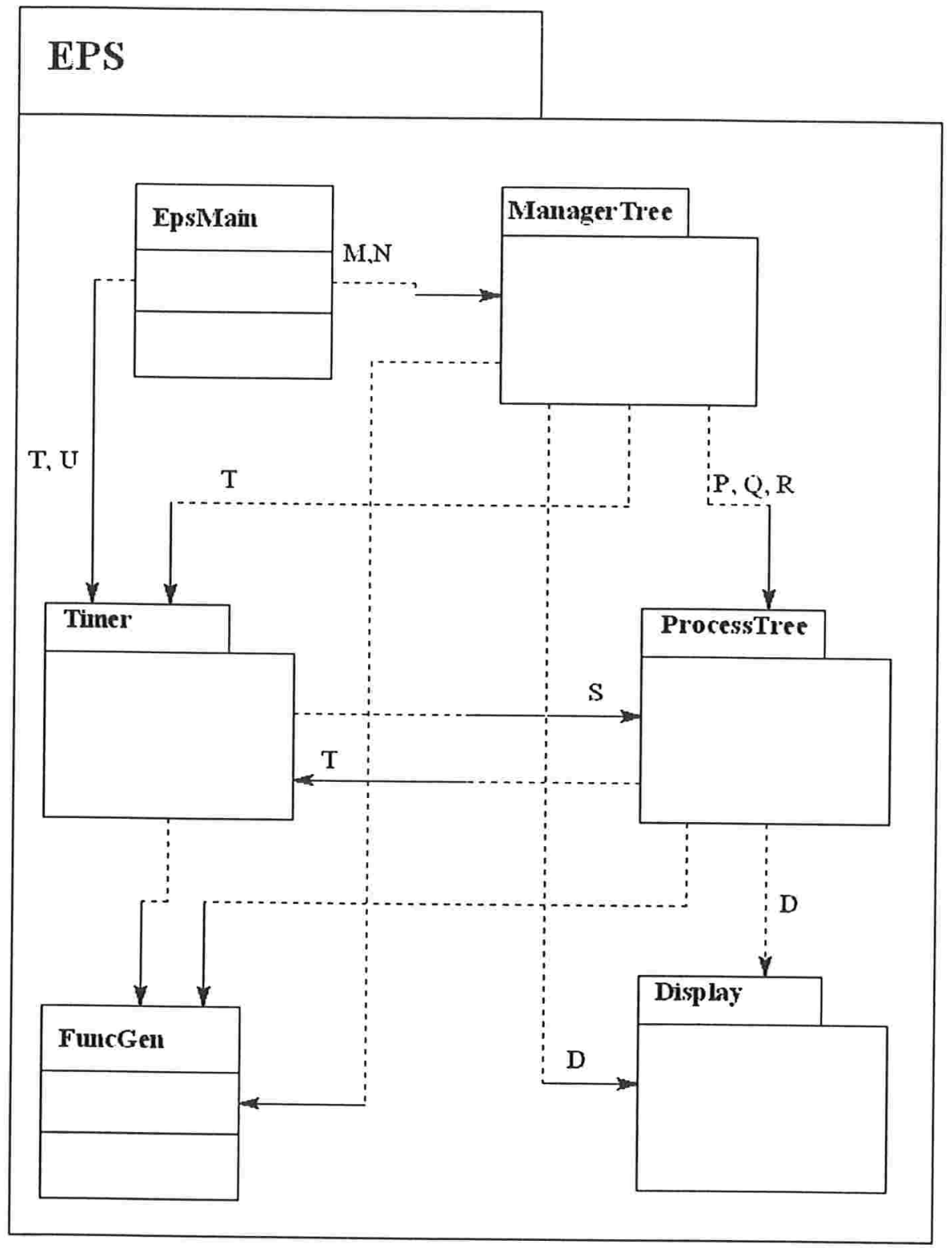

Figura B.2: Diagrama de classes do Eps. 


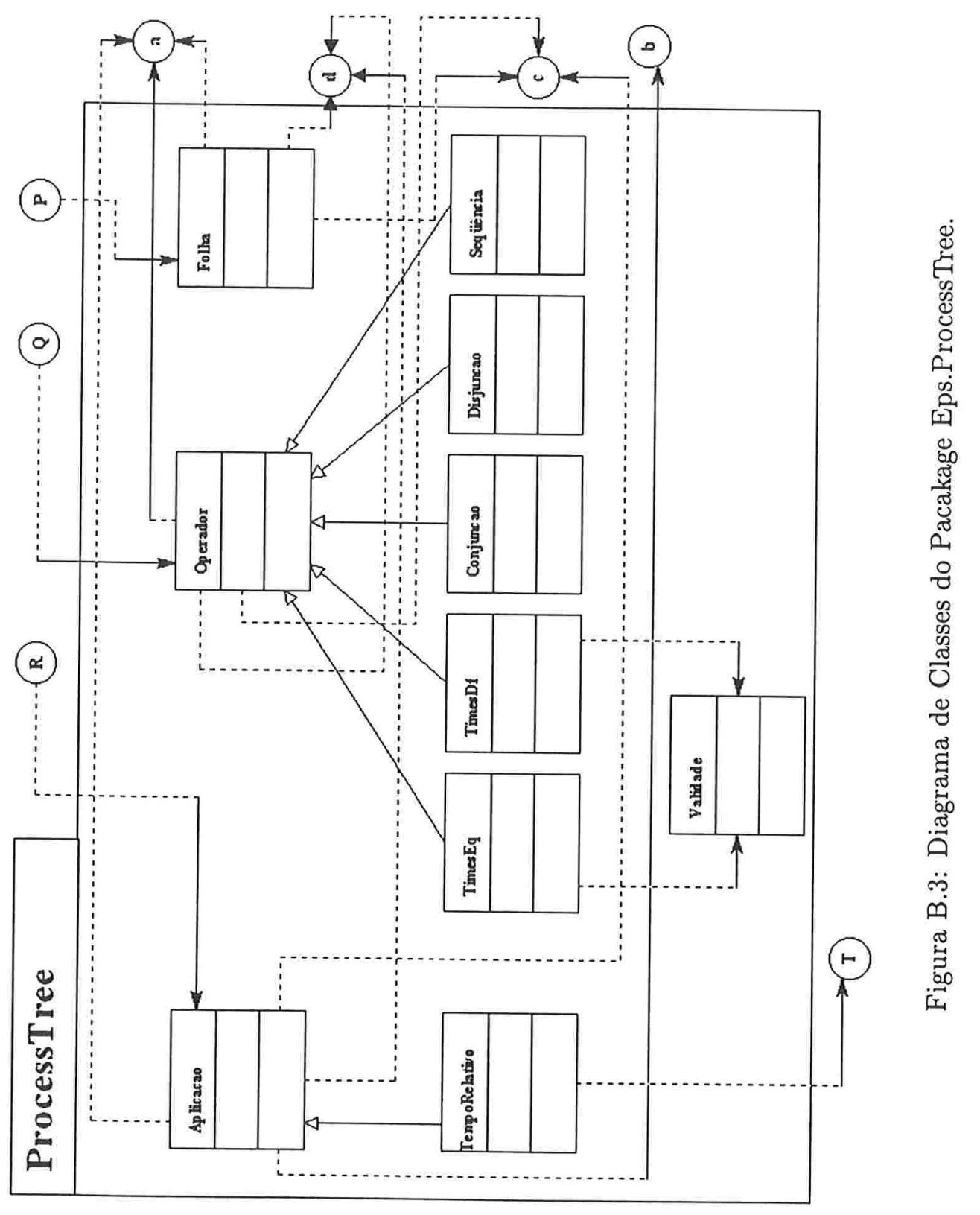




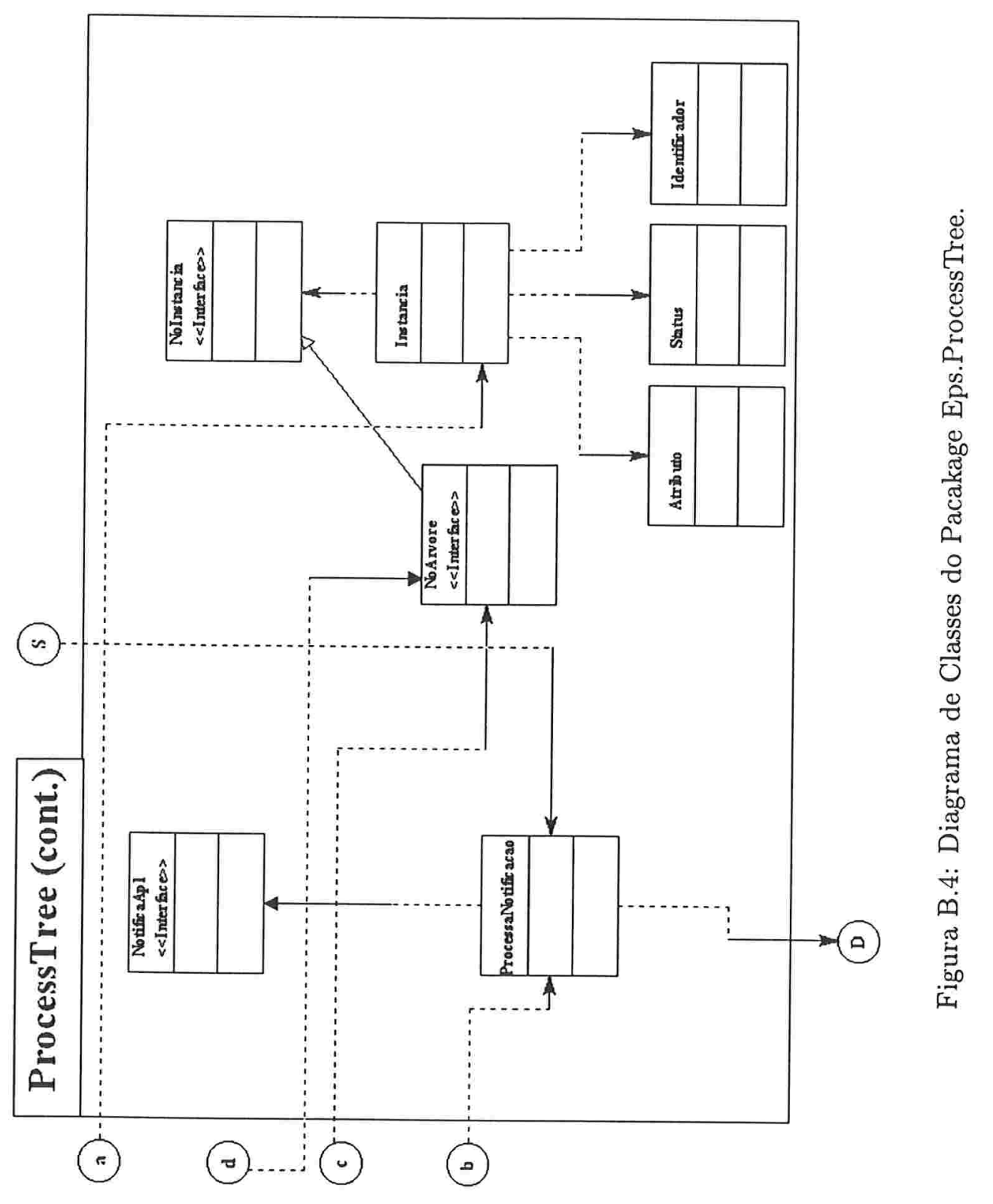




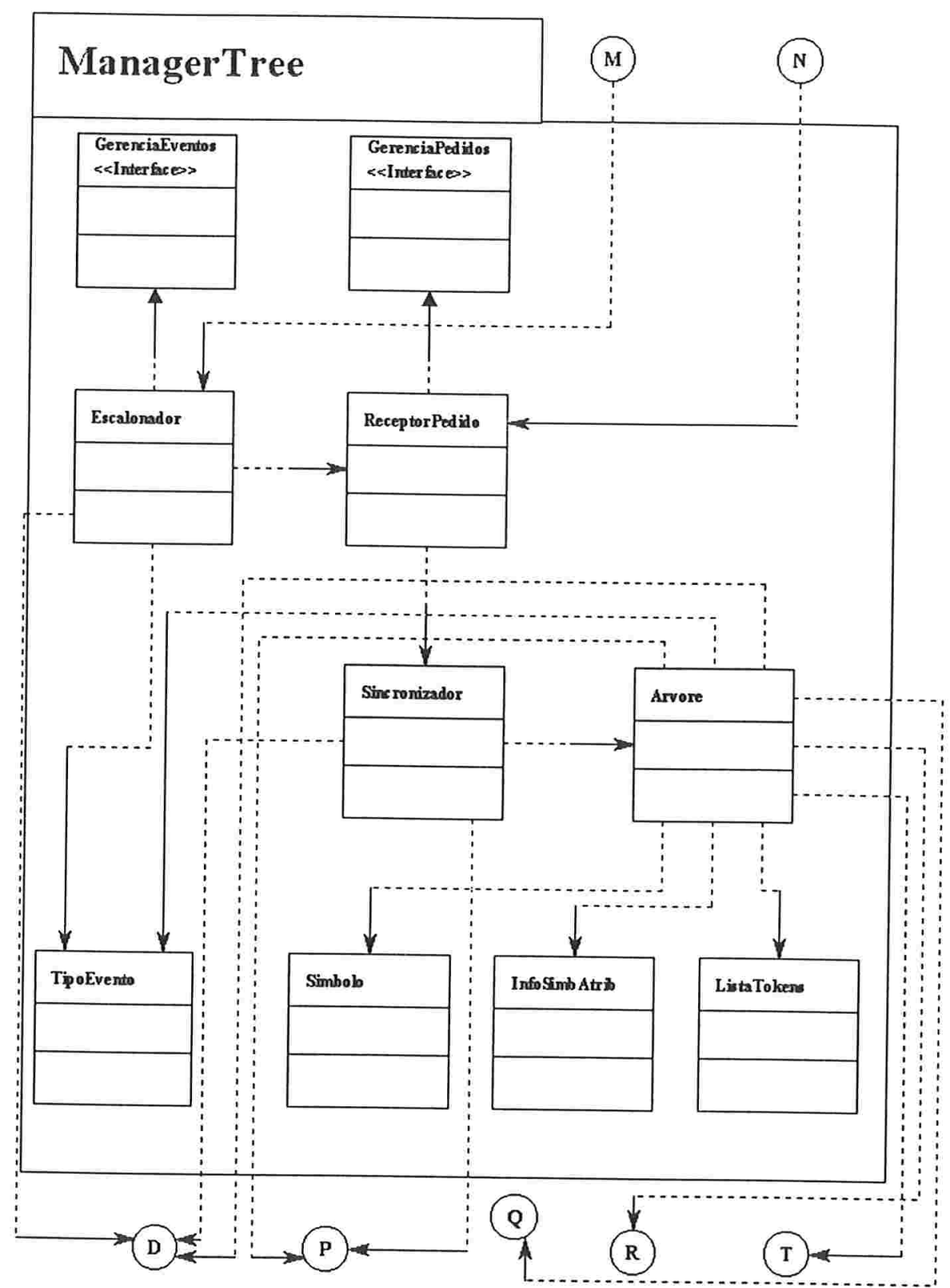

Figura B.5: Diagrama de Classes do Pacakage Eps.ManagerTree. 

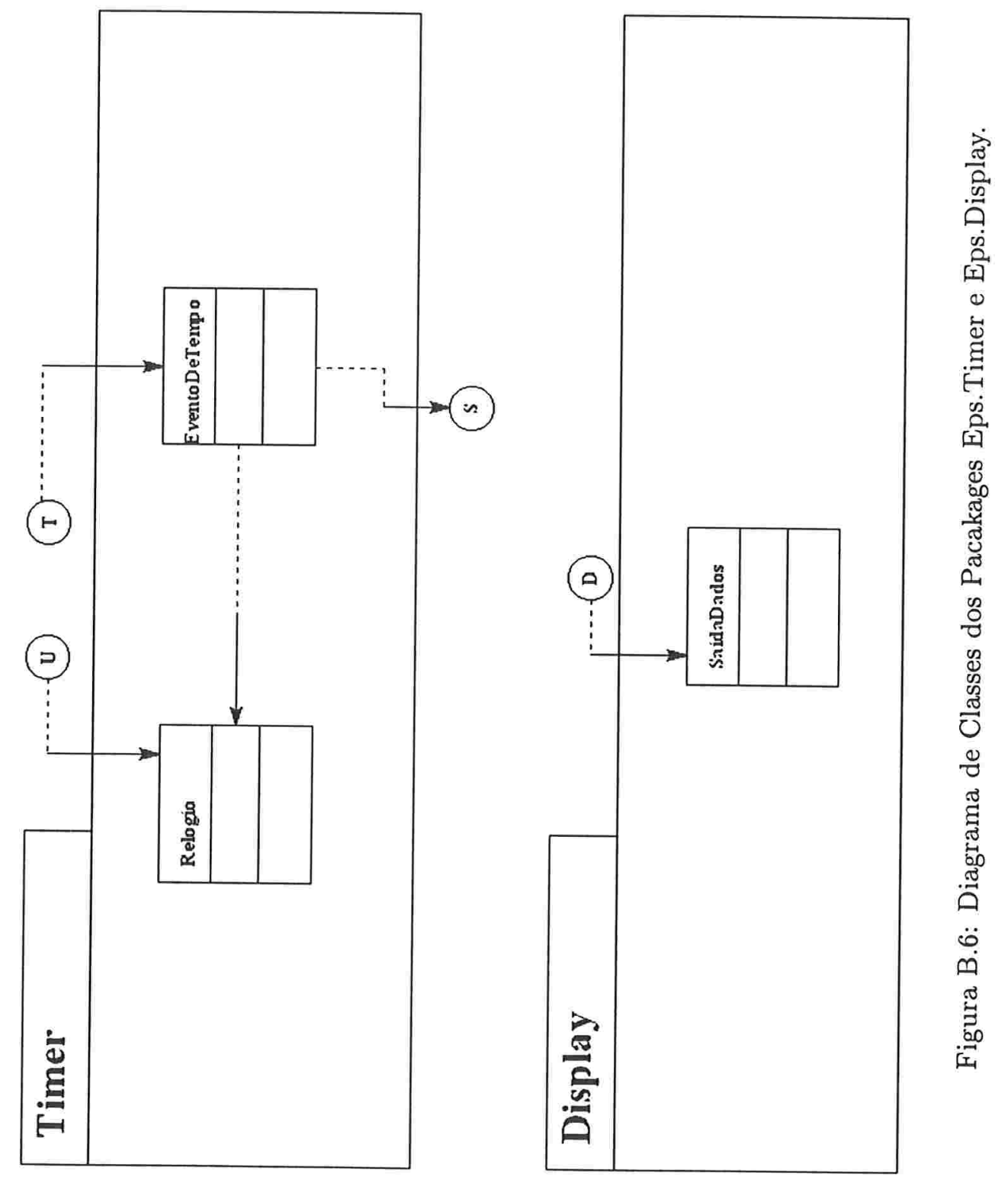


\section{Apêndice C}

\section{Classes do EPS}

\section{C.1 Classes do Package Eps}

\section{C.1.1 Classe Eps.EpsMain}

public class EpsMain

Métodos

- public static void main(String[] args)

\section{C.1.2 Classe Eps.FuncGen}

public class FuncGen

\section{Variáveis}

- static public SaidaDados logNot;

- static public SaidaDados log;

- static final public int numEveAgendados = 10;

- static final public int numEventos $=10$;

- static final public int minUsers $=5$; 
- static final public int minPais $=5$;

- static final public int minInst $=10$;

- static final public int numSimb = 8;

- static public long ultimoNoIdUtil = -1 ;

- static public Vector listaTipoEventos;

- static public Calendar janelaDetec;

- static public Calendar tempoEsclonamento;

- static public int tempoConcorrencia;

\section{Métodos}

- static public long geraIdNo()

- static public Object achaElemento( Vector v, long $\mathrm{x}$ )

- static public Vector selecionaIdsInst (Vector v, long no )

- static public Vector concatena (Vector v1, Vector v2)

- static public boolean contido (Vector v1, Vector v2)

- static public boolean temInterseccao(Vector v1, Vector v2, Vector intersec)

- static public NoArvore achaOperador (Vector v, char tipoOp)

- static public int menor(int i1, int i2)

- static public int maior(int i1, int i2)

- static public boolean eValidoTipoEvento(String tipoEv)

- static public boolean eValidoTipoEvento(String tipoEv, TipoEvento tEvento)

- static public NoArvore exiteTipoEvento (String tipoEv)

- static public Calendar maxTimeStamp(Calendar tempo1, Calendar tempo2) 
- static public Calendar minTimeStamp(Calendar tempo1, Calendar tempo2)

- public static boolean naoConcorrentes(Calendar data1, Calendar data2)

- public static boolean estaNoPrazo(Calendar data)

- public static boolean estaNoPrazo(Calendar data1, Calendar data2)

\section{C.2 Classes do Package ProcessTree}

\section{C.2.1 Classe Eps.ProcessTree.Aplicacao}

public class Aplicacao implements NoArvore

\section{Variáveis}

- public String nomeApl;

- public Vector listaInstancias;

- public Vector filho;

- protected long id;

- public String condicao;

- public Vector simbolos

- protected String msgRetorno;

- protected String porta;

- protected String host;

- protected String servicoRemoto;

\section{Construtores}

- public Aplicacao(NoArvore filhoApl, Vector tabSimb, String cond, String acao, String host, String porta, String servico)

\section{Métodos}


- public long pegaId()

- public Vector pegaInst()

- public Vector pegaFilhos()

- public Vector pegaPais()

- public String pegaTipo()

- public void adicionaPai (NoArvore pai)

- public void removePai(long paiId)

- public void eliminaRefInstPai(long idInstPai)

- public void eliminaStatusInst(long paiId)

- public void eliminaNo()

- public void consomeInstancia(long aplId, String msg, long eId, long paiId, Stack caminho,long idInstPai)

- public void coletaLixo(Vector eIds, long paiId, String msg, Vector idsInstPais)

- public void coletaLixo()

- public void anulaInstancias (long aplId, Vector eIds, Stack caminho)

- public void novasInstancias (Vector xIds, long idFilho)

- public boolean verificaCondicao (Instancia inst)

- private boolean resolveCondLogic(Instancia inst, ListaTokens tokensCond)

- private boolean resolveComp(Instancia inst, ListaTokens tokensCond)

- public int pegaPosSimb(String nome)

- public void notificaApl(Instancia inst)

- public void separaInstNovaVelha(Vector idsNovas, Vector vetInstNovas, Vector vetInstVelhas) 


\section{C.2.2 Classe Eps.ProcessTree.Atributo}

public class Atributo

Variáveis

- public String nomeAtrib;

- public String valor;

Construtor

- public Atributo (String atrib, String val)

\section{C.2.3 Classe Eps.ProcessTree.Conjuncao} re

public class Conjuncao extends Operador implements NoArvo-

\section{Construtores}

- public Conjuncao(NoArvore filhoEsq, NoArvore filhoDir)

Métodos

- public String pegaTipo()

- public void coletaLixo (Vector eIds, long paild, String msg, Vector IdsInstPais)

- public void novasInstancias (Vector xIds, long idFilho)

\section{C.2.4 Classe Eps.ProcessTree.Disjuncao}

public class Disjuncao extends Operador implements NoArvore Variáveis

- public int nFolhasFilhoEsq; 
- public int nFolhasFilhoDir;

\section{Construtores}

- public Disjuncao(NoArvore filhoEsq, NoArvore filhoDir, int numFolhasEsq, int numFolhasDir)

\section{Métodos}

- public String pegaTipo()

- public void coletaLixo (Vector eIds, long paiId, String msg, Vector IdsInstPais)

- public void novasInstancias (Vector xIds, long idFilho)

\section{C.2.5 Classe Eps.ProcessTree.Folha}

public class Folha implements NoArvore

\section{Variáveis}

- protected String tipoEvento;

- public Vector listaPais;

- public Vector listaInstancias;

- protected long id;

\section{Construtores}

- public Folha(String tipoEvento)

\section{Métodos}

- public void novasInstancias (Instancia e)

- public void novasInstancias(Vector xIds, long idFilho)

- public void anulaInstancias(long aplId, Vector eIds, Stack caminho)

- public long pegaId() 
- public Vector pegaInst()

- public Vector pegaFilhos()

- public Vector pegaPais()

- public String pegaTipo()

- public void consomeInstancia (long aplId, String msg, long eId, long paiId, Stack caminho, long idInstPai)

- public void coletaLixo (Vector eIds, long paiId, String msg, Vector idsInstPais)

- public void adicionaPai (NoArvore pai)

- public void removePai(long paiId)

- public void eliminaRefInstPai(long idInstPai)

- public void eliminaNo()

- public void eliminaStatusInst(long paiId)

- public void separaInstNovaVelha(Vector idsNovas, Vector vetInstNovas, Vector vetInstVelhas)

\section{C.2.6 Classe Eps.ProcessTree.Identificador}

public class Identificador

\section{Variáveis}

- public long node;

- public long instance;

\section{Construtor}

- public Identificador (long idNode, long idInstance) 


\section{C.2.7 Classe Eps.ProcessTree.Instancia}

public class Instancia implements NoInstancia

\section{Variáveis}

- public Vector listaIdPais;

- public Vector listaIdFilhos;

- public Vector status;

- public Vector users;

- public Calendar timeStamp;

- static public Vector listaAtributos;

- static Vector listaPosLivres;

- public Vector posUtilizadas;

- public long id;

- static private long ultimoIdUtilizado $=1$;

\section{Construtores}

- public Instancia ()

- public Instancia (Calendar marcaDeTempo)

- public Instancia (Calendar marcaDeTempo, int posAtribs)

\section{Métodos}

- public long pegaId()

- public Status achaStatusPai (long paiId)

- public void uniao(long idApl)

- public void uniao(Vector ids)

- public void uniao(Vector ids1, Vector ids2) 
- public boolean pertenceUsers (long idApl)

- public boolean podeEliminar ()

- public void acrescentaInstPai (long idInstPai, long idNoPai)

- public void retiraPai (long idInstPai)

- public void retiraTodosPais (long idNoPai)

- public String $\mathrm{f}()$

- public void removeStatus (long paiId)

- public void acrescentaStatus (long paiId,String est)

- public String pegaValAtrib(int pos, String nomeAtrib)

- static public int proxPosAtrib()

- static public void devolvePosAtrib(Interger pos)

\section{C.2.8 Interface Eps.ProcessTree.NoArvore}

public interface NoArvore extends NoInstancia

\section{Métodos}

- abstract public void novasInstancias(Vector conjInst, long idFilho);

- abstract public void anulaInstancias(long aplId, Vector eIds, Stack caminho);

- abstract public void consomeInstancia(long aplId, String msg, long eId, long paiId, Stack caminho, long idInstPai);

- abstract public void coletaLixo(Vector eIds, long paiId, String msg, Vector idsInstPais);

- abstract public Vector pegaInst();

- abstract public Vector pegaFilhos();

- abstract public Vector pegaPais(); 
- abstract public String pegaTipo();

- abstract public void adicionaPai (NoArvore pai);

- abstract public void eliminaNo();

- abstract public void eliminaStatusInst(long paiId);

- abstract public void removePai(long paiId);

- abstract public void separaInstNovaVelha(Vector idsNovas, Vector vetInstNovas, Vector vetInstVelhas)

- abstract public void eliminaRefInstPai(long idInstPai)

\section{C.2.9 Interface Eps.ProcessTree.NoInstancia}

public interface NoInstancia

Métodos

- abstract public long pegaId()

\section{C.2.10 Interface Eps.ProcessTree.NotificaApl}

public interface NotificaApl extends Remote

\section{Métodos}

- abstract public void notifica(Calendar timeStamp, String msg) throws RemoteException;

\section{C.2.11 Classe ProcessTree.Operador}

public class Operador

Variáveis

- public Vector listaPais;

- public Vector listaInstancias; 
- public Vector listaFilhos;

- protected long id;

\section{Métodos}

- public Vector pegaInst()

- public Vector pegaFilhos()

- public Vector pegaPais()

- public long pegaId()

- public void consomeInstancia (long aplId, String msg, long eId, long paiId, Stack caminho, long idInstPai)

- public void anulaInstancias (long aplId, Vector eIds, Stack caminho)

- public void adicionaPai (NoArvore pai)

- public void removePai(long paiId)

- public void eliminaRefInstPai(long idInstPai)

- public void eliminaNo()

- public void eliminaStatusInst(long paiId)

- public void separaInstNovaVelha(Vector idsNovas, Vector vetInstNovas, Vector vetInstVelhas)

\section{C.2.12 Classe Eps.ProcessTree.ProcessaNotificacao}

public class ProcessaNotificacao extends Thread

\section{Variáveis}

- private String host;

- private int porta;

- private String servico;

- private String msg; 
- private Calendar instanteGeracao;

\section{Construtores}

- public ProcessaNotificacao(String host, int porta, String servico, Calendar timer, String msg)

\section{Métodos}

- public void run()

\section{C.2.13 Classe Eps.ProcessTree.Sequencia}

public class Sequencia extends Operador implements NoArvore

\section{Construtores}

- public Sequencia(NoArvore filhoEsq, NoArvore filhoDir)

\section{Métodos}

- public String pegaTipo()

- public void coletaLixo (Vector eIds, long paiId, String msg, Vector IdsInstPais)

- public void novasInstancias (Vector xIds, long idFilho)

\section{C.2.14 Classe Eps.ProcessTree.Status}

public class Status

Variáveis

- public String estado;

- public long idPai;

Construtores 
- public Status (String est)

- public Status (long id, String est)

\section{Métodos}

- public void g(String msg, Vector conjUser, Vector conjUserPai, boolean apl)

\section{C.2.15 Classe Eps.ProcessTree.TempoRelativo}

public class TempoRelativo extends Aplicacao

Variáveis

- private Calendar tempoEspera;

\section{Construtores}

- public TempoRelativo(NoArvore filhoApl, Vector tabSimb, String cond, String acao, String host, String porta, String servico,Calendar tempoEspera)

\section{Métodos}

- public void notificaApl(Instancia inst)

\section{C.2.16 Classe Eps.ProcessTree.TimesDf}

public class TimesEq extends Operador implements NoArvore

\section{Variáveis}

- public int numRepete;

- public String nomeAtri;

- public Vector simbolos;

\section{Construtores}


- public TimesDf(NoArvore filho, int n, String atrib, Vector tabSimb)

\section{Métodos}

- public void coletaLixo (Vectcr eIds, long paiId, String msg, Vector IdsInstPais)

- public void novasInstancias (Vector xIds, long idFilho)

- public String pegaTipo()

- public Vector combinacao( Vector $\mathrm{v}$, long $\mathrm{n}$ )

- public void binomial(int $x$, int $n$,Vector conjInst, int idFilho, Vector conjComb, Vector conjAtrib, int posAtrib, String nomeAtrib, NoArvore noFilho)

- public int pegaPosNomeAtrib(StringBuffer nomeAtrib)

\section{C.2.17 Classe Eps.ProcessTree.TimesEq}

public class TimesEq extends Operador implements NoArvore

\section{Variáveis}

- public int numRepete;

- public String nomeAtri;

- public Vector simbolos;

\section{Construtores}

- public TimesEq(NoArvore filho, int n, String atrib, Vector tabSimb)

\section{Métodos}

- public void coletaLixo (Vector eIds, long paiId, String msg, Vector IdsInstPais)

- public void novasInstancias (Vector xIds, long idFilho) 
- public String pegaTipo()

- public Vector combinacao( Vector v, long $\mathrm{n}$ )

- public void binomial(int $x$, int $n$,Vector conjInst, int idFilho, Vector conjComb, Vector conjAtrib, int posAtrib, String nomeAtrib, NoArvore noFilho)

- public int pegaPosNomeAtrib(StringBuffer nomeAtrib)

\section{C.2.18 Classe Eps.ProcessTree.Validade}

\section{class Validade}

\section{Variáveis}

- public Calendar min;

- public Calendar max;

\section{Construtores}

- public Validade()

- public Validade (Calendar dataMin, Calendar dataMax)

\section{Métodos}

- public boolean dentroPeriodo(Calendar instante)

\section{C.3 Classes do Package ManagerTree}

\section{C.3.1 Classe Eps.ManagerTree.Arvore}

public class Arvore

Variáveis

- static public Vector listaFolhas;

- static public Vector listaApl; 


\section{Métodos}

- public static void coletorDeLixo()

- static public NoArvore eventoComposto (ListaTokens str, Vector tabSimb, InfoSimbAtrib posSimbPai)

- static public NoArvore evento(ListaTokens str, Vector tabSimb, InfoSimbAtrib posSimb)

- static public long registraInteresse(String eventoComp, String cond, String acao, String host, String servico, String porta)

- static public void cancelaInteresse(long identApl)

\section{C.3.2 Classe Eps.ManagerTree.Escalonador}

public class Escalonador extends UnicastRemoteObject implements Runnable, GerenciaEventos

\section{Variáveis}

- protected Vector listaEventos;

\section{Construtores}

- public Escalonador()

\section{Métodos}

- public void eventoGerado(String event) throws RemoteException

- private void colocaNaOrdem(Instancia instNova)

- public boolean podeProcessar(Calendar data)

- public void run() 


\section{C.3.3 Interface Eps.ManagerTree.GerenciaEventos}

public interface GerenciaEventos extends Remote

\section{Métodos}

- abstract public void eventoGerado(String event) throws RemoteException;

\section{C.3.4 Interface Eps.ManagerTree.GerenciaPedidos}

public interface GerenciaPedidos extends Remote

\section{Métodos}

- abstract public long registraInteresse(String eventoComp, String cond, String acao, String host, String servico, String porta) throws RemoteException;

- abstract public void cancelaInteresse(long identApl) throws RemoteException;

\section{C.3.5 Classe Eps.ManagerTree.InfoSimbAtrib}

public class InfoSimbAtrib

\section{Variáveis}

- public int posPriSimb;

- public int posUltSimb;

- public int numFolhas;

\section{Construtores}

- public InfoSimbAtrib() 


\section{C.3.6 Classe Eps.ManagerTree.ListaTokens}

public class ListaTokens

Variáveis

- StringTokenizer str;

- String tokenDevolvido;

- boolean temDevolucao;

Construtores

- public ListaTokens(String str)

- public ListaTokens(String str, String delim)

- public ListaTokens(String str, String delim, boolean devolToken)

\section{Métodos}

- public String pegaToken()

- public String pegaToken(int $\mathrm{n}$ )

- public void devolveToken(String item)

\section{C.3.7 Classe Eps.ManagerTree.ReceptorPedidos}

public class ReceptorPedidos extends UnicastRemoteObject implements GerenciaPedidos

\section{Métodos}

- public ReceptorPedidos() throws RemoteException

- public long registraInteresse(String eventoComp, String cond, String acao, String host, String servico, String porta) throws RemoteException

- public void cancelaInteresse(long identApl) throws RemoteException 


\section{C.3.8 Classe Eps.ManagerTree.Simbolo}

public class Simbolo

Variáveis

- public String nomeSimb;

- public int indLista;

\section{Construtores}

- public Simbolo(String nome, int pos)

\section{C.3.9 Classe Eps.ManagerTree.Sincronizador}

\section{public class Sincronizador}

\section{Métodos}

- synchronized static public void novasInstancias(Instancia inst)

- synchronized static public long registraInteresse(String eventoComp, String cond, String acao, String host, String servico, String porta)

- synchronized static public void cancelaInteresse(long identApl)

\section{C.3.10 Classe Eps.ManagerTree.TipoEvento}

public class TipoEvento

\section{Variáveis}

- String tipo;

- Vector listaParametros; 


\section{C.4 Classes do Package Timer \\ C.4.1 Classe Eps.Timer.EventoDeTempo}

public class EventoDeTempo

Variáveis

- protected long id;

- protected String host;

- protected String servicoRemoto;

- protected String portaAcesso;

- protected String msgRetorno;

- public Calendar acordar;

- public String proxInstante[];

\section{Construtores}

- public EventoDeTempo(String host, String servico, String porta, String msg, String ano, String mes, String dia, String hora, String minuto, String segundo)

\section{Métodos}

- public boolean calculaProximoInstante()

- public boolean temProximoInstante()

- public void notificaApl()

- public long pegaId() 


\section{C.4.2 Classe Eps.Timer.Relogio}

public class Relogio implements Runnable

Variáveis

- protected static Vector listaEveAgendados;

\section{Construtores}

- public Relogio()

Métodos

- public static void agendaEvento (EventoDeTempo eve)

- public void run()

\section{C.5 Classes do Package Display}

\section{C.5.1 Classe Eps.Display.SaidaDados}

public class SaidaDados

Variáveis

- protected FileWriter arq;

- protected boolean escreveNoArq;

\section{Construtores}

- public SaidaDados(String titulo)

- public SaidaDados(String titulo, String nomeArq)

\section{Métodos}

- public void escreveSaida (String msg) 


\section{Referências Bibliográficas}

[1] J. Bacon, J. Bates, R. Hayton, and K. Mood. Using Events to Build Distributed Applications. In Proceedings of the 2nd International Workshop on Services in Distributed and Network Enviroments, pages 148-155, 1995.

[2] S. Chakravarthy, E. Anwar, L. Maugis, and D. Mishra. Design of Sentinel: An Object-Oriented DBMS with Event-Based Rules. Information and Software Technology, 36(9):559-568, 1994.

[3] S. Chakravarthy, V. Krishnaprasad, E. Anwar, and S.-K. Kim. Composite events for active databases: Semantics, contexts and detection. In Jorgeesh Bocca, Matthias Jarke, and Carlo Zaniolo, editors, 20th International Conference on Very Large Data Bases, September 12-15, 1994, Santiago, Chile proceedings, pages 606-617, Los Altos, CA 94022, USA, 1994. Morgan Kaufmann Publishers.

[4] S. Chakravarthy and D. Mishra. Snoop: An Expressive Event Specification Language for Active Databases. Data and Knowledge Engineering, 14(1):1-26, November 1994.

[5] S. Crane, J. Magee, N. Dulay, and K. Twidle. Regis Programmer's Manual. Distriburted Systems Group, Imperial College London, August 1995.

[6] M. Endler and A. D'Souza. Supporting Distributed Application Management in Sampa. In Proc. 3rd International Conference on Configurable Distributed Systems, Annapolis, USA, pages 177-184. IEEE, May 1996.

[7] Michael Morrison et al. Java 1.1 Unleashed Third Edition. sams net, 1997. 
[8] S. Gatziu and K. R. Dittrich. Events in an active object-oriented database system. In N. W. Paton and H. W. Williams, editors, Proc. 1st Intl. Workshop on Rules in Database Systems (RIDS), Edinburgh, UK, September 1993. Springer-Verlag, Workshops in Computing.

[9] Stella Gatziu and Klaus R. Dittrich. Detecting composite events in active database systems using petri nets. In Research Issues in Data Engineering, pages 2-9, Los Alamitos, Ca., USA, February 1994. IEEE Computer Society Press.

[10] Stella Gatziu, Andreas Geppert, and Klaus R. Dittrich. The SAMOS active DBMS prototype. Technical Report ifi-94.16, Department of Computer Science, University of Zurich, November 1 1994. Fri, 16 Feb 96 14:06:51 GMT.

[11] N. Gehani, H. V. Jagadish, and O. Shmueli. COMPOSE: A system for composite specification and detection. Lecture Notes in Computer Science, 759:3-??, 1993.

[12] Narain H. Gehani and H. V. Jagadish. Ode as an active database: Constraints and triggers. In Guy M. Lohman, Amílcar Sernadas, and Rafael Camps, editors, 17th International Conference on Very Large Data Bases, pages 327-336, Barcelona, Catalonia, Spain, 3-6 September 1991. Morgan Kaufmann.

[13] Narain H. Gehani, H. V. Jagadish, and Oded Shmueli. Composite event specification in active databases: Model and implementation. In LeYan Yuan, editor, 18th International Conference on Very Large Data Bases, pages 327-338, Vancouver, Canada, 23-27 August 1992. Morgan Kaufmann.

[14] Andreas Geppert and Dimitrios Tombros. Event-based distributed workflow execution with EVE. Technical Report ifi-96.05, Department of Computer Science, University of Zurich, May 201996.

[15] W. Hseush and Kaiser. Modeling concurrency in parallel debugging. ACM SIGPLAN Notices, 25(3):11-20, March 1990.

[16] M. Mansouri-Samani and M. Sloman. A Generalised Event Monitoring Lanaguage for Distributed Systems. IEE/IOP/BCS Distributed Systems Engineering Journal, 4(2), Jun 1997. 
[17] Masoud Mansouri-Samani. Monitoring of Distributed Systems Distributed. $\mathrm{PhD}$ thesis, Imperial College of Science, Technology and Medicine, University of London, Dec 1995.

[18] Deep Mishra. Snoop: an Event Specification Language for Active Database System. PhD thesis, University of Florida, Dec 1991.

[19] Y.S. Ramakrishna, P.M. Melliar-Smith, L.E. Moser, L.K. Dillon, and G. Kutty. Interval Logics and Their Decision Procedures, Part I: An Interval Logic. Theoretical Computer Science, 166(1 and 2):1-47, October 1996.

[20] E. Anwar \& S. Kim S. Chakravarthy, V. Krishnaprasad. Anatomy of a Composite Event Detector. Technical Report UF-CIS-TR-93-039, University of Florida, Dec 1993.

[21] Scarlet Schwiderski. Monitoring the Behaviour of Distributed Systems. PhD thesis, Selwyn College, University of Cambrige, Apr 1996.

[22] M. Sloman, J. Magee, K. Twidle, and J. Kramer. An Architecture for Managing Distributed Systems. In Proceeding of Fourth IEEE Workshop on Future Trends of Distributed Computing Systems, pages 40-46. IEEE Computer Society Press, September 1993. 